\title{
Deep Vadose Zone Treatability Test for the Hanford Central Plateau: Interim Post-Desiccation Monitoring Results, Fiscal Year 2015
}

\section{September 2015}

MJ Truex

CE Strickland

M Oostrom

CD Johnson
GD Tartakovsky

TC Johnson

RE Clayton

GB Chronister 


\title{
DISCLAIMER
}

This report was prepared as an account of work sponsored by an agency of the United States Government. Neither the United States Government nor any agency thereof, nor Battelle Memorial Institute, nor any of their employees, makes any warranty, express or implied, or assumes any legal liability or responsibility for the accuracy, completeness, or usefulness of any information, apparatus, product, or process disclosed, or represents that its use would not infringe privately owned rights. Reference herein to any specific commercial product, process, or service by trade name, trademark, manufacturer, or otherwise does not necessarily constitute or imply its endorsement, recommendation, or favoring by the United States Government or any agency thereof, or Battelle Memorial Institute. The views and opinions of authors expressed herein do not necessarily state or reflect those of the United States Government or any agency thereof.

\author{
PACIFIC NORTHWEST NATIONAL LABORATORY \\ operated by \\ BATTELLE \\ for the \\ UNITED STATES DEPARTMENT OF ENERGY \\ under Contract DE-AC05-76RL01830
}

Printed in the United States of America
Available to DOE and DOE contractors from the Office of Scientific and Technical Information,
P.O. Box 62, Oak Ridge, TN 37831-0062;
ph: (865) 576-8401
fax: $(865)$ 576-5728
email: reports@adonis.osti.gov
Available to the public from the National Technical Information Service
5301 Shawnee Rd., Alexandria, VA 22312
ph: (800) 553-NTIS (6847)
email: orders@ntis.gov $<$ http://www.ntis.gov/about/form.aspx $>$
Online ordering: http://www.ntis.gov

This document was printed on recycled paper. 


\title{
Deep Vadose Zone Treatability Test for the Hanford Central Plateau: Interim Post-Desiccation Monitoring Results, Fiscal Year 2015
}

\author{
MJ Truex \\ CE Strickland \\ M Oostrom \\ CD Johnson \\ GD Tartakovsky \\ TC Johnson \\ RE Clayton \\ GB Chronister $^{1}$
}

September 2015

Prepared for

the U.S. Department of Energy

under Contract DE-AC05-76RL01830

Pacific Northwest National Laboratory

Richland, Washington 99352

\footnotetext{
${ }^{1}$ CH2M HILL Plateau Remediation Company, Richland, Washington.
} 



\section{Summary}

Over decades of operation, the U.S. Department of Energy (DOE) and its predecessors have released nearly 2 trillion L (450 billion gal.) of liquid into the vadose zone at the Hanford Site. Much of this discharge of liquid waste into the vadose zone occurred in the Central Plateau, a $200 \mathrm{~km}^{2}\left(75 \mathrm{mi}^{2}\right)$ area that includes approximately 800 waste sites. Some of the inorganic and radionuclide contaminants in the deep vadose zone at the Hanford Site are at depths below the limit of direct exposure pathways, but may need to be remediated to protect groundwater. The Tri-Party Agencies (DOE, U.S. Environmental Protection Agency, and Washington State Department of Ecology) established Milestone M-015-50, which directed DOE to submit a treatability test plan for remediation of technetium-99 (Tc-99) and uranium in the deep vadose zone. These contaminants are mobile in the subsurface environment and have been detected at high concentrations deep in the vadose zone, and at some locations have reached groundwater. Testing technologies for remediating Tc-99 and uranium will also provide information relevant for remediating other contaminants in the vadose zone. A field test of desiccation is being conducted as an element of the DOE test plan published in March 2008 to meet Milestone M-015-50. The active desiccation portion of the test has been completed. Monitoring data have been collected at the field test site during the post-desiccation period and are reported herein. This is an interim data summary report that includes about 4 years of post-desiccation monitoring data. The DOE field test plan proscribes a total of 5 years of post-desiccation monitoring.

The desiccation field test was conducted at the Hanford Site 200-BC-1 Operable Unit. This waste site contains 26 cribs and trenches that received about 110 million L (29 million gal.) of liquid waste primarily in the mid-1950s. The waste contained about 410 curies of Tc-99. There is no evidence that the contami-

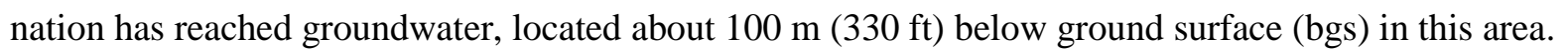
Initial characterization efforts indicated that the Tc-99 inventory is located mostly at a depth in the vadose zone of between about 30 and $70 \mathrm{~m}$ (98 and $230 \mathrm{ft}$ ) bgs. However, transport model predictions have indicated that the potential exists for this contamination to adversely affect groundwater in the future.

The active desiccation portion of the field test occurred over a 164-day period, ending on June 30, 2011. The injection and extraction wells were $12 \mathrm{~m}$ apart with multiple monitored locations surrounding the injection well. A clustered monitoring approach was used in the test, whereby a borehole (sensor borehole) containing sensors, gas-sampling ports, and electrical resistance tomography electrodes was placed nominally adjacent to a cased, unscreened well (logging well) that was used both to conduct neutron moisture logging and for application of cross-hole ground penetrating radar (GPR). Monitoring with the in situ sensors and geophysical techniques has been continued for the post-desiccation (rewetting) phase of the test.

Rewetting data since the end of active desiccation are consistent with expectations based on related laboratory data and numerical simulation analyses. Analysis of current data after 4 years of rewetting and associated numerical modeling herein demonstrated the importance of 3-D moisture migration, and a dominant effect of vertical moisture migration due to drainage of water from the vadose zone above the desiccated zone. These analyses have shown that the rewetting process and rate can be reasonably estimated. Thus, the treatability test is on track to provide suitable desiccation technology design information for use in subsequent feasibility studies. 



\section{Acknowledgments}

This work was funded by the CH2M Hill Plateau Remediation Company as part of the Deep Vadose Zone Treatability Test activities for the Hanford Central Plateau. The Pacific Northwest National

Laboratory is operated by Battelle Memorial Institute for the DOE under Contract DE-AC05-76RL01830. 



\section{Acronyms and Abbreviations}

$\begin{array}{ll}2 \mathrm{D} & \text { two-dimensional } \\ 3 \mathrm{D} & \text { three-dimensional } \\ \mathrm{bgs} & \text { below ground surface } \\ \mathrm{cfm} & \text { cubic feet per minute } \\ \mathrm{cm} & \text { centimeter } \\ \mathrm{C}_{\mathrm{R}} & \text { count ratio } \\ \mathrm{DOE} & \text { U.S. Department of Energy } \\ \mathrm{EC} & \text { electrical conductivity } \\ \mathrm{EPA} & \text { U.S. Environmental Protection Agency } \\ \mathrm{ERT} & \text { electrical resistivity tomography } \\ \mathrm{GPR} & \text { ground penetrating radar } \\ \mathrm{HDU} & \text { Heat Dissipation Unit } \\ \mathrm{kPa} & \text { kilopascal } \\ \mathrm{L} & \text { liter } \\ \mathrm{m} & \text { meter } \\ \mathrm{m}^{3} & \text { cubic meter } \\ \mathrm{mA} & \text { milliampere } \\ \mathrm{mbar} & \text { millibar } \\ \mathrm{MHz} & \text { megahertz } \\ \mathrm{min} & \text { minute } \\ \mathrm{MPa} & \text { megapascal } \\ \mathrm{PNNL} & \text { Pacific Northwest National Laboratory } \\ \mathrm{s} & \text { second } \\ \mathrm{S} / \mathrm{m} & \text { siemens/meter } \\ \mathrm{TCP} & \text { Thermocouple Psychrometer } \\ \mathrm{VMC} & \text { volumetric moisture content } \\ \mathrm{VMC} & \text { volumetric moisture content at the end of active desiccation } \\ & \end{array}$





\section{Contents}

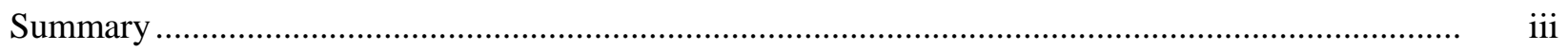

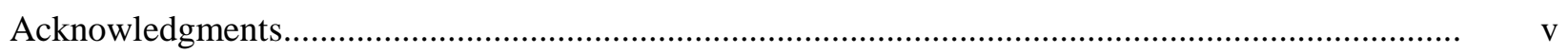

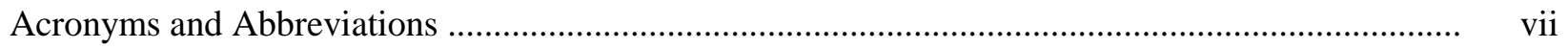

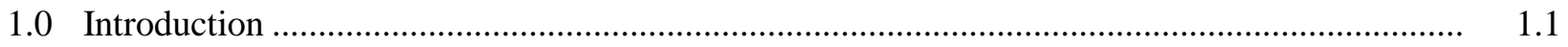

2.0 Summary of Active Desiccation Results ..................................................................... 2.1

3.0 Post-Desiccation Monitoring Approach …........................................................................ 3.1

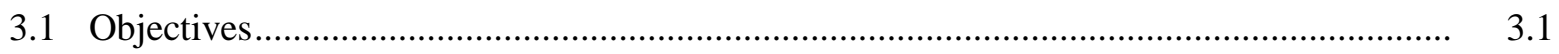

3.2 Experimental Design and Procedures................................................................... 3.1

3.2.1 Test Site Background ................................................................................ 3.1

3.2.2 Test Layout, Operations, and Equipment .......................................................... 3.4

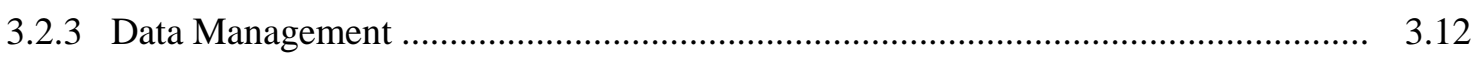

4.0 Post-Desiccation Monitoring Results ..........................................................................

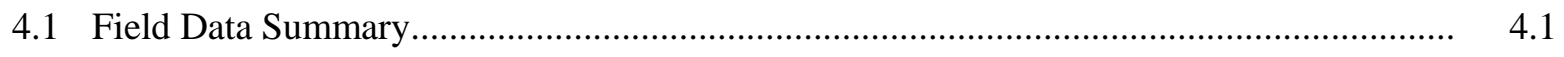

4.1.1 Post-Desiccation Data ............................................................................. 4.1

4.2 Rewetting Assessment using Three-Dimensional Flow Modeling ................................... 4.19

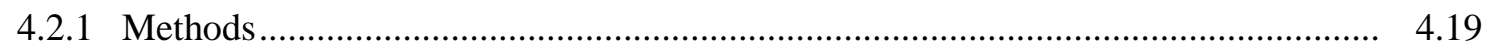

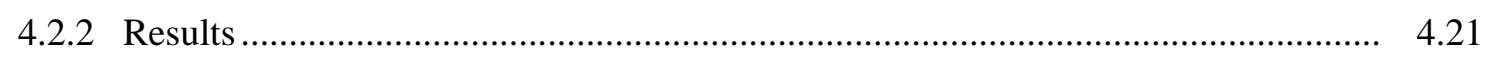

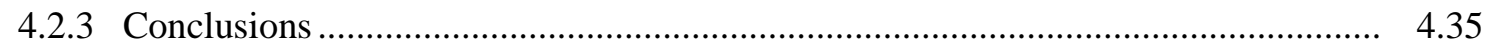

4.3 Post-Desiccation Monitoring Data Assessment …........................................................ 4.35

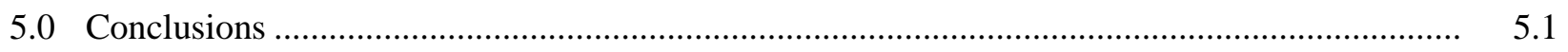

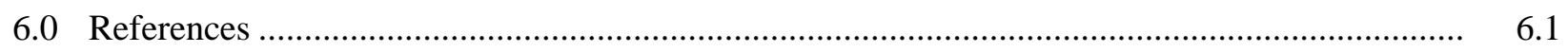

Appendix A: Neutron Moisture Probe Data …........................................................................ A.1 


\section{Figures}

3.1 Test site location in the BC Cribs and Trenches area of the Hanford Site ................................ 3.2

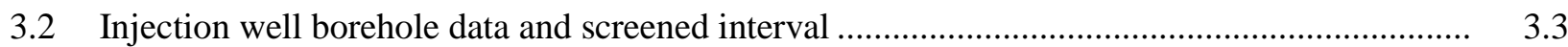

3.3 Injection and extraction well borehole initial laboratory moisture content, extracted pore water electrical conductivity, and well screened interval .................................................... 3.4

3.4 Basic components of the desiccation field test system.......................................................... 3.5

3.5 Flow conditions and cumulative volumes for field test operations ........................................ 3.6

3.6 Location of test site logging wells, sensor boreholes, and post-desiccation boreholes for collection of sediment samples

3.7 Calibration relation for neutron moisture probe count ratio data and corresponding laboratory-measured volumetric moisture content

4.1 Post-desiccation temperature response over time for the sensors at a depth of $32.5 \mathrm{ft}$ bgs ........ 4.1

4.2 Post-desiccation temperature response over time for the sensors at a depth of $36.5 \mathrm{ft}$ bgs ........ 4.2

4.3 Post-desiccation temperature response over time for the sensors at a depth of $42.5 \mathrm{ft}$ bgs ........ 4.2

4.4 Post-desiccation temperature response over time for the sensors at a depth of $46.5 \mathrm{ft}$ bgs ........ $\quad 4.3$

4.5 Post-desiccation heat dissipation unit response over time for the sensors at a depth of $42.5 \mathrm{ft}$ bgs.

4.6 Post-desiccation heat dissipation unit response over time for the sensors at a depth of $47.5 \mathrm{ft}$ bgs.

4.7 Post-desiccation relative humidity probe response over time for the sensors at a depth of $42.5 \mathrm{ft}$ bgs.

4.8 Post-desiccation relative humidity probe response over time for the sensors at a depth of $47.5 \mathrm{ft}$ bgs.

4.9 Neutron moisture probe response over time for location C7523

4.10 Neutron moisture probe response over time for location C7525

4.11 Neutron moisture probe response over time for location C7527

4.12 Neutron moisture probe response over time for location C7529

4.13 Neutron moisture probe response over time for location C7531

4.14 Neutron moisture probe response over time for location $\mathrm{C} 7533$

4.15 Neutron moisture probe response over time for location C7537

$4.162 \mathrm{D}$ interpretation of volumetric moisture content from cross-hole ground penetrating radar data during desiccation at Day 137 and after the end of active desiccation

4.17 2D interpretation of initial volumetric moisture content from cross-hole ground penetrating radar data prior to desiccation....

4.18 2D image showing regions where GPR low-loss conditions are valid, resulting in higher confidence in GPR-derived moisture content estimates

4.19 Ratio of Volumetric Moisture Content to the Volumetric Moisture Content at the End of Active Desiccation over time along the axis between the injection and extraction wells from cross-hole electrical resistivity tomography

4.20 Location of test site logging wells, injecting and extraction wells, and plan views of desiccated zones 
4.21 Simulated volumetric water content responses over time at location C7523 for the $7 \times 7 \mathrm{~m}$ desiccated zone, showing the full depth profile and details of the rewetting responses for the desiccated zone at $12.25-16 \mathrm{~m}$ bgs

4.22 Simulated volumetric water content responses over time at location $\mathrm{C} 7527$ for the $7 \times 7 \mathrm{~m}$ desiccated zone, showing the full depth profile and details of the rewetting responses for the desiccated zone at $12.25-16 \mathrm{~m}$ bgs.

4.23 Simulated volumetric water content responses over time at location C7533 for the $7 \times 7 \mathrm{~m}$ desiccated zone

4.24 Water mass fluxes over time across the boundaries of the $7 \times 7 \mathrm{~m}$ desiccated zone up to 10 years and 100 years after desiccation

4.25 Cumulative water mass in the $7 \times 7 \mathrm{~m}$ desiccated zone up to 10 years and 100 years after desiccation. Positive values indicate an increase in water storage.

4.26 Comparison of water mass as a function of distance to the injection well.

4.27 Comparison of water mass fluxes at the boundaries of the initially $7 \times 7 \mathrm{~m}$ desiccated zone between 12.25 and $16 \mathrm{~m}$ bgs and at equal-size surfaces at a one-meter distance in the undesiccated sediment.

4.28 Comparison of water mass fluxes for simulations with and without the initially $7 \times 7 \mathrm{~m}$ desiccated zone between 12.25 and $16 \mathrm{~m}$ bgs

4.29 Simulated volumetric water content responses over time at location $\mathrm{C} 7527$ for the $5 \times 5 \mathrm{~m}$ desiccated zone, showing the full depth profile and details of the rewetting responses for the desiccated zone at $12.25-16 \mathrm{~m}$ bgs

4.30 Simulated volumetric water content responses over time at location $\mathrm{C} 7525$ for the $5 \times 5 \mathrm{~m}$ desiccated zone

4.31 Water mass fluxes over time across the surfaces of the $5 \times 5 \mathrm{~m}$ desiccated zone up to 10 years and 100 years after desiccation

4.32 Water mass fluxes over time across the surfaces of the $5 \times 5 \mathrm{~m}$ desiccated zone up to 10 years and 100 years after desiccation

\section{Tables}

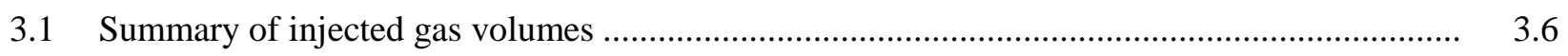

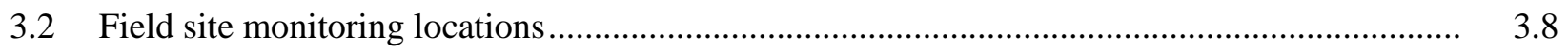

4.1 Hydraulic properties of the sediments used in the STOMP simulations .................................. 4.19

4.2 Vertical location of lower-permeability layers.................................................................. 4.19 


\subsection{Introduction}

Although the depth of some inorganic and radionuclide contamination in the vadose zone at the Hanford Site is beyond the point where direct exposure pathways are relevant, remediation may still be required to protect groundwater (DOE/RL 2008a). However, remediation options for contamination deep in the vadose zone are limited by the physical and hydrogeologic properties of the vadose zone (Dresel et al. 2011). In response to the Tri-Party Agreement Milestone M-015-50, the Deep Vadose Treatability Test Plan for the Hanford Central Plateau was issued in March 2008 (DOE/RL 2008a). This plan is for a treatability test program to evaluate potential deep vadose zone remedies for groundwater protection. Accordingly, the field test of vadose zone desiccation was conducted (Truex et al. 2012a and b, 2013a) and continued post-desiccation monitoring is now under way as part of this effort, with monitoring documented over time in interim data summary reports (Truex et al. 2013b, 2014).

The Hanford Site 200-BC-1 Operable Unit (the BC Cribs and Trenches Area) has subsurface conditions that serve as an example of vadose zone contamination issues and was selected as the location of the desiccation field test site. This waste site contains 26 cribs and trenches that received about 110 million liters of liquid waste, primarily in the mid-1950s. The waste contained about 410 curies of technetium-99 (Tc-99) (Corbin et al. 2005). There is no evidence that the contamination has reached groundwater, located about $100 \mathrm{~m}$ below ground surface (bgs) in this area. Initial characterization efforts indicated that the Tc-99 inventory is located mostly at a depth in the vadose zone of between about 30 and $70 \mathrm{~m}$ bgs. However, transport model predictions have indicated that the potential exists for this contamination to adversely affect groundwater in the future (Ward et al. 2004). The groundwater contaminant concentrations that can result from vadose zone contamination are a function of the rate of contaminant movement through the vadose zone. For remediation, contaminant discharge from the vadose zone to the groundwater must be maintained at a magnitude low enough to achieve groundwater protection goals.

Desiccation of a portion of the vadose zone, in conjunction with a surface infiltration barrier, has the potential to minimize migration of deep vadose zone contaminants towards the water table (Truex et al. 2011). To apply desiccation, a dry gas is injected into the subsurface. The dry gas evaporates water from the porous medium until the gas reaches $100 \%$ relative humidity, after which the gas can no longer evaporate water. Evaporation can remove pore water and may result in very low moisture contents and decreased water relative permeability in the desiccated zone (Ward et al. 2008; Oostrom et al. 2009, 2012a and b; Truex et al. 2011, 2012a and b, 2013a and b, 2014). Because of these desiccation-induced changes, the future rate of movement of moisture and contaminants through this zone is decreased.

Laboratory and modeling studies have been conducted to study desiccation and provide a technical basis for its use as a potential remedy (Truex et al. 2011; Ward et al. 2008; Oostrom et al. 2009, 2011, $2012 \mathrm{a}$ and $\mathrm{b}$ ). In these studies, the overall performance of desiccation in limiting water and contaminant flux through the vadose zone to the groundwater was shown to be a function of the final moisture content in the desiccated zone, contaminant concentration, sediment properties, size of the desiccated zone, the hydraulic properties and conditions in surrounding subsurface zones, and the net surface recharge rate. In the laboratory, desiccation was shown to be capable of reducing the moisture content to below the residual moisture content of the porous medium (Truex et al. 2011; Ward et al. 2008; Oostrom et al. 2009). Data from the field test of desiccation also demonstrated reduction of moisture content to below the residual moisture content of the porous medium in some locations near the dry-gas injection well 


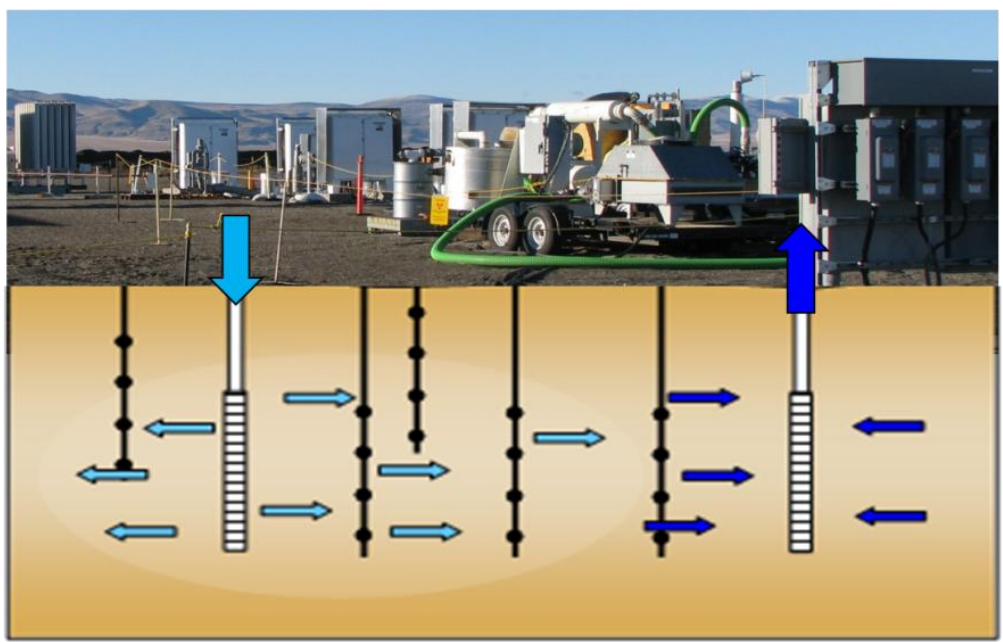

Soil Desiccation Test Site and Depiction of Subsurface Gas Flow
(Truex et al. 2012a and b, 2013a). However, the desiccation during the field test varied as a function of subsurface properties, flow patterns of the dry gas, and time, producing a range of moisture content reductions throughout the monitored portion of the test site.

After a portion of the vadose zone is desiccated, rewetting of this zone can occur by vapor- and aqueous-phase moisture transport. The timescale of rewetting impacts the overall performance of desiccation in minimizing contaminant flux to the groundwater. Truex et al.

(2011) examined rewetting of desiccated zones in the laboratory and found that vapor-phase rewetting from adjacent humid soil gas, in the absence of advective soil gas movement, occurs slowly by diffusion of water vapor and increases the moisture content of desiccated porous medium to a limited extent, nominally to near the residual moisture content for the porous medium. The aqueous-phase rewetting rate was found to be a function of the relative aqueous-phase permeability of the porous medium and hydraulic capillary pressure gradients.

This report describes and interprets the fourth year of post-desiccation monitoring conducted at the field test site, extending the information about rewetting processes and rates presented in the initial field treatability test documents (Truex et al. 2012a and b, 2013a) and the previous post-desiccation interim data summary reports (Truex et al. 2013b, 2014). This is the third interim report including about four years of post-desiccation monitoring data out of the five years of post-desiccation monitoring specified in the field test plan (DOE/RL 2010b). Section 2.0 provides a summary of the results of active desiccation. The monitoring approach is described in Section 3.0, followed by a presentation of the post-desiccation monitoring results in Section 4.0. Section 5.0 presents conclusions from the post-desiccation data collected to date. 


\subsection{Summary of Active Desiccation Results}

The objectives outlined in the field test plan (DOE/RL 2010b) associated with active desiccation were successfully addressed through the field testing and associated laboratory and modeling efforts conducted as part of the treatability test. In the field test, a portion of the subsurface was desiccated, creating conditions that reduce the rate of moisture and contaminant movement toward the groundwater. A design basis to apply desiccation for vadose zone remediation was developed and is available for use in subsequent feasibility and remedial design efforts (Truex et al. 2012a).

The distribution, rate, and extent of desiccation observed in the field were affected by subsurface heterogeneity in geologic materials. A more rapid reduction in moisture content was observed for higher permeability materials. However, the moisture content in initially wetter, lower-permeability zones of limited extent was also reduced over time. Field test results were consistent with expectations based on previous laboratory and modeling efforts that investigated aspects of the desiccation process. Note that the field test targeted desiccation in a portion of the subsurface with significant contrasts in permeability to allow evaluation of desiccation performance across multiple types of subsurface conditions. Full-scale application of desiccation would seek target depth intervals for dry gas injection that enable creation of thick desiccated zones and would avoid zones where injected gas flow would be minimal.

The test results and related laboratory and modeling efforts provide information to guide design and implementation of desiccation. Desiccation observed in the field test was consistent with design calculations and simulations based on the water-holding capacity of the injected gas. In addition, the distribution of desiccated zones met expectations; higher permeability zones dried first, followed by expansion of desiccation into lower-permeability zones over time. Analysis of data and use of numerical simulations indicate that full-scale designs can be made more cost effective than the design of the field test (which was designed to collect specific data, not as a full-scale remediation) by using ambient air as the injected dry gas and by using an injection-only design (i.e., no extraction well).

Selected results from pre-desiccation characterization and active desiccation are incorporated into this report to provide a starting point and context for interpreting post-desiccation data. Detailed descriptions of pre-desiccation data and the active desiccation test results are available in the following reports and articles.

$\underline{\text { Reports }}$

- Truex MJ, M Oostrom, CE Strickland, TC Johnson, VL Freedman, CD Johnson, WJ Greenwood, AL Ward, RE Clayton, MJ Lindberg, JE Peterson, SS Hubbard, GB Chronister, and MW Benecke. 2012. Deep Vadose Zone Treatability Test for the Hanford Central Plateau: Soil Desiccation Pilot Test Results. PNNL-21369, Pacific Northwest National Laboratory, Richland, Washington.

- Truex MJ, M Oostrom, VL Freedman, C Strickland, and AL Ward. 2011. Laboratory and Modeling Evaluations in Support of Field Testing for Desiccation at the Hanford Site. PNNL-20146, Pacific Northwest National Laboratory, Richland, Washington.

- DOE/RL (U.S. Department of Energy, Richland Operations Office). 2010. Characterization of the Soil Desiccation Pilot Test Site. DOE/RL-2009-119, Rev. 0, Richland, Washington. 
- Um W, RJ Serne, MJ Truex, AL Ward, MM Valenta, CF Brown, C Iovin, KN Geiszler, IV Kutnyakov, ET Clayton, H-S Chang, SR Baum, and DM Smith. 2009. Characterization of Sediments from the Soil Desiccation Pilot Test (SDPT) Site in the BC Cribs and Trenches Area. PNNL-18800, Pacific Northwest National Laboratory, Richland, Washington.

- Ward AL, M Oostrom, and DH Bacon. 2008. Experimental and Numerical Investigations of Soil Desiccation for Vadose Zone Remediation: Report for Fiscal Year 2007. PNNL-17274, Pacific Northwest National Laboratory, Richland, Washington.

$\underline{\text { Articles }}$

- Truex MJ, TC Johnson, CE Strickland, JE Peterson, and SS Hubbard. 2013. "Monitoring Vadose Zone Desiccation with Geophysical Methods.” Vadose Zone Journal doi:10.2136/vzj2012.0147

- Oostrom M, VL Freedman, TW Wietsma, and MJ Truex. 2012. "Effects of porous medium heterogeneity on vadose zone desiccation: Intermediate-scale laboratory experiments and simulations." Vadose Zone Journal doi:10.2136/vzj2011.0168.

- Truex MJ, M Oostrom, CE Strickland, GB Chronister, MW Benecke, and CD Johnson. 2012. "Field-Scale Assessment of Desiccation Implementation for Deep Vadose Zone Contaminants." Vadose Zone Journal doi:10.2136/vzj2011.0144

- Chronister GB, MJ Truex, and MW Benecke. 2012. "Soil Desiccation Techniques - Strategies for Immobilization of Deep Vadose Contaminants at the Hanford Central Plateau." In Proceedings of Waste Management Symposia 2012.

- Truex MJ, M Oostrom, JE Szecsody, CE Strickland, GB Chronister, and MW Benecke. 2012. "Technical Basis for Gas-Phase Vadose Zone Remediation Technologies at Hanford: A Review." In Proceedings of Waste Management Symposia 2012.

- Oostrom M, TW Wietsma, CE Strickland, VL Freedman, and MJ Truex. 2012. "Instrument Testing during Desiccation and Rewetting at the Intermediate Laboratory Scale. Vadose Zone Journal doi:10.2136/vzj2011.0089.

- Oostrom M, GD Tartakovsky, TW Wietsma, MJ Truex, and JH Dane. 2011. "Determination of Water Saturation in Relatively Dry and Desiccated Porous Media Using Gas-Phase Partitioning Tracer Tests. Vadose Zone Journal 10:1-8; doi:10.2136/vzj2010.0101.

- Oostrom M, TW Wietsma, JH Dane, MJ Truex, and AL Ward. 2009. "Desiccation of Unsaturated Porous Media: Intermediate-Scale Experiments and Numerical Simulation." Vadose Zone Journal $8: 643-650$. 


\subsection{Post-Desiccation Monitoring Approach}

The post-desiccation monitoring approach featured an experimental design and procedures developed to meet the test objectives presented in the field test plan (DOE 2010b).

\subsection{Objectives}

The objectives relevant to the post-desiccation monitoring phase of the field test are as follows:

- Desiccation Field Test Performance: Demonstrate field-scale desiccation for targeted areas within the vadose zone.

- After desiccation is completed, determine the rate of change in soil moisture for the desiccated zone.

- Determine the best types of instrumentation for monitoring key subsurface and operational parameters to provide feedback to operations and evaluate long-term effectiveness.

\subsection{Experimental Design and Procedures}

The experimental design and procedures are described by Truex et al. (2012a) and are briefly summarized below to provide context for the post-desiccation monitoring effort.

\subsubsection{Test Site Background}

The field treatability test for desiccation was conducted in the Hanford Site 200-BC-1 Operable Unit, commonly referred to as the BC Cribs and Trenches Area (Figure 3.1). The site was selected for the field test because relatively high concentrations of mobile Tc-99 contamination and high moisture contents are present at relatively shallow depths, facilitating test operations, yet representing conditions found deeper in the vadose zone where desiccation could be considered as part of a remedy. For the test, the deep vadose zone was mimicked by covering the ground surface with an impermeable barrier to limit surface interaction with the test injection and extraction operations. The test area is located between adjacent waste disposal cribs where the subsurface was affected by lateral movement of crib discharges in the subsurface but where drilling and other test operations could take place outside the hazardous footprint of the former disposal cribs. Figure 3.2 shows the vertical stratigraphy, technetium, and moisture distribution at the injection well location in relation to the well screen interval. Porous media grain-size variations in the test interval generally range from sands to loamy sands with some zones of silty sand and silt, similar to the porous media observed throughout the full depth interval. 


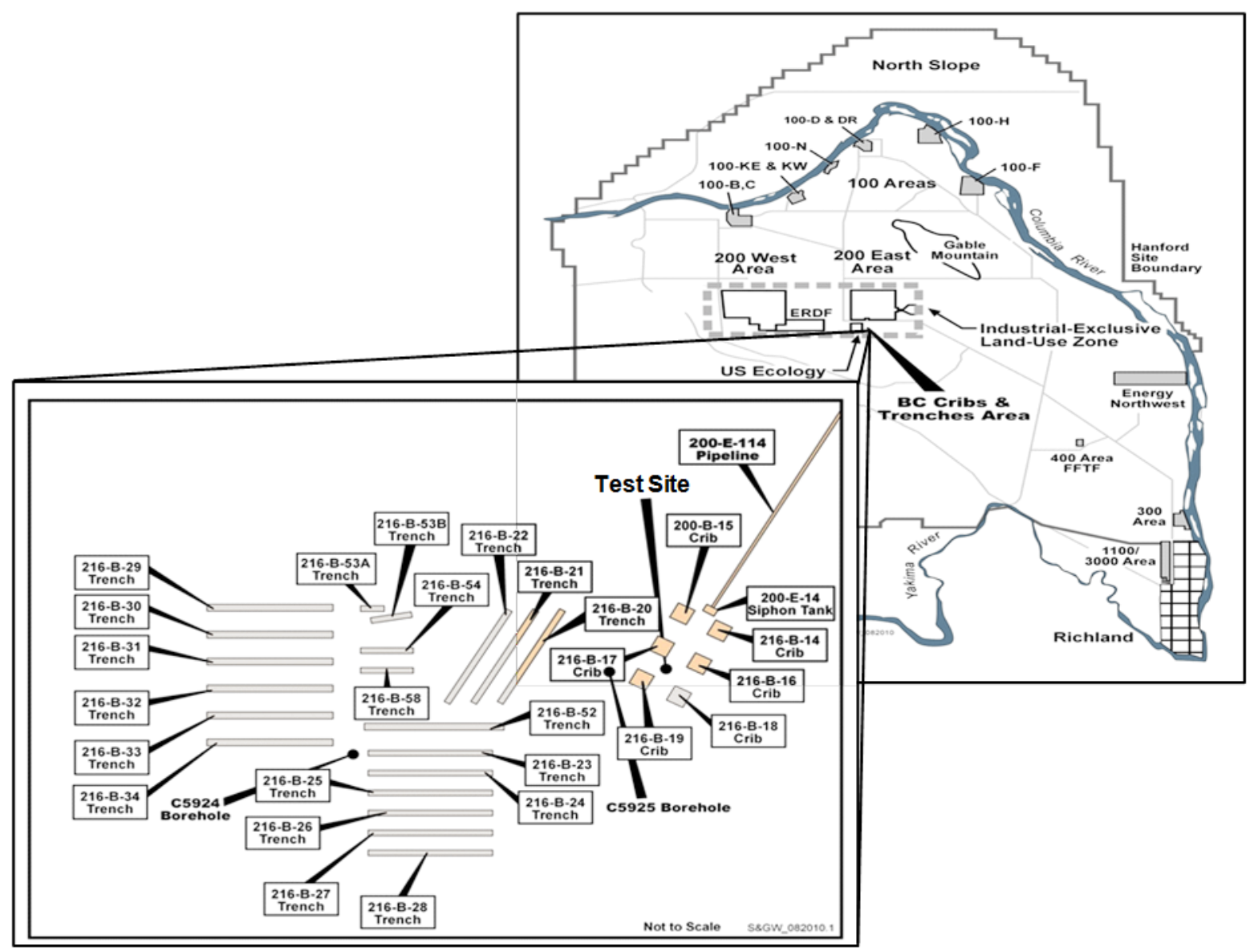

Figure 3.1. Test site location in the BC Cribs and Trenches area (inset, 200-BC-1 Operable Unit) of the Hanford Site (map) (after DOE 2010b). Note that the test site is centered around borehole C5923 (coincident with the "Test Site" labeled on the figure), one of three characterization boreholes (C5923, C5924, C5925) from site investigation activities associated with electrical resistivity studies at the site (Serne et al. 2009). 


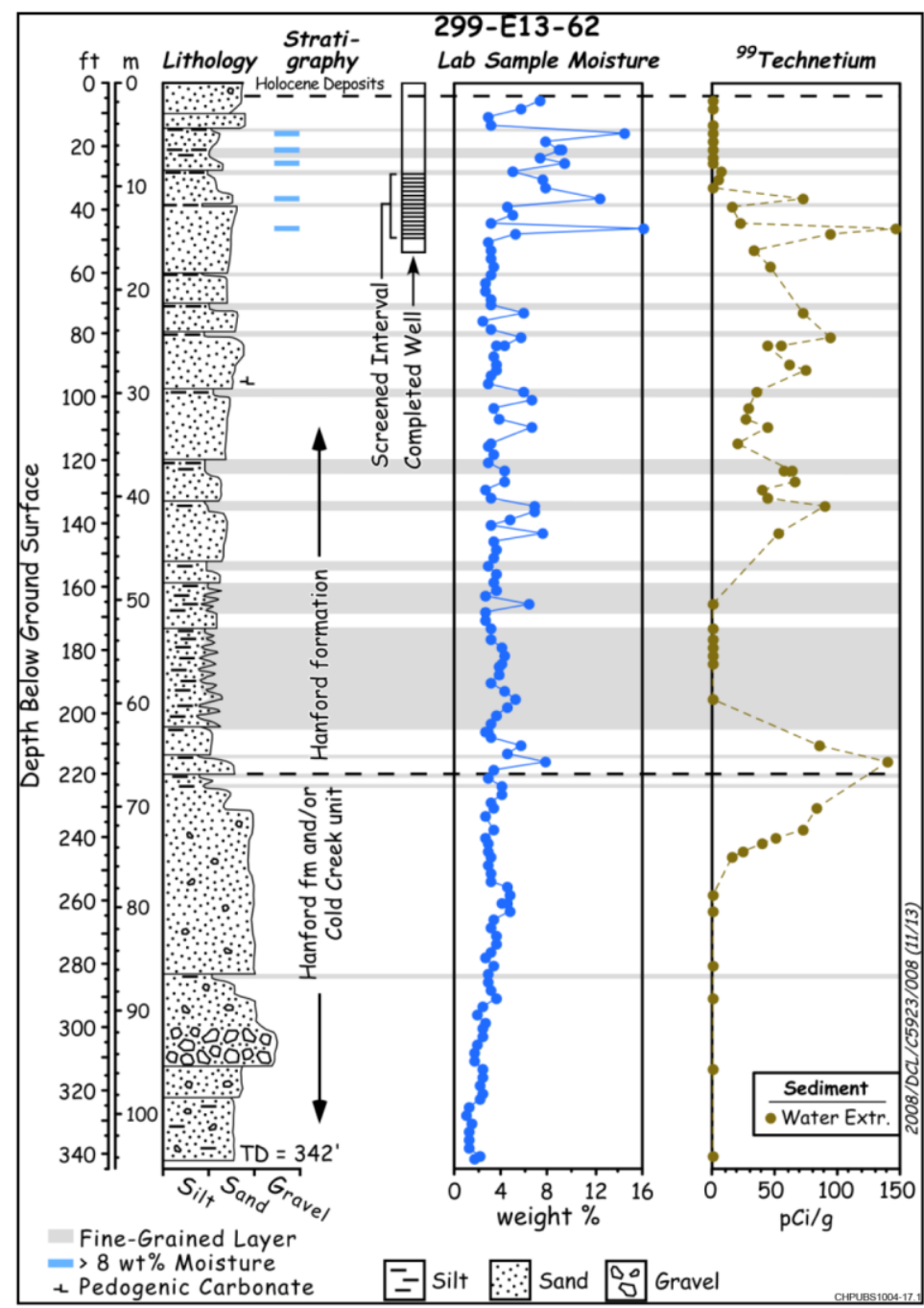

Figure 3.2. Injection well borehole data and screened interval (after DOE 2010b)

Borehole data provides information about the vertical distribution of moisture and contaminant concentrations at the injection and extraction well locations of the field test site (e.g., Figure 3.3) (Serne et al. 2009; Um et al. 2009). 


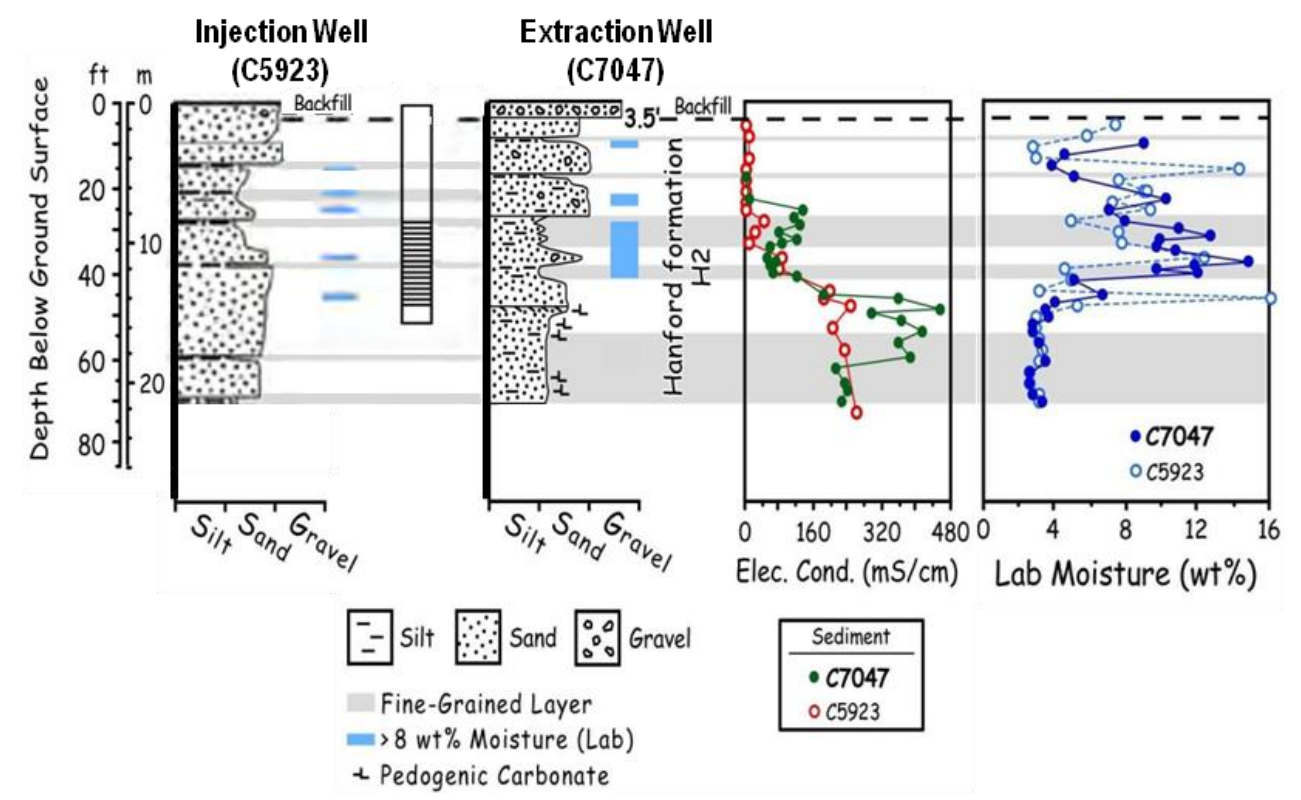

Figure 3.3. Injection and extraction well borehole initial laboratory moisture content, extracted pore water electrical conductivity, and well screened interval (after DOE 2010a; Serne et al. 2008; Um et al. 2009)

\subsubsection{Test Layout, Operations, and Equipment}

The desiccation technology relies on removal of water from a portion of the subsurface such that the resultant low moisture conditions inhibit downward movement of water and dissolved contaminants. Implementation requires establishing sufficiently dry conditions within the targeted zone to effectively inhibit downward water transport. Nominally, the targeted zone would need to extend laterally across the portion of the vadose zone where contaminants have the potential to move downward at a flux that will affect groundwater above the remediation objectives for groundwater concentration. Thus, the experimental design was developed to evaluate the process of establishing a desiccated zone that extends laterally away from a dry gas injection well within a specific depth interval of the vadose zone. To obtain this type of desiccation zone, the field test design used a dipole configuration with injection of nitrogen and extraction of soil gas through wells screened in a target depth interval to favor soil gas flow within this interval and within a defined monitoring zone (Figure 3.4). 


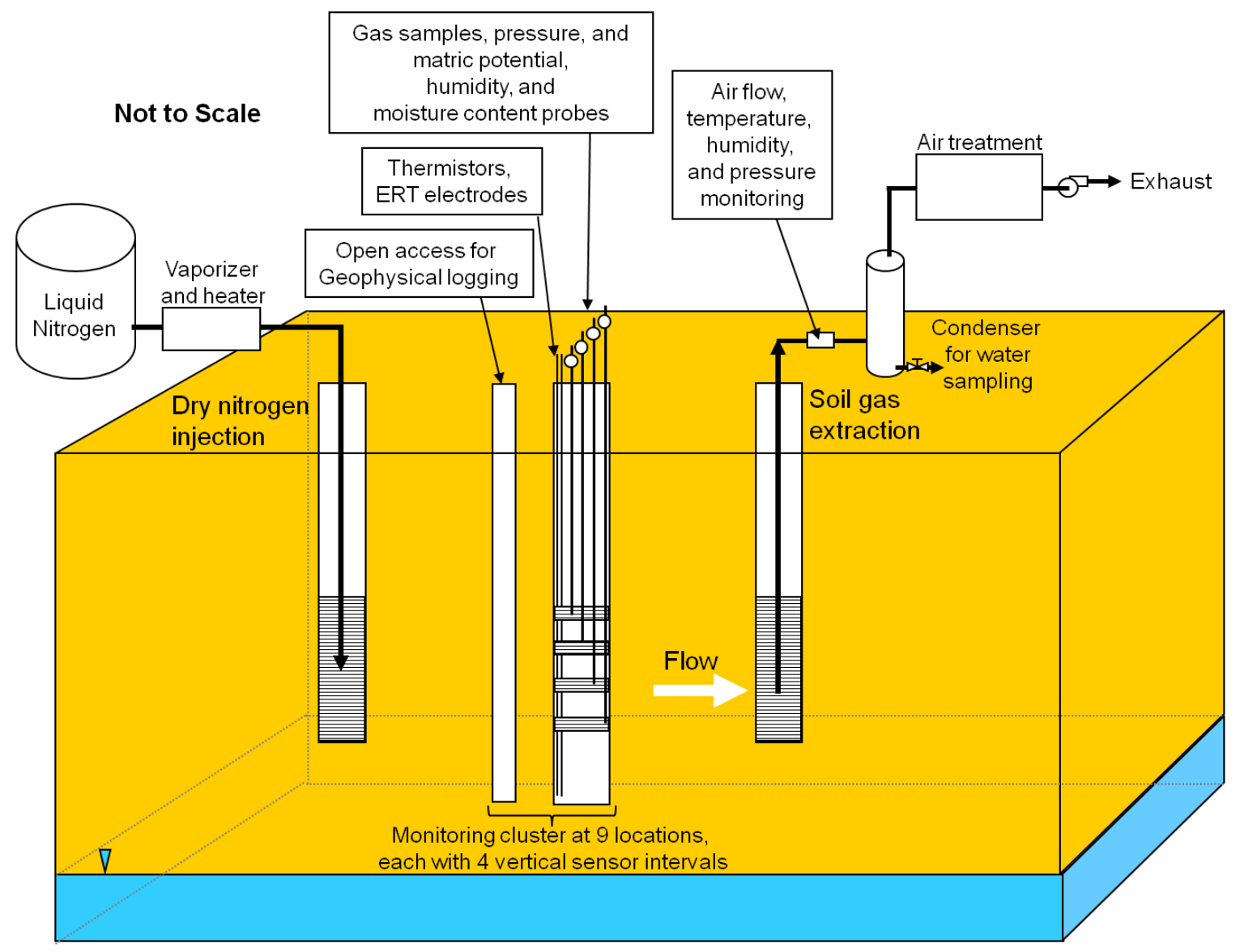

Figure 3.4. Basic components of the desiccation field test system

The general operational and in situ monitoring strategy is depicted in Figure 3.4. Dry nitrogen gas produced from liquid nitrogen tankers was injected at a controlled temperature of $20^{\circ} \mathrm{C}$ into a screened interval from 9.1 to $15.2 \mathrm{~m}$ (30 to $50 \mathrm{ft}$ ) bgs. Equipment testing, including trial nitrogen gas injections and the initial tracer test, occurred between November 22 and December 6, 2010. The active desiccation portion of the field test occurred with nitrogen injection at a stable flow rate of $510 \mathrm{~m}^{3} / \mathrm{h}(300$ cubic feet per minute [cfm]) from January 17, 2011, through June 30, 2011, (164 days) except during a 13-day interval from April 21 through May 4, 2011, when there was no injection. Extraction of soil gas from a well screened from 9.1 to $15.2 \mathrm{~m}$ ( 30 to $50 \mathrm{ft}$ ) bgs was maintained for the full test duration at a stable flow rate of $170 \mathrm{~m}^{3} / \mathrm{h}(100 \mathrm{cfm})$. Extracted soil gas was routed through a heat exchanger to condense water that was collected and periodically sampled. The injection and extraction wells were $12 \mathrm{~m}$ apart.

Operational data were collected during injection and extraction operations at the test site. Of these parameters, the injected gas flow rate and temperature are key drivers for desiccation. Dry nitrogen (relative humidity of zero) was used for the injection gas during the test (Table 3.1). Extraction parameters were also measured to define test conditions, but are not specifically related to the desiccation rate other than the impact on soil gas flow rates and patterns. Figure 3.5 shows the operational parameter data for injection gas flow and extraction flow rate over the duration of active desiccation. Injection gas temperature was held essentially constant at about $20^{\circ} \mathrm{C}$. 
Table 3.1. Summary of injected gas volumes

\begin{tabular}{llllc}
\hline \multicolumn{2}{c}{ Time On } & \multicolumn{2}{c}{ Time Off } & Cumulative Volume Injection $\left(\mathrm{m}^{3}\right)$ \\
\hline $11 / 22 / 2010$ & $09: 00$ & $11 / 23 / 2010$ & $10: 24$ & 12,812 \\
$11 / 29 / 2010$ & $11: 13$ & $11 / 30 / 2010$ & $08: 20$ & 16,354 \\
$12 / 2 / 2010$ & $09: 40$ & $12 / 6 / 2010$ & $11: 40$ & 32,969 \\
$1 / 17 / 2011$ & $15: 35$ & $4 / 21 / 2011$ & $13: 00$ & $1,108,884$ \\
$5 / 2 / 2011$ & $12: 30$ & $5 / 2 / 2011$ & $12: 45$ & $1,109,014$ \\
$5 / 4 / 2011$ & $10: 15$ & $6 / 30 / 2011$ & $13: 55$ & $1,799,790$ \\
\hline
\end{tabular}

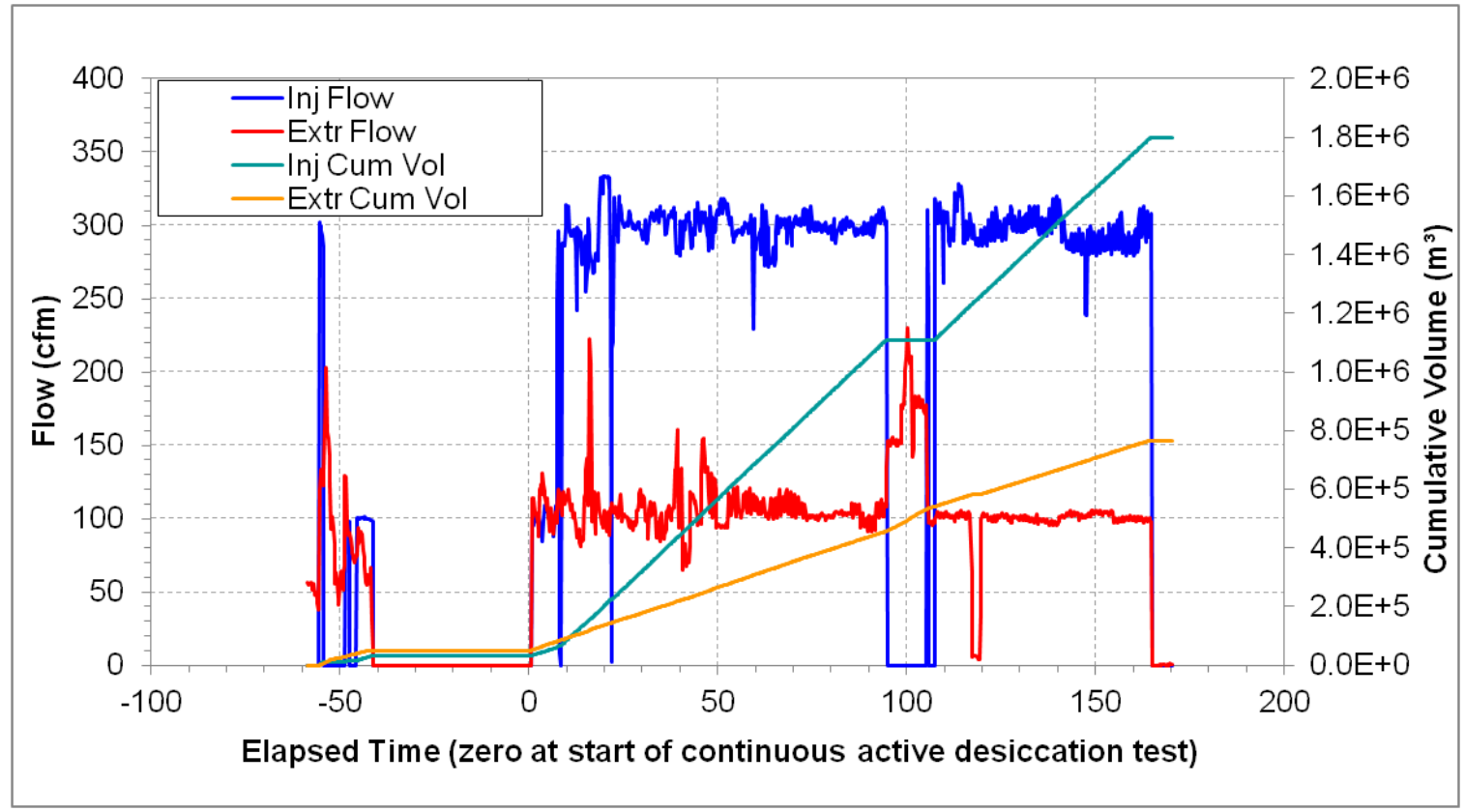

Figure 3.5. Flow conditions and cumulative volumes for field test operations

Figure 3.6 depicts the lateral layout of injection and extraction wells and the monitoring locations. Distances from the injection well to the monitoring locations are listed in Table 3.2. A 30-m by 45-m gas-impermeable membrane barrier was installed at the surface and centered over the well network. A clustered monitoring approach was used in the test whereby a borehole (sensor borehole) containing sensors, gas-sampling ports, and electrical resistance tomography electrodes was placed nominally adjacent to a cased, unscreened well (logging well) that was used to conduct neutron moisture logging and for application of cross-hole ground penetrating radar (GPR). Sensor boreholes contained four intervals of 100-mesh (> 0.125 and $<0.149 \mathrm{~mm}$ ) Colorado sand (Colorado Silica, Colorado Springs, Colorado) separated by granular bentonite. Matric potential sensors, moisture content sensors, humidity sensors (sensors are described in Section 3.2.2.1), and porous polyethylene gas-sampling ports (model X-6081, Porex Technologies Corporation) were installed in each sand interval. The sand intervals were placed nominally at $9.5-10.1,11-11.6,12.5-13.1$, and $14-14.6 \mathrm{~m}(31-33,36-38,41-43$, and $46-48 \mathrm{ft})$ bgs to provide vertically discrete monitoring across the injection/extraction well screen interval. The

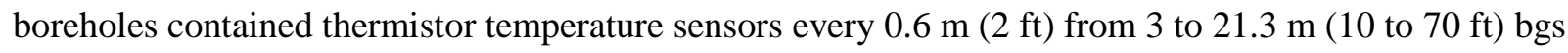


and electrical resistivity electrodes every $1.5 \mathrm{~m}(5 \mathrm{ft})$ within the bentonite intervals of the borehole fill material from 3 to $21.3 \mathrm{~m}$ (10 to $70 \mathrm{ft}$ ) bgs. Electrical resistivity tomography (ERT) electrodes were placed within the bentonite zones with tubing installed to enable the addition of water around each electrode to locally hydrate the bentonite and maintain effective coupling between the electrode and the subsurface. Electrical connectivity was checked periodically during the test and water added when necessary to maintain adequate coupling. Logging wells, which provided access for neutron moisture logging and cross-hole GPR, extended to $21.3 \mathrm{~m}$ (70 ft) bgs with a 2-in. polyvinyl chloride casing (plugged at the bottom) in a 4-in.-diameter borehole and 100-mesh Colorado sand in the annular space.

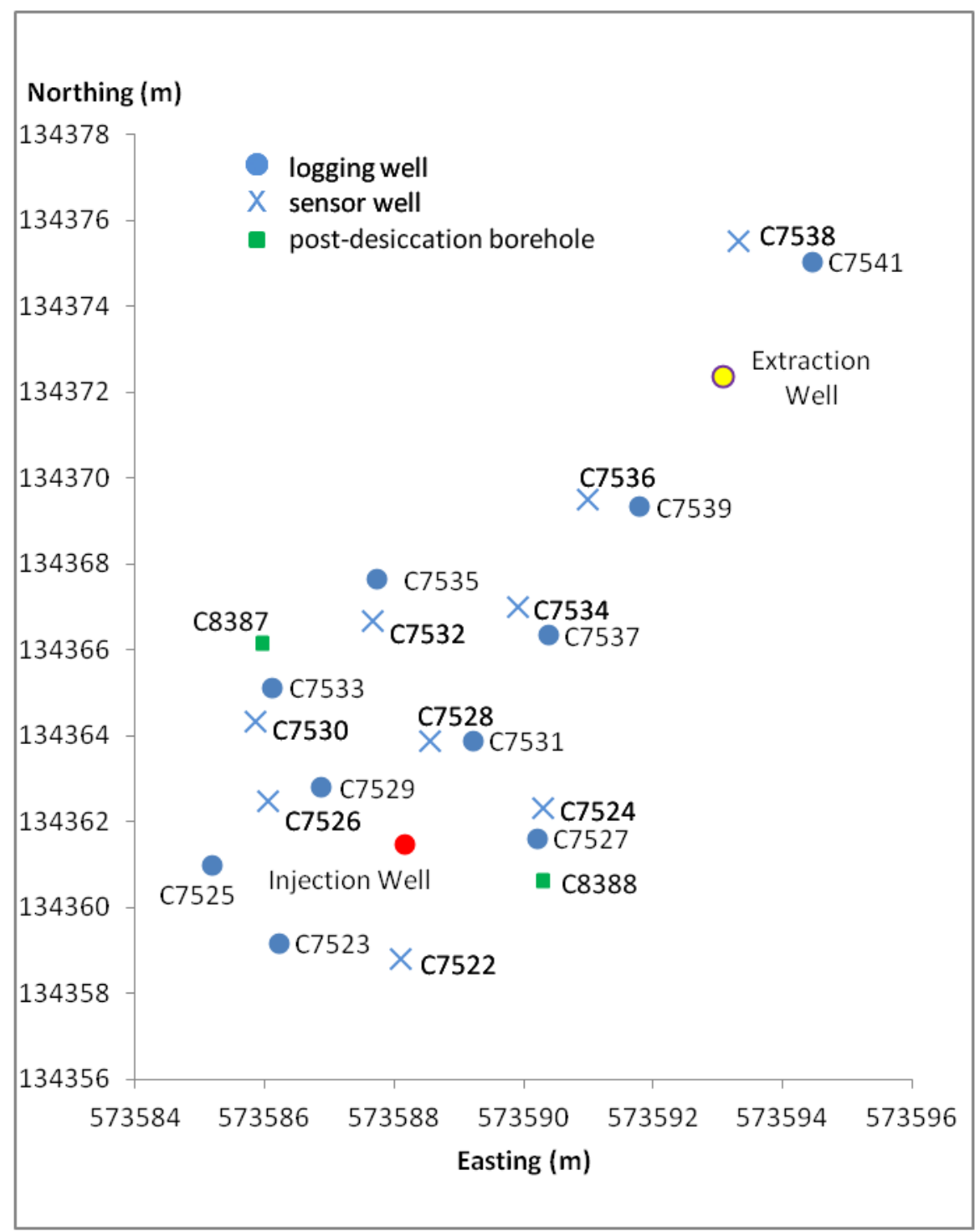

Figure 3.6. Location of test site logging wells, sensor boreholes, and post-desiccation boreholes for collection of sediment samples. A background sensor borehole (C7540, not shown) was $15 \mathrm{~m}$ southeast from the injection well. 
Table 3.2. Field site monitoring locations

\begin{tabular}{cc}
\hline $\begin{array}{c}\text { Monitoring } \\
\text { Location }\end{array}$ & $\begin{array}{c}\text { Distance from } \\
\text { Injection Well }(\mathrm{m})\end{array}$ \\
\hline C7526-S & 2.33 \\
C7529-L & 1.85 \\
C7524-S & 2.28 \\
C7527-L & 2.04 \\
C7528-S & 2.43 \\
C7531-L & 2.62 \\
C7522-S & 2.68 \\
C7523-L & 3.02 \\
C7525-L & 3.02 \\
C7530-S & 3.67 \\
C7533-L & 4.18 \\
C7534-S & 5.79 \\
C7537-L & 5.34 \\
C7532-S & 5.22 \\
C7535-L & 6.18 \\
C7536-S $7739-L$ & 8.49 \\
C7539-S & 8.64 \\
C7538-S & 14.96 \\
C7541-L & 14.94 \\
\hline An "S" designation is for boreholes that contained in \\
situ sensors. An "L" designation is for cased wells \\
that were used for logging access. \\
\hline
\end{tabular}

\subsubsection{Borehole Sensor Descriptions}

Thermistors (USP8242 encapsulated, negative temperature coefficient thermistors, U.S. Sensor, Orange, California) were used to monitor temperature. To achieve accurate temperature measurements over the range of interest, a fifth-order polynomial was used to relate resistance to temperature for each of the thermistors used in the field test. The manufacturer's calibration relationship was verified for a subset of the thermistors in a precision water bath spanning a $0^{\circ} \mathrm{C}-40^{\circ} \mathrm{C}$ temperature range, with measured accuracies better than $0.07^{\circ} \mathrm{C}$. Temperatures were logged continuously (10-min intervals) at each thermistor. In addition to providing important information concerning desiccation progress, the temperature field data are also used to correct the ERT-derived electrical conductivity to a standard temperature prior to using the ERT data for estimating volumetric water content.

Matric potential data were collected using Heat Dissipation Unit (HDU) sensors (229-L HDU, Campbell Scientific, Inc., Logan, Utah) to indirectly determine the air-water capillary pressure. A 50-mA current excitation module was used to supply current to the HDU sensors. The HDU temperature was measured prior to heating and again at $1 \mathrm{~s}$ and $30 \mathrm{~s}$ after the onset of heating; these values were used to compute the associated matric potential (Oostrom et al. 2012a). The measurement range of the units is typically from -0.01 to $-2.5 \mathrm{MPa}$ (-0.1 to -25 bar) with an accuracy of $1 \mathrm{kPa}$ (Flint et al. 2002). The procedure described by Bilskie et al. (2007) was used for HDU calibration, which simplifies the extended procedure presented by Flint et al. (2002) by only requiring calibration data in the range up to $-70 \mathrm{kPa}$. 
Once installed, the sand zones containing the HDU sensors were allowed to equilibrate with the conditions in the native formation before the injection operations were initiated.

Soil gas relative humidity was monitored using a CS215 capacitive relative humidity and temperature sensor (Campbell Scientific, Inc., Logan, Utah) with the electronics integral to the unit. The signal excitation and measurement are all completed within the device, followed by a conversion to a digital signal that can be monitored remotely. The sensing element is housed within a sintered high-density polyethylene filter to protect it from impact and environmental conditions. Each humidity probe is factory calibrated and the accuracy of the device is $2 \%$ within the $10 \%$ to $90 \%$ relative humidity range and $4 \%$ from $0 \%$ to $100 \%$ relative humidity.

Borehole sensors also included Thermocouple Psychrometer (TCP) units (PST-55, Wescor Inc., Logan, Utah) and Dual-Probe Heat Pulse sensors (Specific Heat Sensors, East 30 Sensors, Pullman, Washington), but these sensors were not tracked during the rewetting period due to poor responses and sensor failures observed during the active desiccation phase (Truex et al. 2012a).

\subsubsection{Neutron Moisture Logging Measurements}

Neutron moisture logging was conducted using a CPN 503DR Hydroprobe (InstroTek Inc., Raleigh, North Carolina). Neutron probe measurements were acquired at depth increments of approximately $7.5 \mathrm{~cm}$ using a count time of $30 \mathrm{~s}$ and then converted to count ratio $\left(\mathrm{C}_{\mathrm{R}}\right)$ by dividing each measurement by the standard count. For the desiccation field test, neutron probes were deployed periodically in wells at the site to collect neutron moisture logs with data at discrete depth intervals in the subsurface.

Neutron probe data were converted to volumetric moisture content using a site-specific relationship that was developed from core measurements of gravimetric moisture content and bulk density (full description provided by Truex et al. [2012a]). In summary, core samples were collected adjacent to logging location C7527 after the active desiccation phase of the test. Neutron moisture probe $\mathrm{C}_{\mathrm{R}}$ data were plotted with corresponding post-desiccation laboratory-measured volumetric moisture content (computed using measured gravimetric moisture content and bulk density) from samples at the same depth, laterally within $0.9 \mathrm{~m}$ of the neutron logging well (Figure 3.7). Assuming that soil moisture content values are not substantially different at that lateral distance from the logging well, the laboratory data were used to establish a calibration for the neutron moisture probe data. Regression of volumetric moisture content $(\theta)$ (see Truex et al. 2012a) and $C_{R}$ data for all core samples resulted in the relationship $\theta=0.714 C_{R}^{2}-0.1363 C_{R}$, with a root mean square error of 0.015 for $\theta$ and a coefficient of determination of 0.93 . 


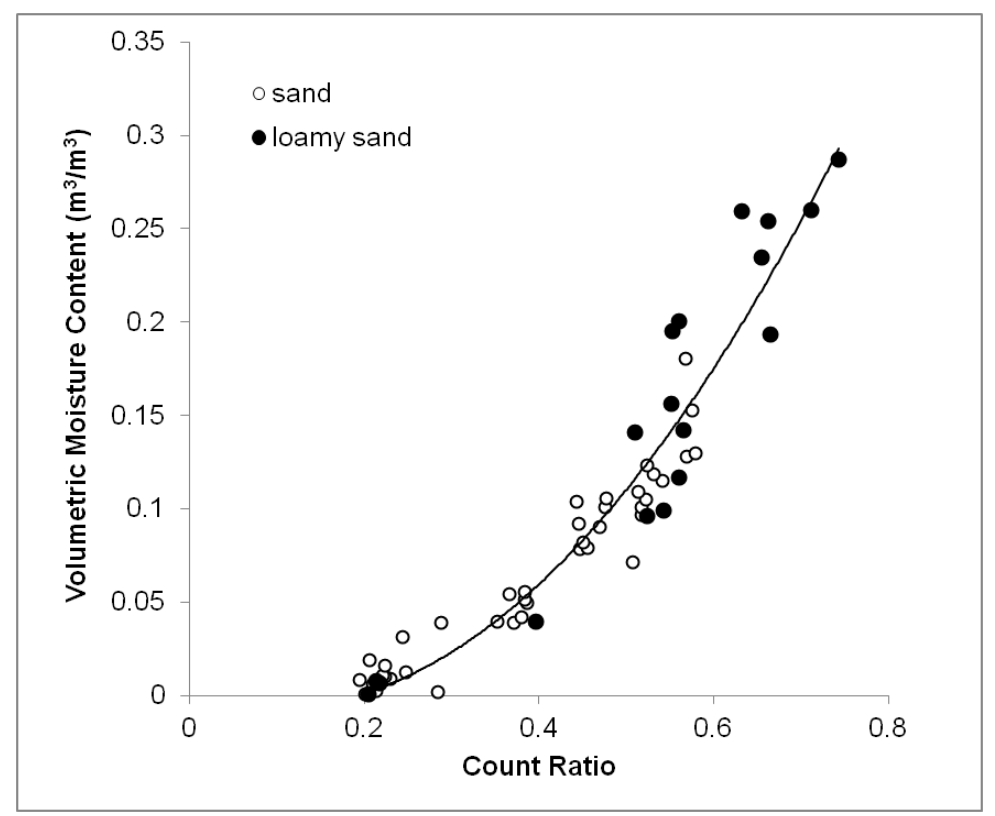

Figure 3.7. Calibration relation for neutron moisture probe count ratio data and corresponding laboratory-measured volumetric moisture content

\subsubsection{Cross-Hole Electrical Resistivity Measurements}

ERT is a method of remotely imaging the electrical conductivity (EC) of the subsurface. Electrodes installed along the ground surface and/or within boreholes are used to strategically inject currents and measure the resulting potentials to produce a data set that is used to reconstruct the subsurface EC structure (Daily and Owen 1991; Johnson et al. 2010). With respect to soil desiccation, EC is a useful metric for characterizing the subsurface because it is governed by properties that influence gas flow, including soil texture and moisture content. EC is also a useful metric for monitoring desiccation because it is sensitive to moisture content and temperature (Slater and Lesmes 2002), the two primary properties altered during desiccation.

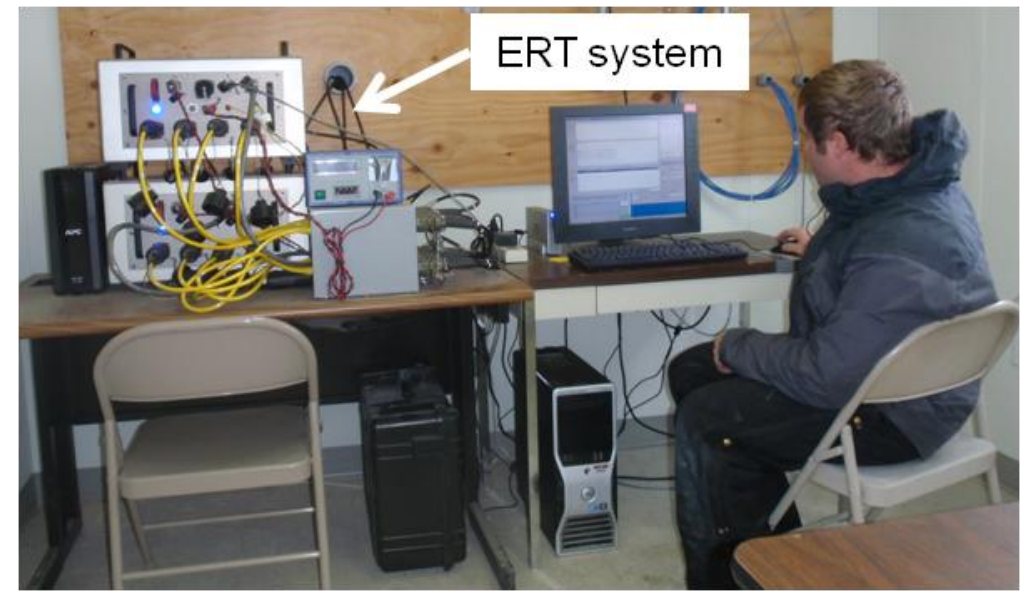

Control System for Electrical Resistivity Tomography
The ERT electrode array deployed in this study was first used to characterize pre-desiccation subsurface structure, providing important 3D information regarding permeability and likely gas flow pathways. During desiccation, the same array was used to image $3 \mathrm{D}$ changes in EC from background caused primarily by decreasing moisture content but also by evaporative cooling. ERT surveys were collected twice per day during the desiccation phase, and weekly during the post-desiccation phase. 
The resulting changes in EC were temperature-corrected and converted to changes in moisture content using a site-specific, laboratory-validated relationship (Archie 1942). Results of pre-desiccation and desiccation ERT monitoring are provided by Truex et al. (2012a, 2013a).

For the previously reported pre-desiccation and active desiccation test phases and for the postdesiccation test phase reported herein, ERT data were collected using 99 electrodes - 11 electrodes in each of the 9 sensor wells. Full forward and reciprocal measurements were collected to estimate data noise and quality, and each data set contained 6114 measurements after filtering. Measurements were collected using an 8-channel MPT DAS-1 impedance tomography system. ${ }^{1}$ These data were inverted with isotropic regularization smoothing constraints on an unstructured tetrahedral mesh with 354,544 elements using the imaging software described by Johnson et al. (2010). The EC data collected from the ERT system provide a means to image changes in the volumetric moisture content over time in three dimensions.

\subsubsection{Cross-Hole Ground Penetrating Radar Measurements}

GPR methods are also commonly used to characterize or monitor subsurface moisture content. GPR systems consist of an impulse generator that repeatedly sends a particular voltage and frequency source to a transmitting antenna. Cross-hole GPR methods involve lowering a transmitter into a wellbore and measuring the energy with a receiving antenna that is lowered down another wellbore, and moving the transmitting and receiving antennae manually to different positions in the wellbores to facilitate transmission of the energy through a large fraction of the targeted area.

Soil electrical permittivity is strongly dependent on moisture content because of the large difference between water and bulk soil permittivity. The relative permittivity of water is approximately 80 , com-

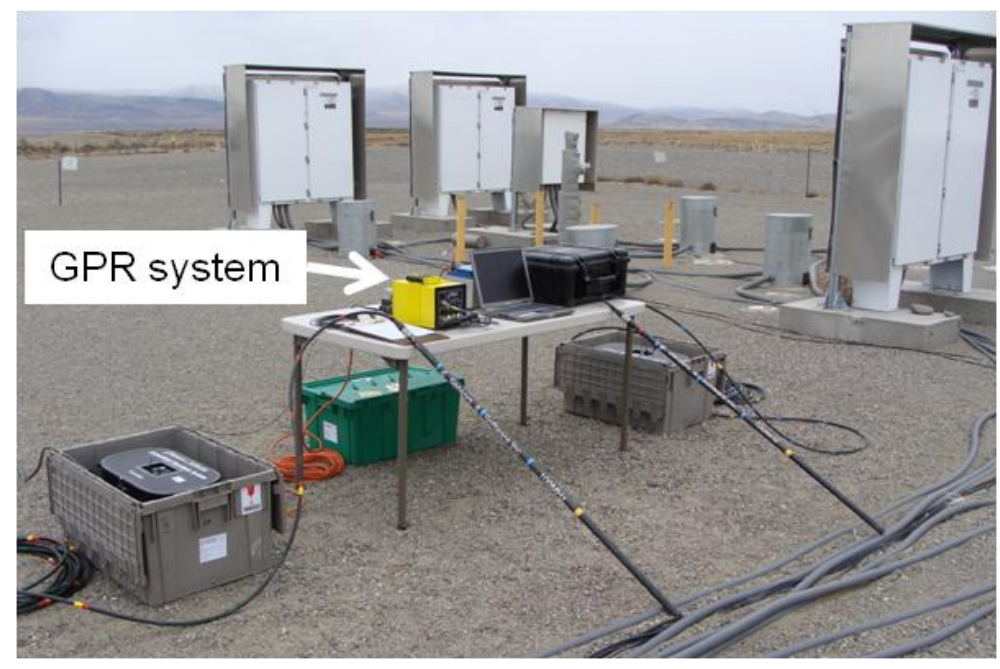

Ground Penetrating Radar Data Collection Equipment pared to values between 3 and 7 for typical soil mineral components. The permittivity can be determined from the observed velocity of an electromagnetic pulse propagating through the soil matrix. Studies have demonstrated that GPR methods can effectively estimate subsurface moisture content using measured electromagnetic velocities (Hubbard et al. 1997; Van Overmeeren et al. 1997; Huisman et al. 2001). In general, the electromagnetic velocity depends on both the permittivity and conductivity; however, when the conductivity is sufficiently low (i.e., low-loss conditions), GPR-derived velocities can be used to accurately determine permittivity and therefore moisture content.

\footnotetext{
${ }^{1}$ http://www.mpt3d.com/.
} 
At the desiccation site, cross-borehole GPR surveys were conducted with the transmitting and receiving antennae placed in separate boreholes to measure the electromagnetic velocity between boreholes. Using measurements acquired from antennae located at many different vertical positions within each borehole, a two-dimensional (2D) image of properties between boreholes can be produced (Jackson and Tweeton 1994). These images can provide information that can be interpreted with respect to the geologic structure and moisture content between boreholes (Binley et. al 2002; Day-Lewis et al. 2002). For the desiccation field test, $2 \mathrm{D}$ images of electromagnetic velocity were generated with GPR and converted to volumetric moisture content changes using an established petrophysical relationship assuming low-loss conditions (Topp and Ferré 2002; Evett 2005). At the desiccation site, the electrical conductivity varies between 0 and $0.250 \mathrm{~S} / \mathrm{m}$ and the low-loss assumption is not valid at all locations. Thus, GPR data are analyzed and interpreted in conjunction with the subsurface EC data provided by the ERT system.

GPR data were collected with a PulseEKKO 100 using a 100-MHz borehole antennae (Sensors and Software, Inc. Missasauga, Ontario, Canada). Multiple offset gather surveys were periodically collected in a set of four logging well pairs (using locations C7523, C7531, C7537, C7539, and the injection well). From these data, 2D electromagnetic velocity images were constructed using MIGRATOM, a curved ray inversion software (Jackson and Tweeton 1994).

\subsubsection{Data Collection System}

Sensor data for the field test were collected using CR3000 data loggers (Campbell Scientific Inc., Logan, Utah). Data were continuously and automatically retrieved from the data loggers and stored on a Dell T3400 computer located at the field site. A Raven X cellular phone modem (Sierra Wireless, Richmond, British Columbia, Canada) was installed to allow for remote monitoring of the data acquisition system and data transfer.

\subsubsection{Data Management}

Data from sensors were maintained on both data loggers and an onsite computer and were backed up periodically to an office computer. Sensor data were imported to spreadsheets at least twice per month during active desiccation and every 6 months during the rewetting phase. The spreadsheets were used to convert raw sensor data to the required outputs, to plot results, and to serve as an additional data storage file for the plotted data. Manual test logs were maintained to document primary test events and for operations where no electronic sensor was available (e.g., condensate collection). The electronic and manual data are stored as part of project records and are documented in project reports. 


\subsection{Post-Desiccation Monitoring Results}

The results of the field test are presented in the next two sections. Results from sensors and geophysical monitoring are presented in Section 4.1 and the data assessment with respect to the field test objectives is discussed in Section 4.2.

\subsection{Field Data Summary}

Post-desiccation monitoring was conducted to collect data to quantify the stability of the desiccated zone (i.e., the rate of rewetting) and to evaluate the field performance of monitoring instruments. The sections below present the data with respect to each of these basic field test elements.

\subsubsection{Post-Desiccation Data}

The three primary types of monitoring - in situ sensor monitoring, neutron moisture logging, and GPR surveying - for the rewetting period (July 2011 through August 2015) are discussed, respectively, in the sections below on sensor, neutron, and geophysical data.

\subsubsection{Sensor Data}

In situ sensor monitoring was continued without interruption from the time of the last data reported in the prior year interim reports (Truex et al. 2013b, 2014). Figures 4.1 through 4.8 below show the temperature, matric potential, and humidity responses for the sensor locations where a response was observed during active desiccation. Data are shown from the end of active desiccation, with elapsed times of 1000 and 1500 days equating to March 26, 2014 and August 8, 2015, respectively.

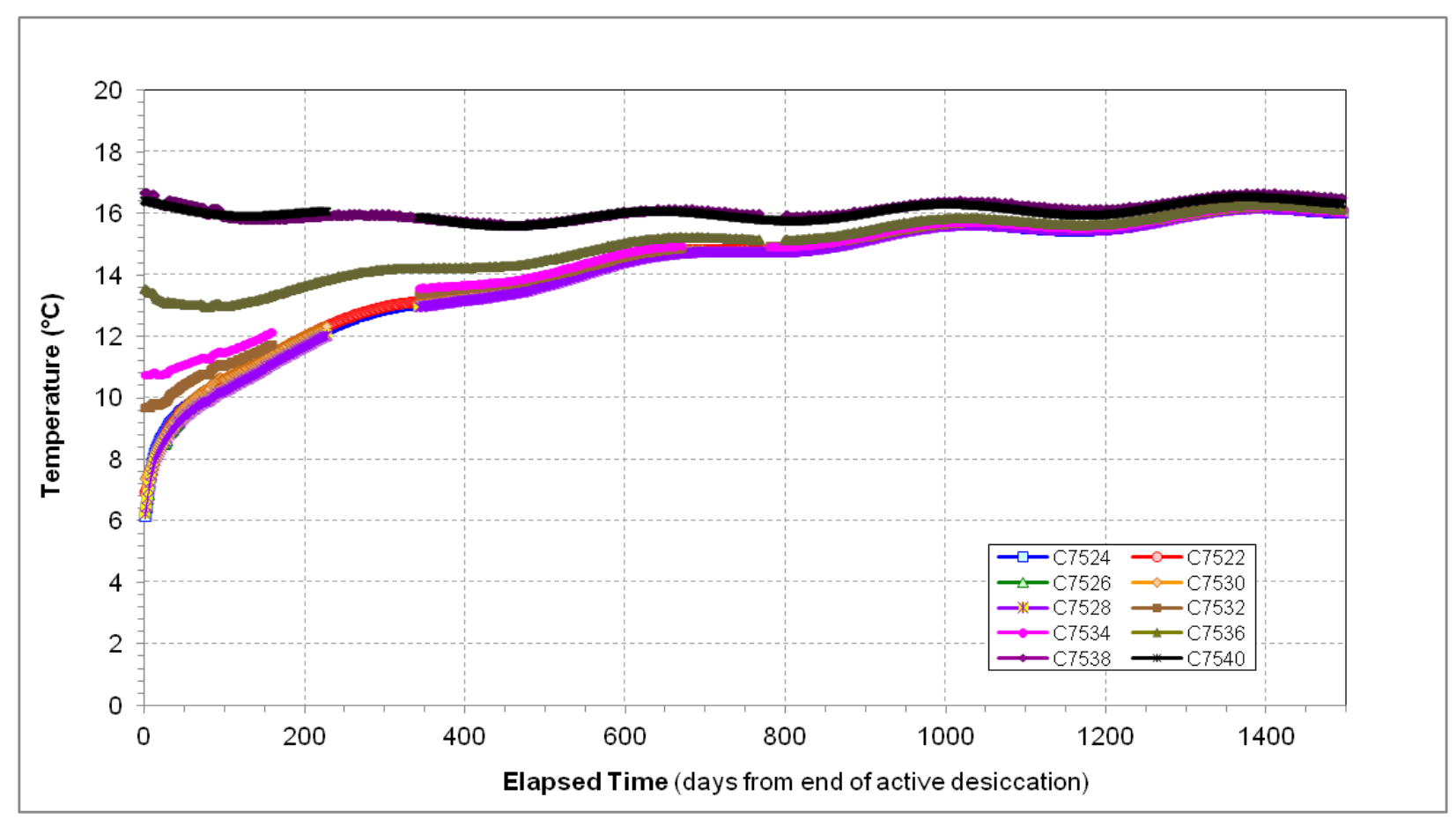

Figure 4.1. Post-desiccation temperature response over time for the sensors at a depth of $32.5 \mathrm{ft}(9.9 \mathrm{~m})$ bgs 


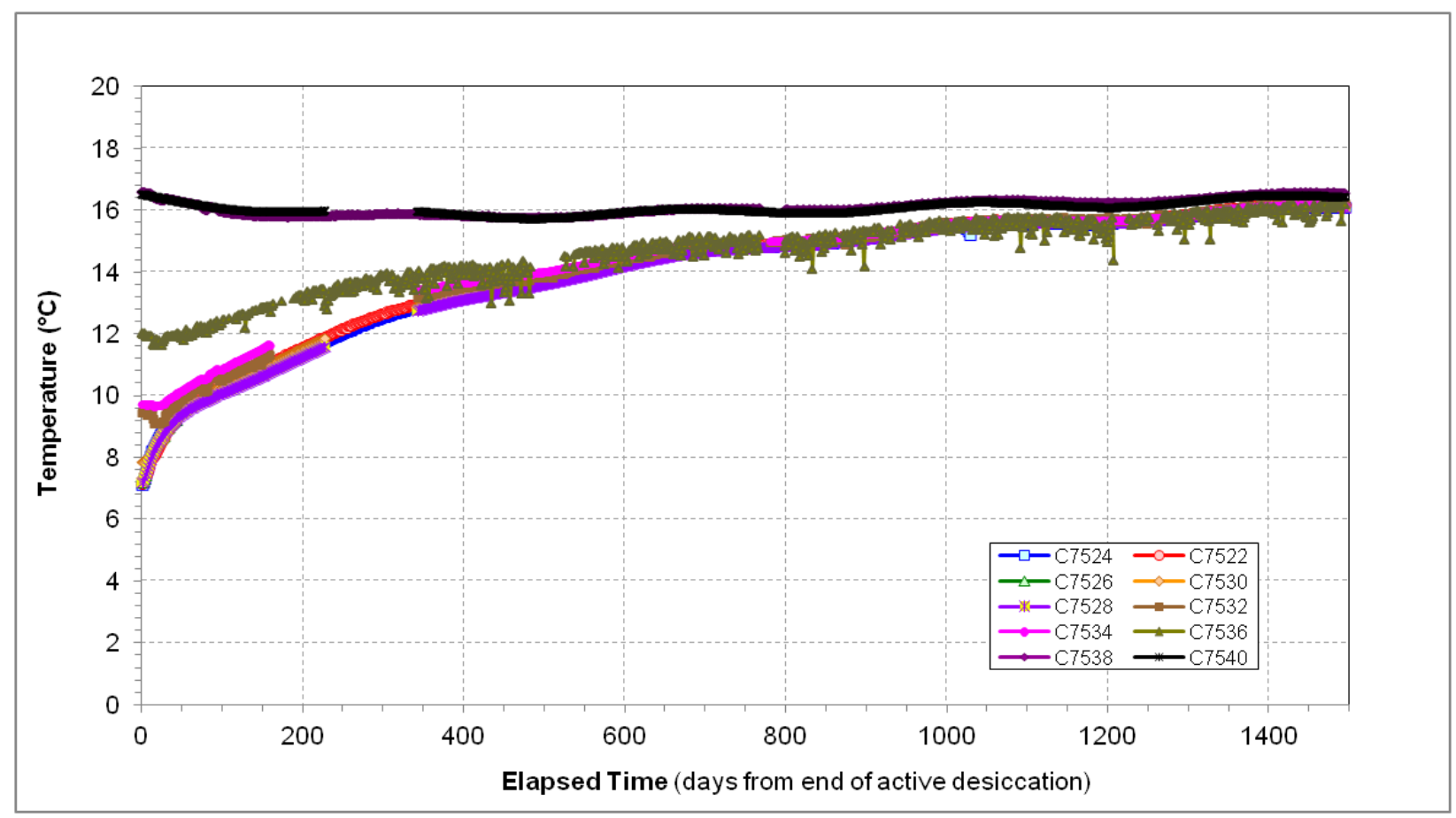

Figure 4.2. Post-desiccation temperature response over time for the sensors at a depth of $36.5 \mathrm{ft}(11.1 \mathrm{~m})$ bgs

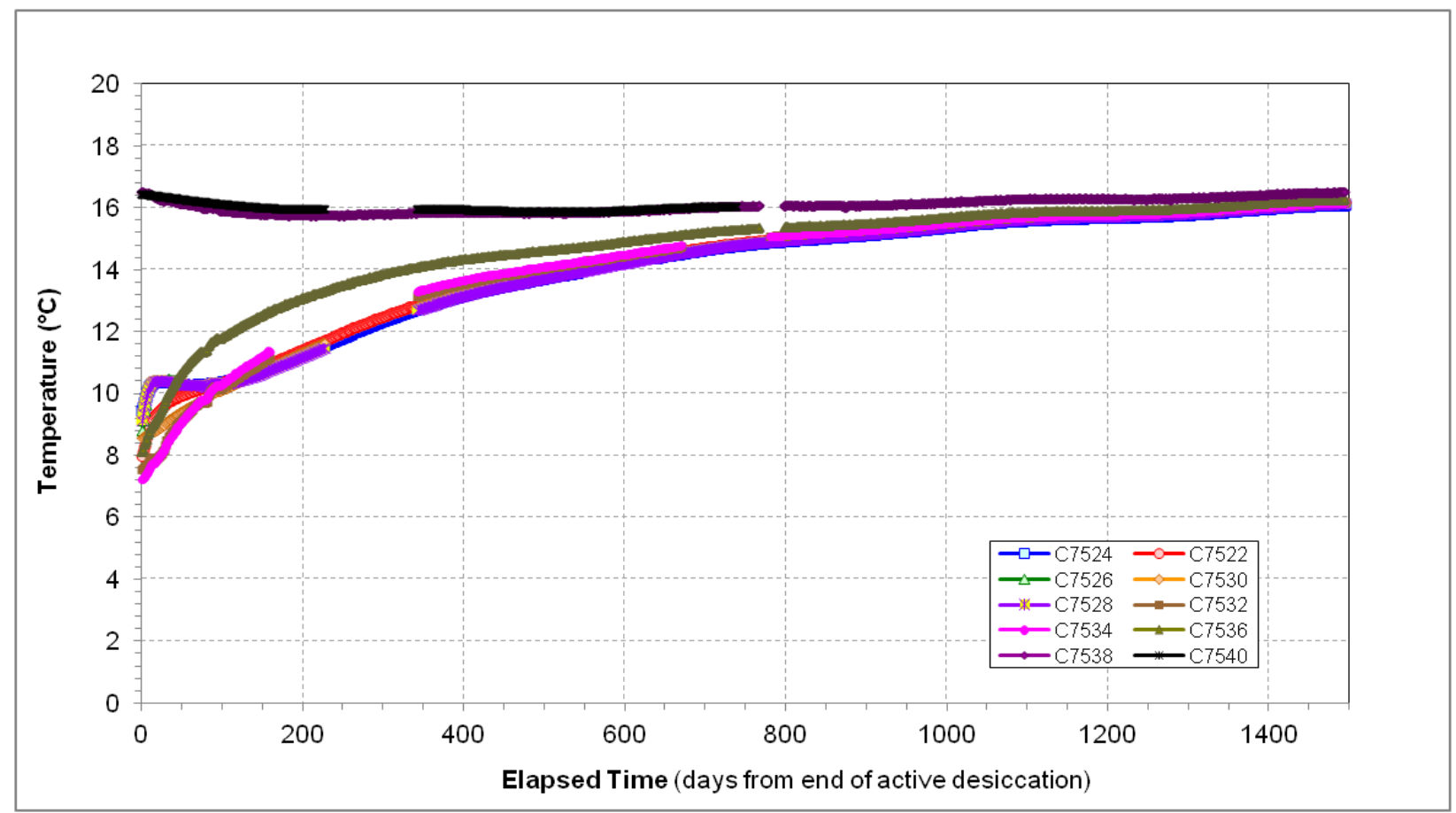

Figure 4.3. Post-desiccation temperature response over time for the sensors at a depth of $42.5 \mathrm{ft}(13 \mathrm{~m})$ bgs 


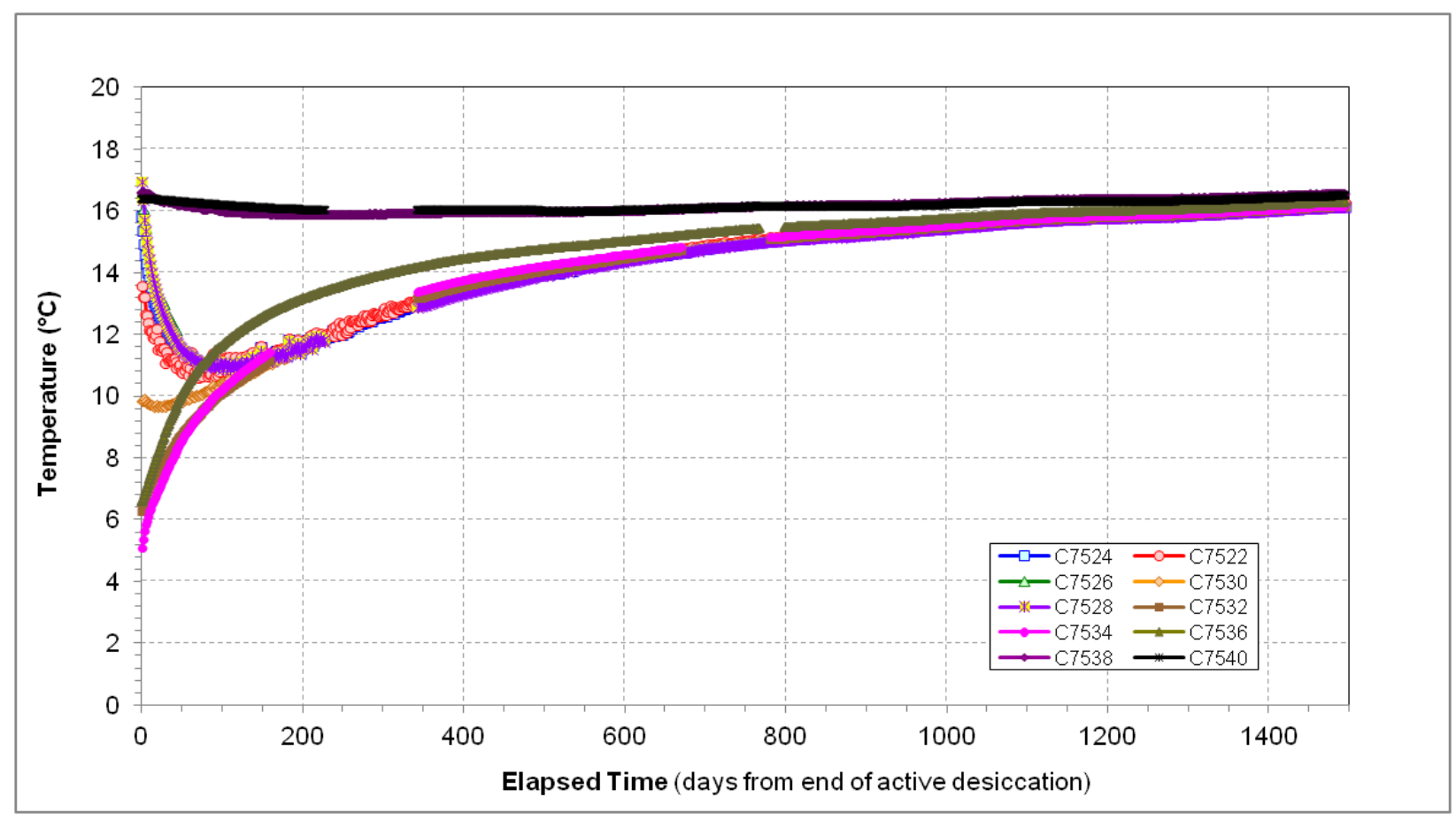

Figure 4.4. Post-desiccation temperature response over time for the sensors at a depth of $46.5 \mathrm{ft}(14.2 \mathrm{~m})$ bgs

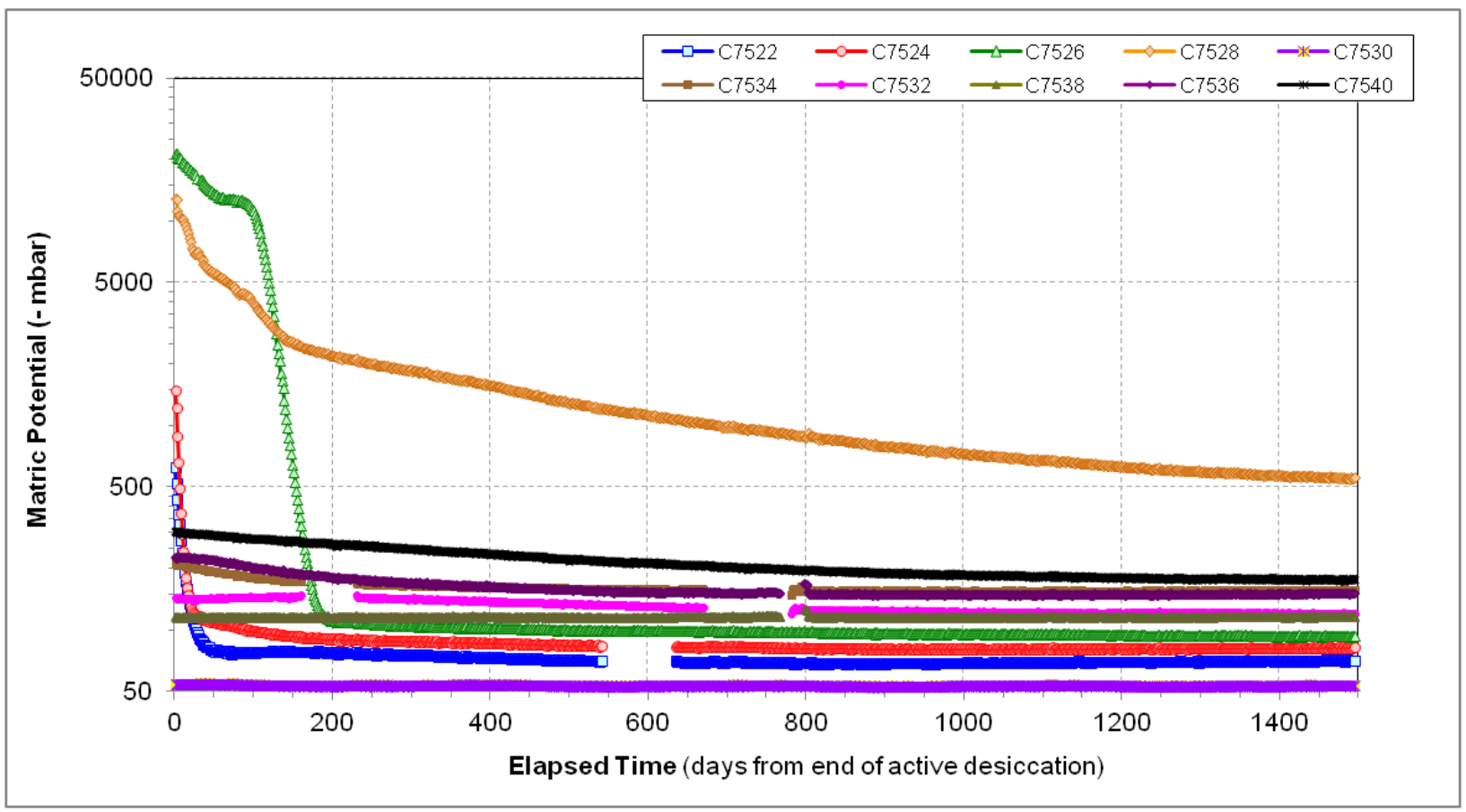

Figure 4.5. Post-desiccation heat dissipation unit response over time for the sensors at a depth of $42.5 \mathrm{ft}$ $(13 \mathrm{~m})$ bgs. Note that the y-axis uses a logarithmic scale. 


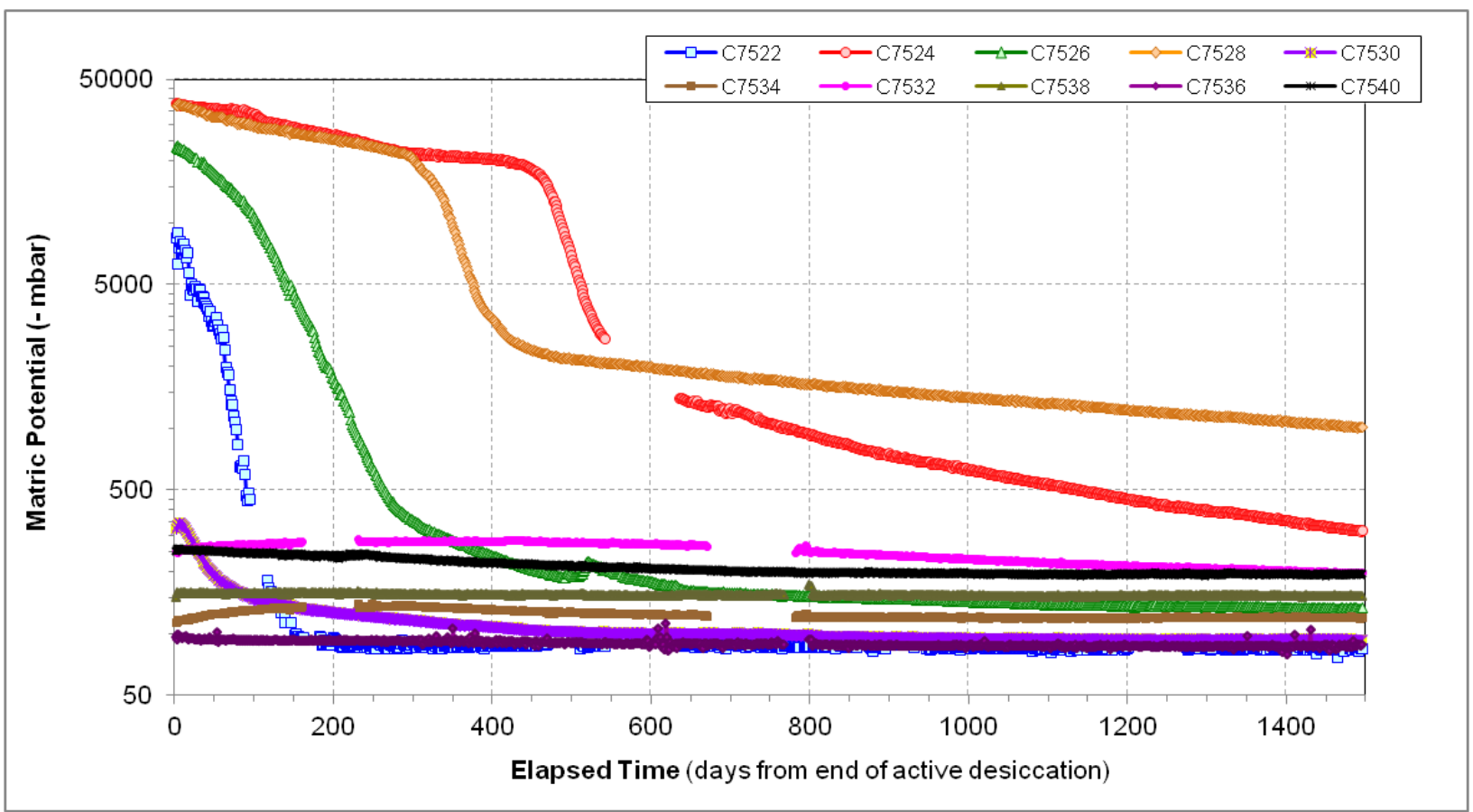

Figure 4.6. Post-desiccation heat dissipation unit response over time for the sensors at a depth of $47.5 \mathrm{ft}$ $(14.5 \mathrm{~m})$ bgs. Note that the $y$-axis uses a logarithmic scale.

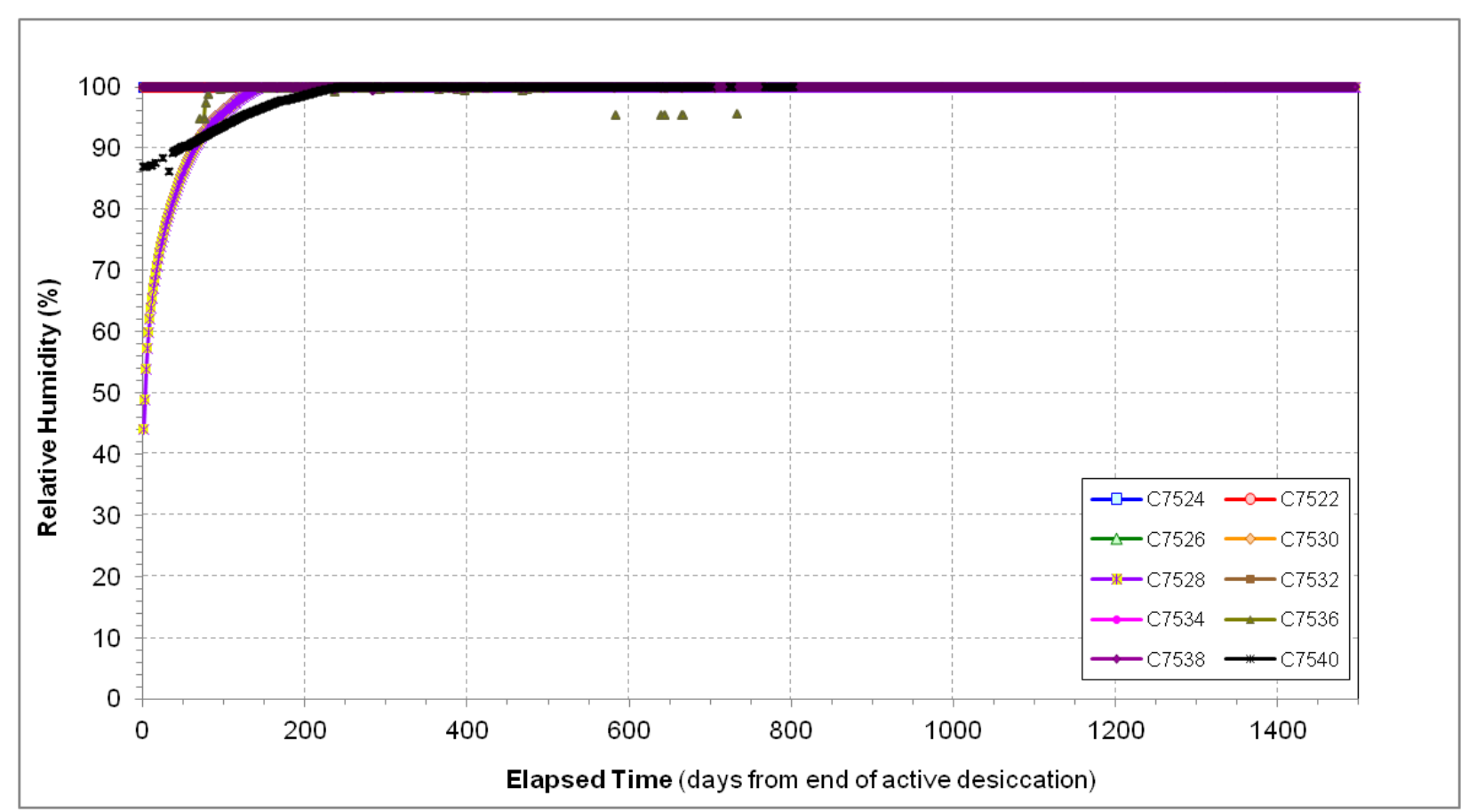

Figure 4.7. Post-desiccation relative humidity probe response over time for the sensors at a depth of $42.5 \mathrm{ft}(13 \mathrm{~m}) \mathrm{bgs}$ 


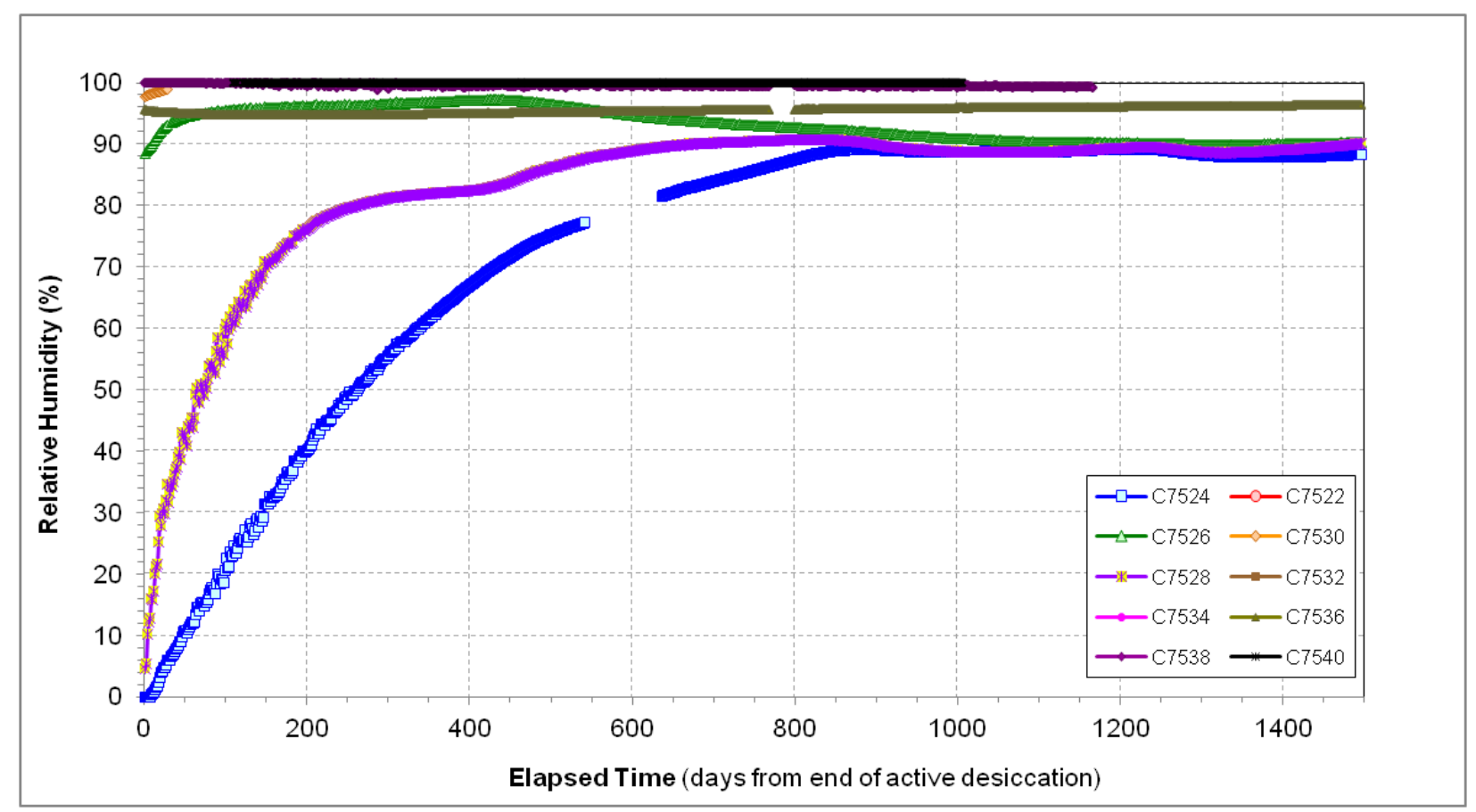

Figure 4.8. Post-desiccation relative humidity probe response over time for the sensors at a depth of $47.5 \mathrm{ft}(14.5 \mathrm{~m})$ bgs

Temperatures at the key depths of $32.5,36.5,42.5$, and $46.5 \mathrm{ft}$ bgs exhibited some variation within about the first 100 days after the end of active desiccation. For the depth of $46.5 \mathrm{ft}$ (14.2 $\mathrm{m}$ ) bgs, several locations (C7524, C7522, C7526, C7528, and, to some extent, C7530) had reached a state of higher temperatures during active desiccation as a result of drying to the point where evaporative cooling was no longer occurring. In contrast, evaporative cooling was still occurring at locations C7532, C7534, and C7536 for the $46.5 \mathrm{ft}$ bgs depth, so those locations had low temperatures at the end of active desiccation operations. By about 100 days after active desiccation, temperatures at all locations for the $46.5 \mathrm{ft}$ bgs depth were converging. Beyond these initial post-active desiccation variations, the temperatures at all four key depths have continued a gradual increase over time at locations near the injection well and are now less than $1{ }^{\circ} \mathrm{C}$ different from temperatures at distant/background locations. All temperatures at these four depths are converging to approximately $16^{\circ} \mathrm{C}$.

Several locations at depths of 42.5 and $47.5 \mathrm{ft}$ (13 and $14.5 \mathrm{~m}$ ) bgs had exhibited a significant change in matric potential (as measured with the heat dissipation unit sensors) to values between -5000 and -50000 mbar during active desiccation, indicating that significant drying occurred. After the end of active desiccation, the matric potential returned to nominally the pre-desiccation levels for most locations that had indicated drying. At a depth of $42.5 \mathrm{ft}(13 \mathrm{~m}) \mathrm{bgs}$, the matric potential at locations $\mathrm{C} 7522$ and $\mathrm{C} 7524$ returned to around -75 to -100 mbar in a fairly short time frame $(<100$ days) after the end of active desiccation. Matric potential at location C7526 for the $42.5 \mathrm{ft}$ bgs depth shows a 100-day lag before a relatively rapid change from -13000 mbar to values near -100 mbar by 200 days after end of active desiccation. At location C7528 for the $42.5 \mathrm{ft}$ depth, the matric potential indicated a more gradual rewetting, with conditions slowly getting wetter with current conditions at about -500 mbar, drier than pre-desiccation conditions (about -180 mbar). At the deeper $47.5 \mathrm{ft}$ (14.5 m) locations, matric potential 
indicated a somewhat slower rewetting. Location C7530, which was just beginning to show changes in matric potential indicative of drying at the end of active desiccation, quickly returned to pre-desiccation levels within about 100 days. Matric potential at C7522 for the $47.5 \mathrm{ft}$ depth also had a relatively quick (within about 200 days) return to pre-desiccation matric potential. The return to pre-desiccation matric potential at the $\mathrm{C} 7526$ location for the $47.5 \mathrm{ft}$ depth was delayed and more gradual than observed by the corresponding sensor at the $42.5 \mathrm{ft}$ depth for that location. Matric potential at the $47.5 \mathrm{ft}$ depth at the C7528 location exhibited a similar gradual rewetting and has continued a slow rewetting rate with current readings at about -1000 mbar. At the $C 7524$ location for the $47.5 \mathrm{ft}$ depth, unlike the $42.5 \mathrm{ft}$ depth, the matric potential showed rewetting after a much longer delay (about 450 days after the end of active desiccation) and a more gradual rewetting that is currently near -400 mbar.

Several humidity sensors exhibited a transition to low relative humidity during active desiccation operation, indicating that drying was occurring. After the end of active desiccation, the lower relative humidity at a depth of $42.5 \mathrm{ft}(13 \mathrm{~m})$ for the $\mathrm{C} 7528$ location showed a relatively prompt (within about 150 days after the end of active desiccation) return to $100 \%$ relative humidity. While the humidity at a depth of $42.5 \mathrm{ft}(13 \mathrm{~m})$ for the $\mathrm{C} 7540$ location (background sensor) appeared to show a recovery to $100 \%$ relative humidity, this probe had previously shown essentially constant readings of about $85-90 \%$ since installation, so its readings are not considered accurate indications of humidity at that location. Humidity sensors at the $47.5 \mathrm{ft}(14.5 \mathrm{~m})$ depth for locations C7524 and C7528 have shown a much more gradual return to high humidity values. Since about 800 days after the end of active desiccation, these two sensors appear to have stabilized at around $90 \%$ relative humidity. At the C7526 location for the 47.5 $\mathrm{ft}(14.5 \mathrm{~m})$ depth, moderate decreases in humidity were observed near the end of the active desiccation period. The humidity quickly rebounded at this location, although the humidity values have drifted over time, showing a decrease to about $90 \%$ relative humidity in the most recent readings. Several of the humidity probes both during and after active desiccation have shown readings below $100 \%$ relative humidity when it was expected that the relative humidity should be $100 \%$. Thus, it is unclear whether these readings are accurate.

\subsubsection{Neutron Data}

Vertical profiles from neutron moisture logging events conducted pre-desiccation, just after active desiccation, and for three years of annual surveys after desiccation are plotted in Figures 4.9 through 4.15 to depict the relative rewetting that has occurred during this time frame. These data show a clear progression of rewetting. At the C7527 and C7529 monitoring locations, the thicker desiccated zones have shown the least rewetting. These thicker desiccated zones were areas of high injected air flow due

to the presence of coarser, lower-moisture content sediments. Plots containing all of the neutron surveys that have been conducted (pre-desiccation, July 2011, August 2011, September 2011, December 2011, February 2012, May 2013, August 2013, March 2014, August 2014, March 2015, and August 2015) are included in Appendix A. 


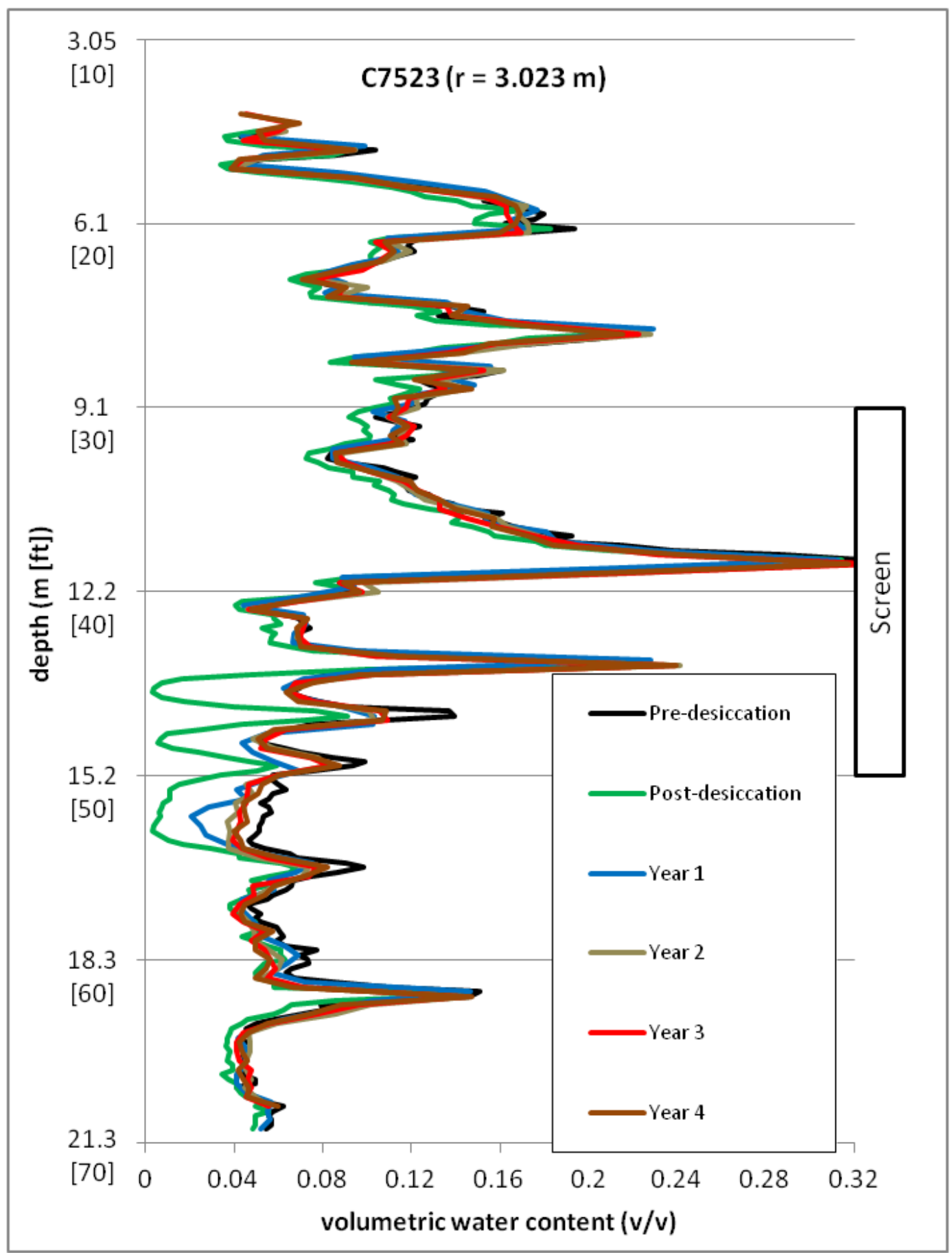

Figure 4.9. Neutron moisture probe response over time for location C7523 (3.023 $\mathrm{m}$ from injection well). The pre-desiccation data are from a logging event in December 2010, prior to the continuous active desiccation period. Other data are for logging events after active desiccation ended. 


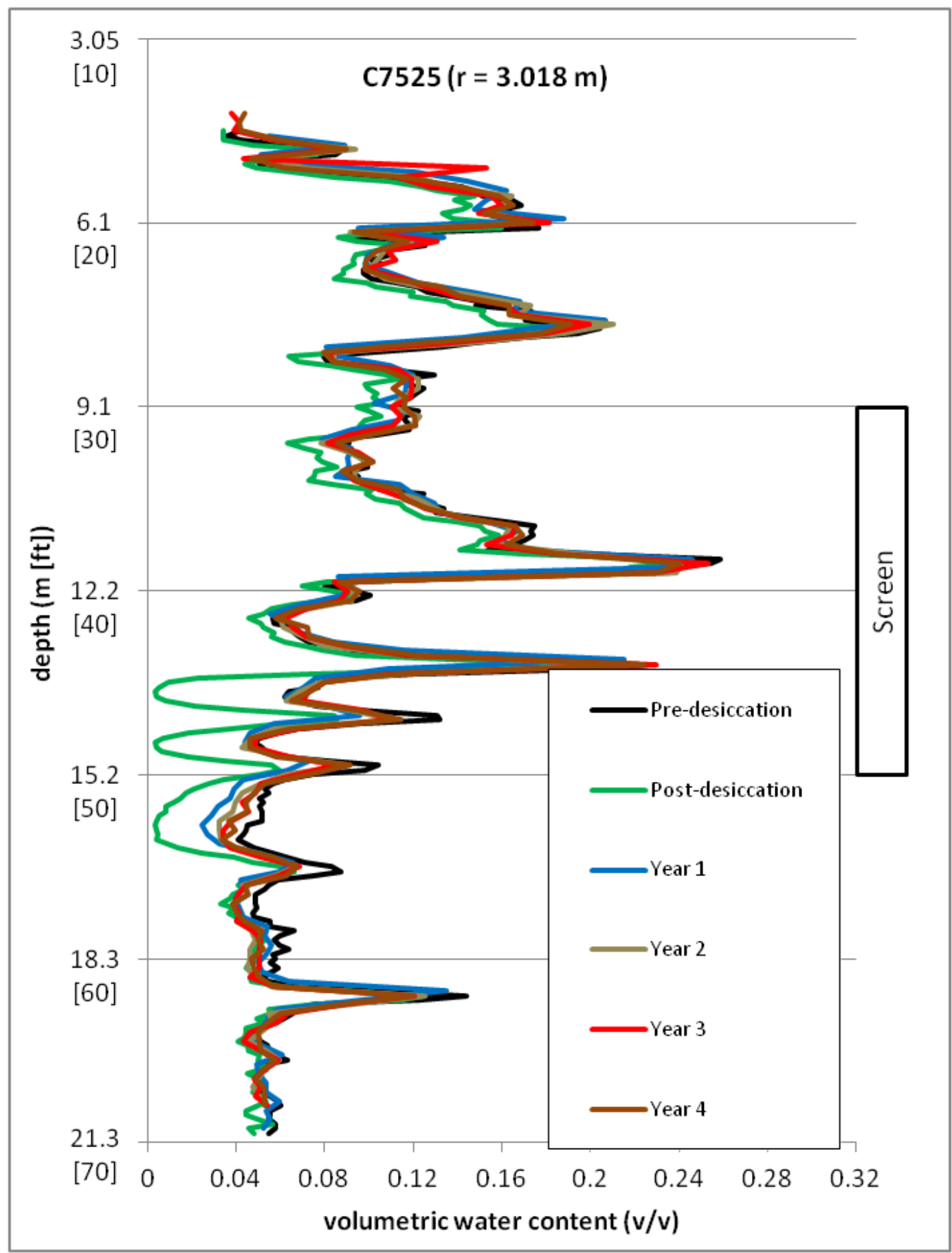

Figure 4.10. Neutron moisture probe response over time for location C7525 (3.018 m from injection well). The pre-desiccation data are from a logging event in December 2010, prior to the continuous active desiccation period. Other data are for logging events after active desiccation ended. 


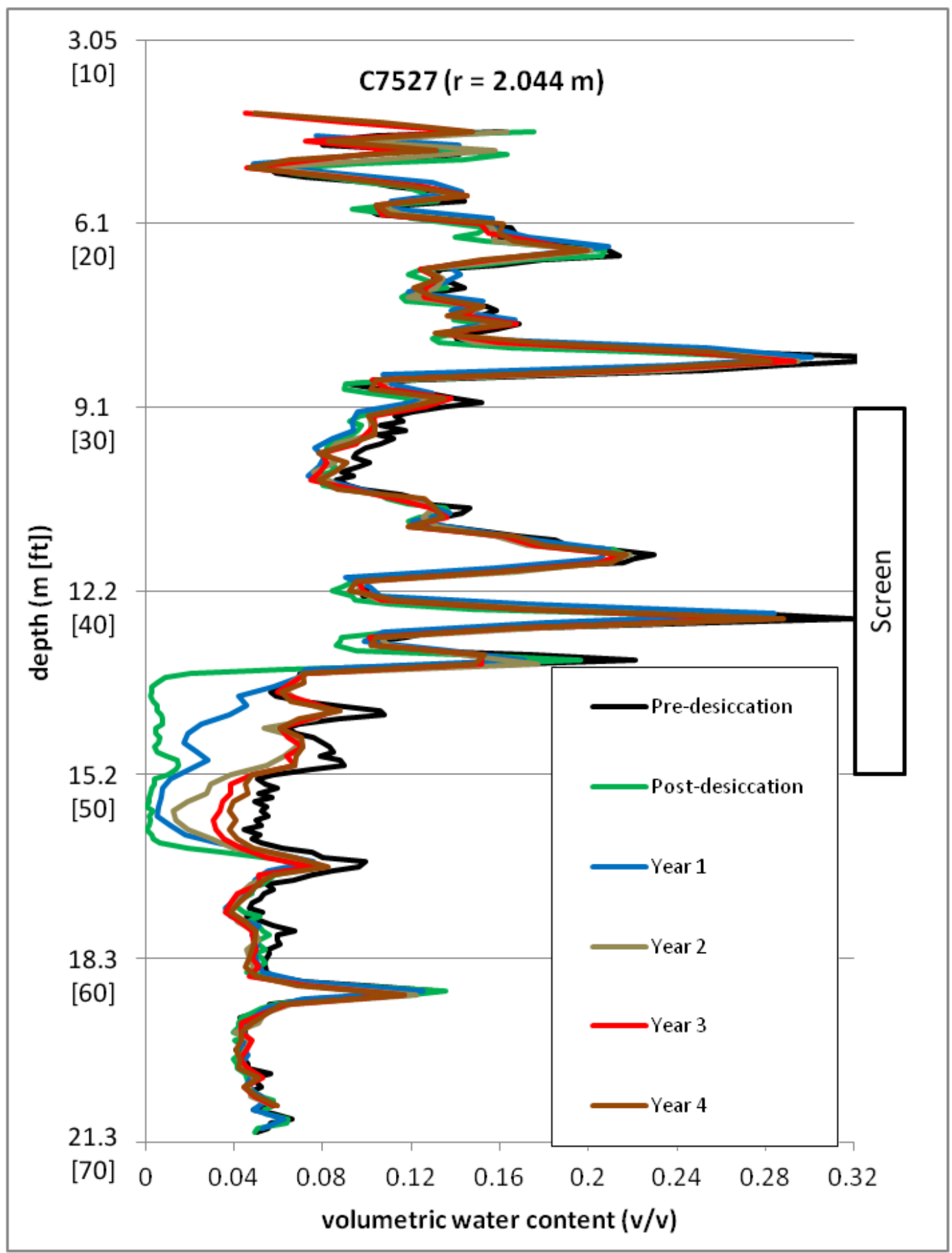

Figure 4.11. Neutron moisture probe response over time for location C7527 (2.044 m from injection well). The pre-desiccation data are from a logging event in December 2010, prior to the continuous active desiccation period. Other data are for logging events after active desiccation ended. 


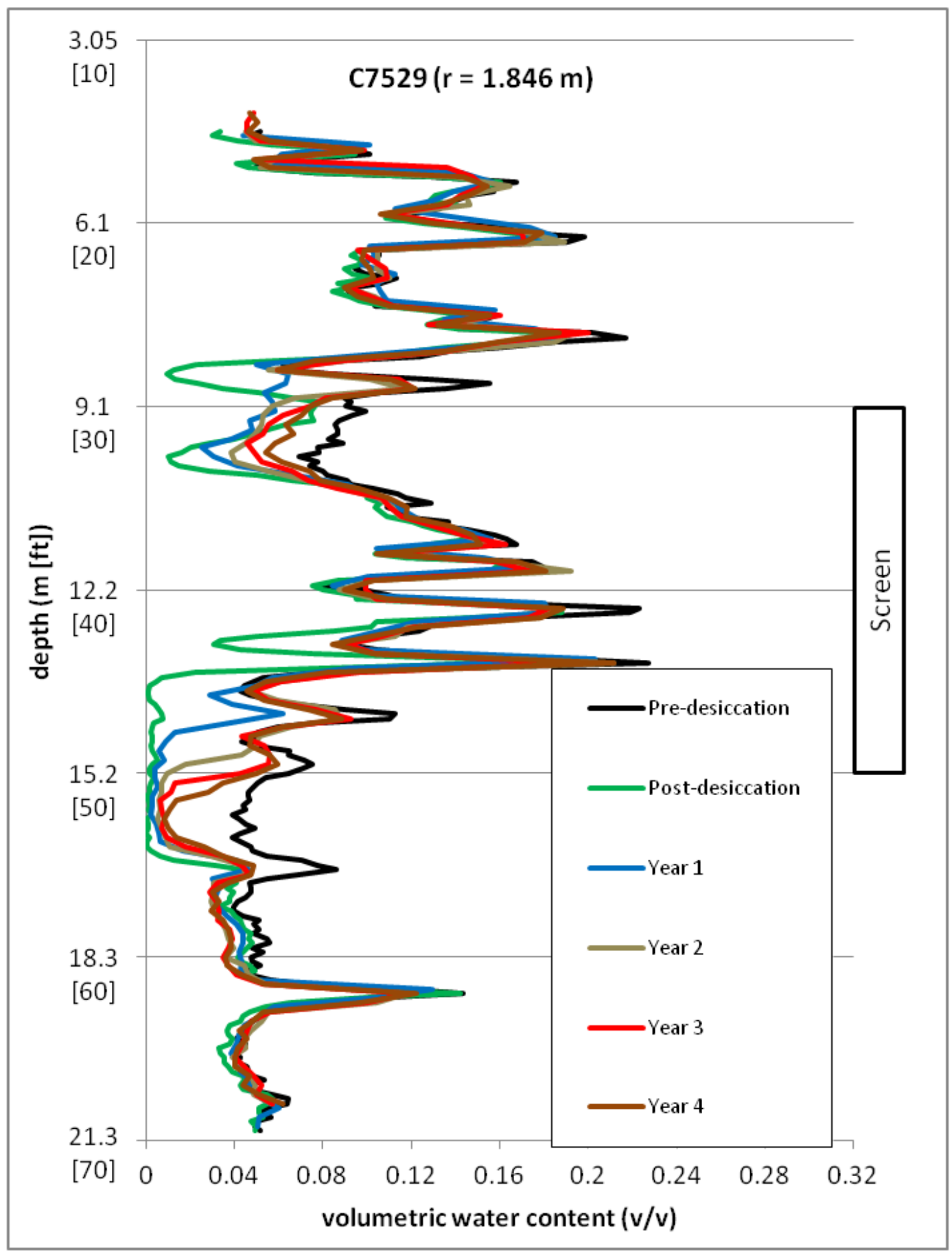

Figure 4.12. Neutron moisture probe response over time for location C7529 (1.846 m from injection well). The pre-desiccation data are from a logging event in December 2010, prior to the continuous active desiccation period. Other data are for logging events after active desiccation ended. 


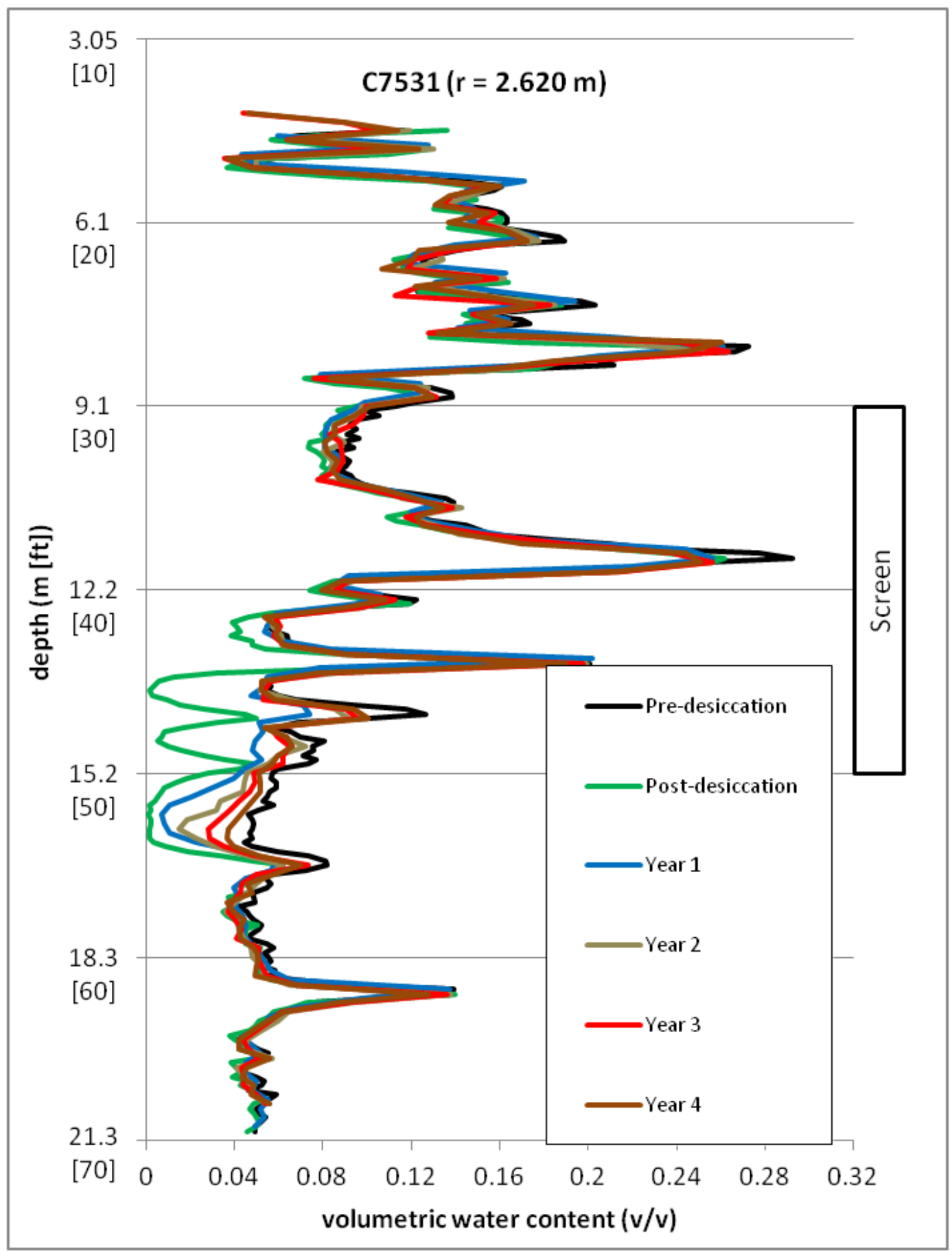

Figure 4.13. Neutron moisture probe response over time for location C7531 (2.620 m from injection well). The pre-desiccation data are from a logging event in December 2010, prior to the continuous active desiccation period. Other data are for logging events after active desiccation ended. 


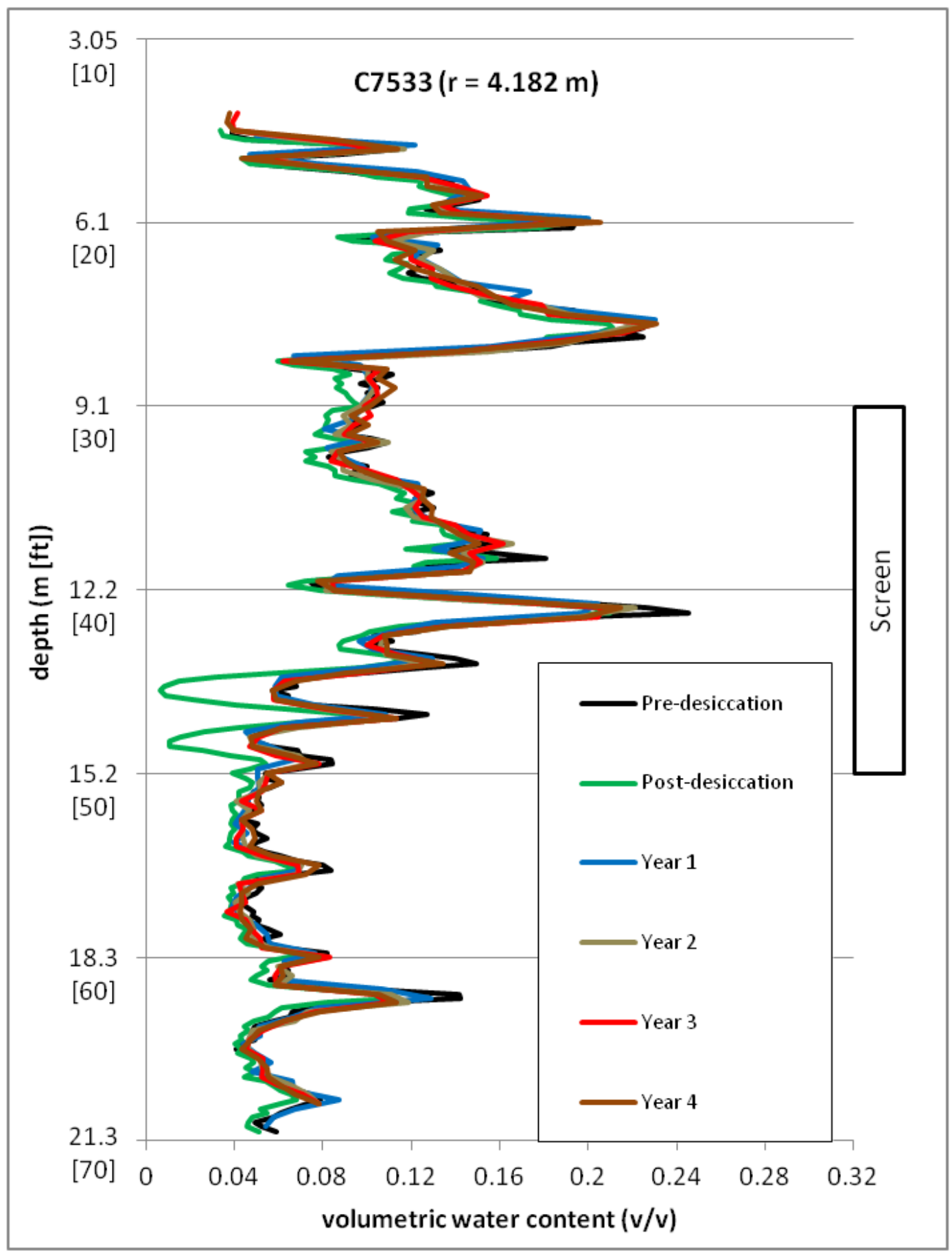

Figure 4.14. Neutron moisture probe response over time for location C7533 (4.182 $\mathrm{m}$ from injection well). The pre-desiccation data are from a logging event in December 2010, prior to the continuous active desiccation period. Other data are for logging events after active desiccation ended. 


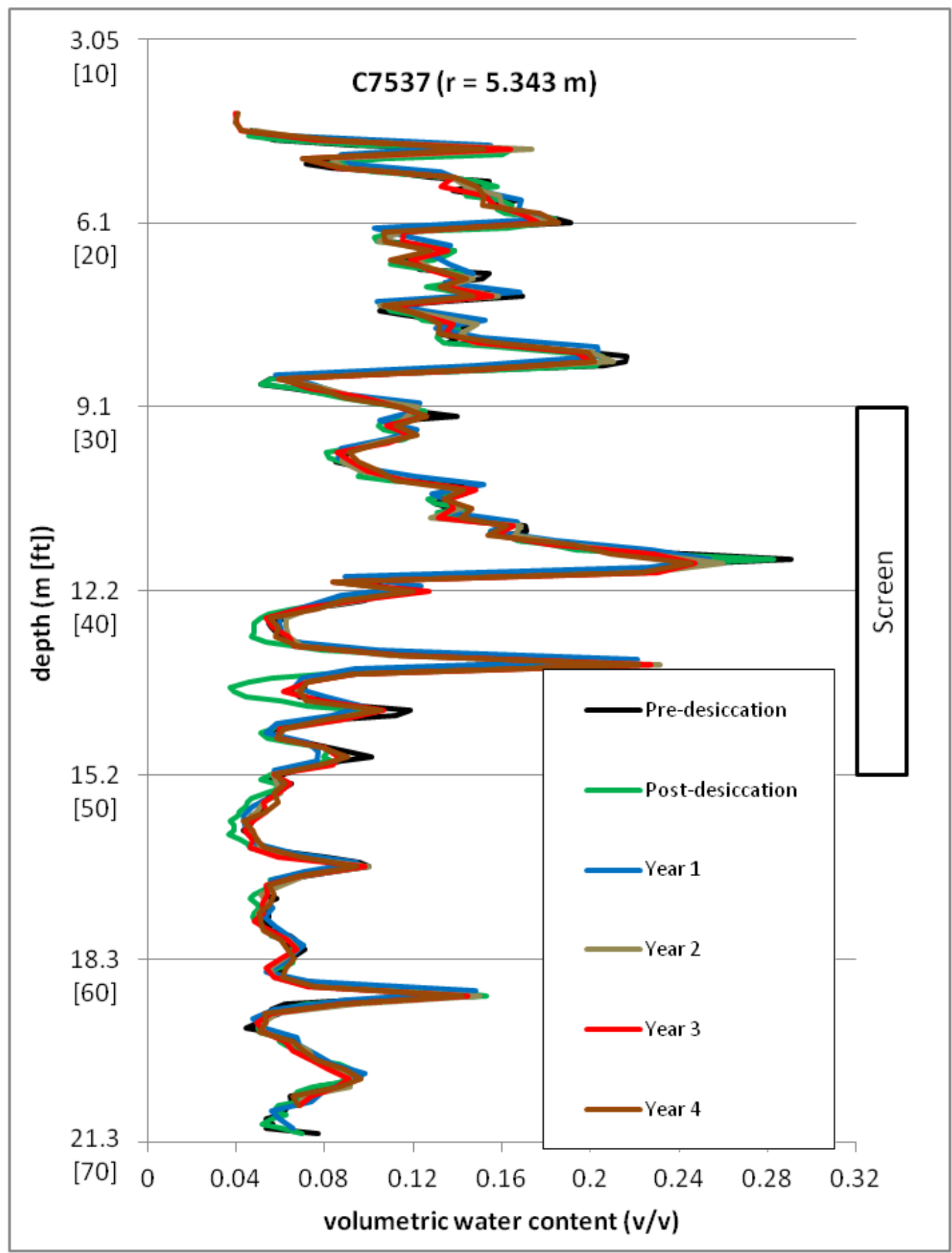

Figure 4.15. Neutron moisture probe response over time for location C7537 (5.343 m from injection well). The pre-desiccation data are from a logging event in December 2010, prior to the continuous active desiccation period. Other data are for logging events after active desiccation ended. 


\subsubsection{Geophysical Data}

Periodic GPR survey data were collected during post-desiccation monitoring. The GPR-interpreted volumetric moisture content distribution at day 137 during active desiccation and days 193, 265, 650, 770, 980, and 1500 after the end of active desiccation are shown in Figure 4.16. Note that the GPR data at day 137, during desiccation, are prior to the end of active desiccation (e.g., day 164) such that conditions were likely dryer at the onset of the post-desiccation monitoring period. The post-desiccation GPR data show a general increase in volumetric moisture content over time within the $2 \mathrm{D}$ survey cross section. In some areas, localized re-distribution of moisture has caused drying of some small zones as water moved to adjacent dryer zones. The GPR data indicate that the driest zones during desiccation near the injection well, including about $10 \mathrm{~m}$ bgs and about $15 \mathrm{~m} \mathrm{bgs}$, have remained the driest over time, although, within the resolution of the GPR analysis, they have increased in moisture content after the end of active desiccation. The GPR data show that the moisture content within these portions of the survey cross section is still dryer than pre-desiccation conditions (Figure 4.17). 

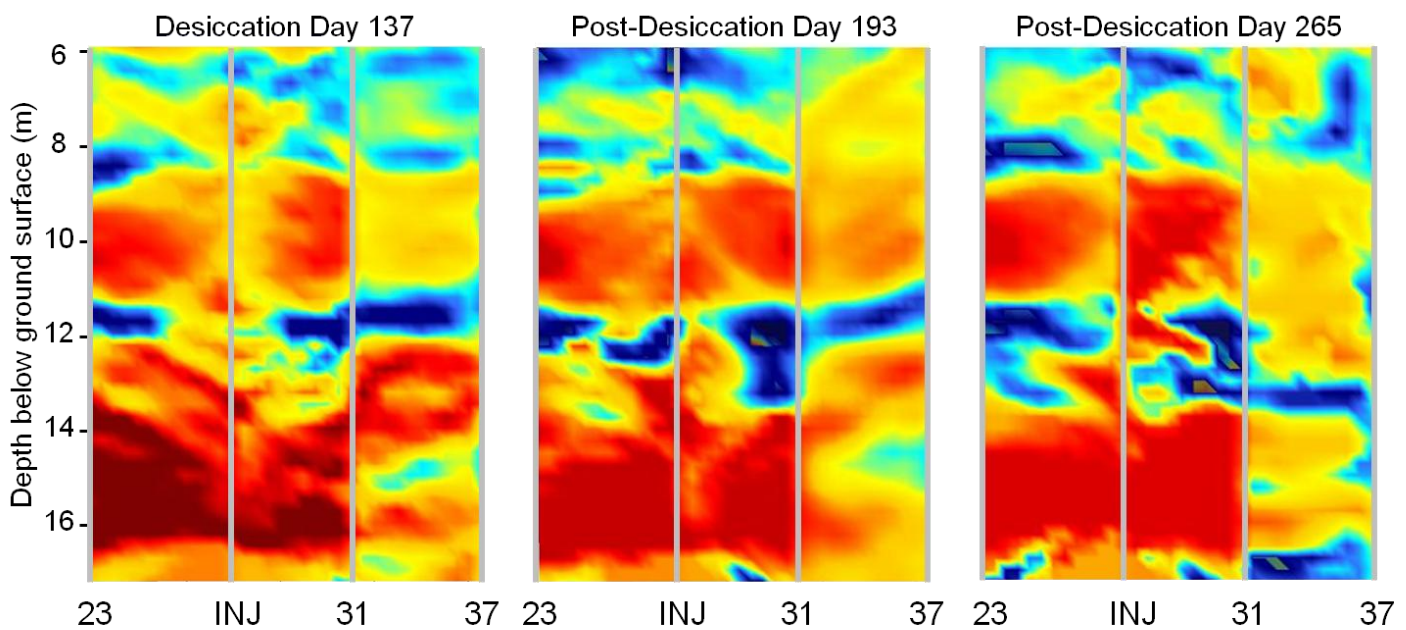

$\stackrel{+}{\dot{t}}$
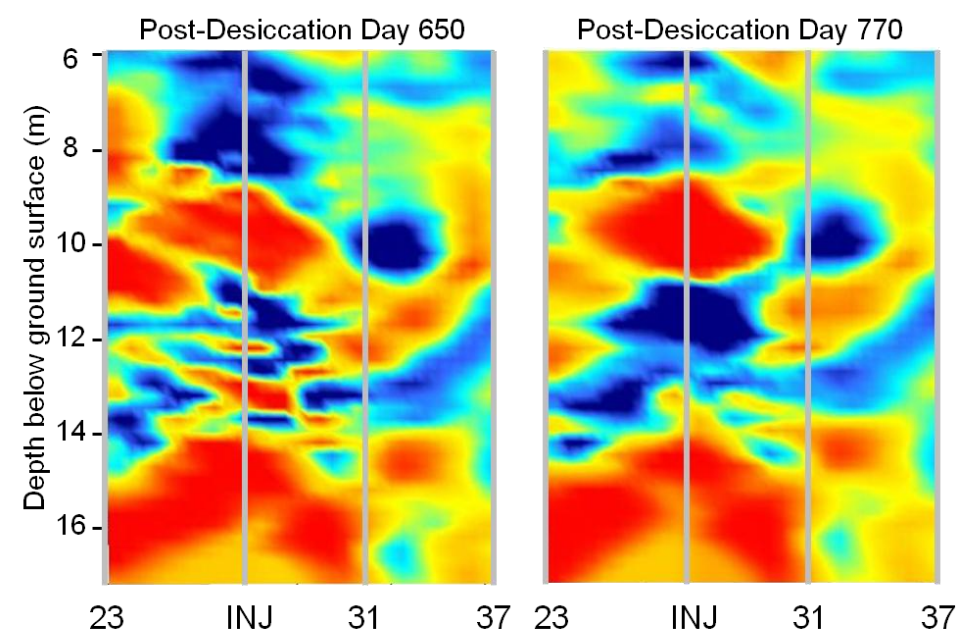

Post-Desiccation Day 980

Post-Desiccation Day 1500
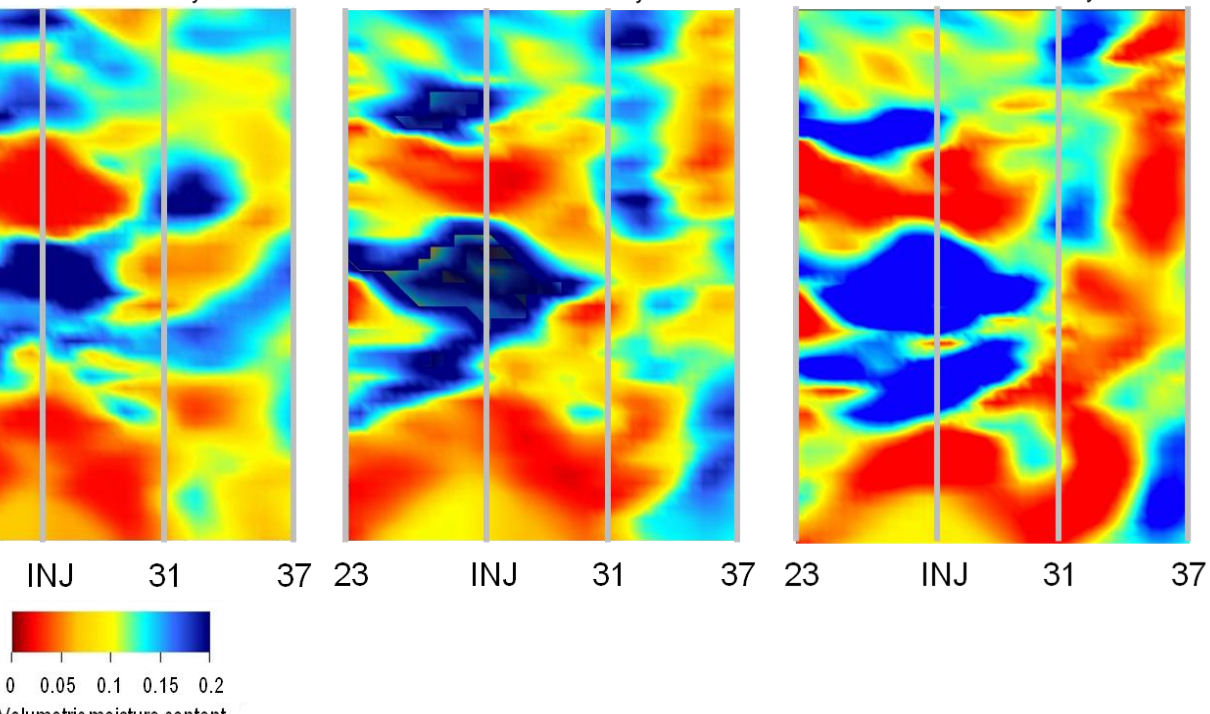

Volumetric moisture content

Figure 4.16. 2D interpretation of volumetric moisture content from cross-hole ground penetrating radar data during desiccation (left) at day 137 (June 3, 2011) and after the end of active desiccation. Locations are shown as INJ (injection well) and logging well locations are indicated by the last two numbers in the location identifier (e.g., $23=$ C7523). 


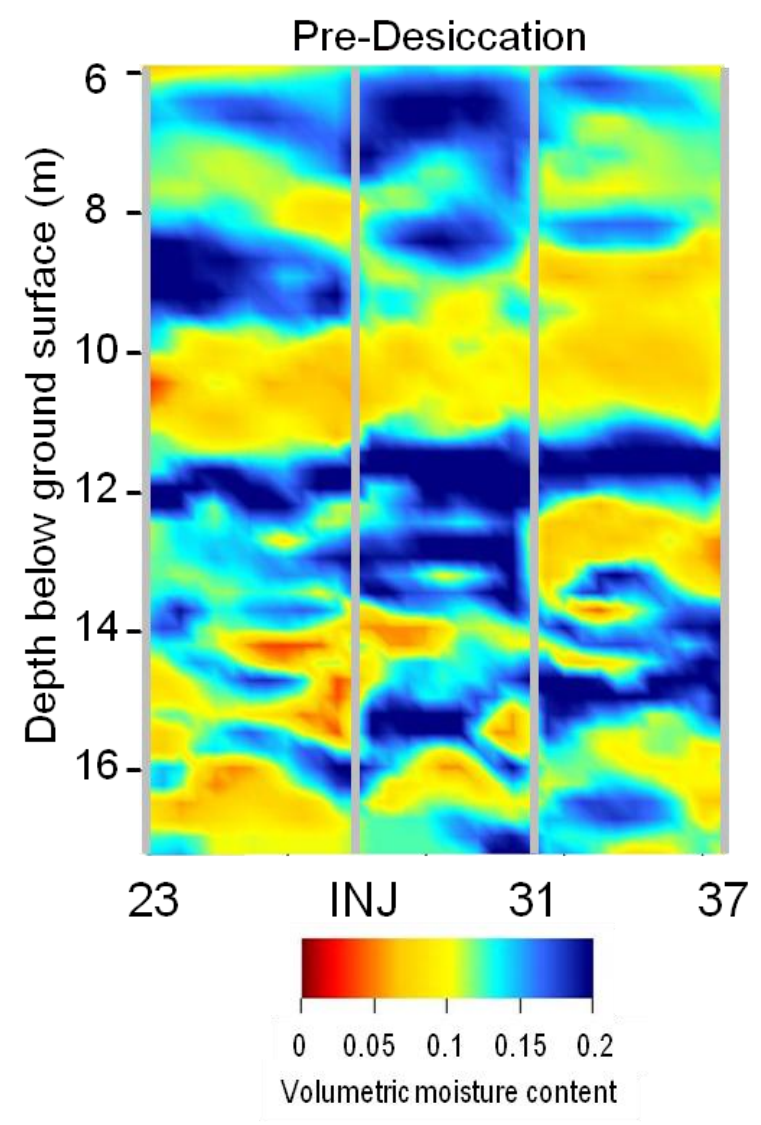

Figure 4.17. $2 \mathrm{D}$ interpretation of initial volumetric moisture content from cross-hole ground penetrating radar data prior to desiccation. Locations are shown as INJ (injection well) and logging well locations are indicated by the last two numbers in the location identifier (e.g., $23=$ C7523).

Interpretation of the 2D moisture content representation should consider that conversion of GPRderived permittivity to volumetric moisture content (VMC) is affected by EC. Desiccation reduces the EC, which renders GPR data acquisition more favorable within desiccated zones, and improves the accuracy of the GPR-derived moisture content estimate. For example, Figure 4.18 shows the ERTderived EC distribution along the GPR survey transect at the end of desiccation and at days 650, 770, 980, and 1500 post-desiccation. The black regions illustrate where low EC, or low-loss, assumptions may not be valid $(\mathrm{EC}>0.05 \mathrm{~S} / \mathrm{m})$. Prior to desiccation, the low-loss assumption was generally valid above a depth of $10 \mathrm{~m}$ and invalid below $10 \mathrm{~m}$. At the end of desiccation, low-conductivity conditions have been established within a zone from depths of approximately $13 \mathrm{~m}$ to $15 \mathrm{~m}$ (Figure 4.18). Within this depth interval, GPR-derived moisture content estimates correlated well with estimates from neutron moisture logging (Truex et al. 2012a). Within zones where desiccation has decreased the EC, GPR can be used with confidence to estimate the moisture content distribution between wells. At 650 days postdesiccation, low-loss conditions mostly remain within the 13-m to 15-m zone. However, by postdesiccation days 770 and 980 , this zone appears to be recovering sufficiently such that low-loss conditions may no longer be applicable. Day 1500 data shows some apparent recovery of the low conductivity conditions, although this is contrary to the expected trend based on neutron moisture data. 

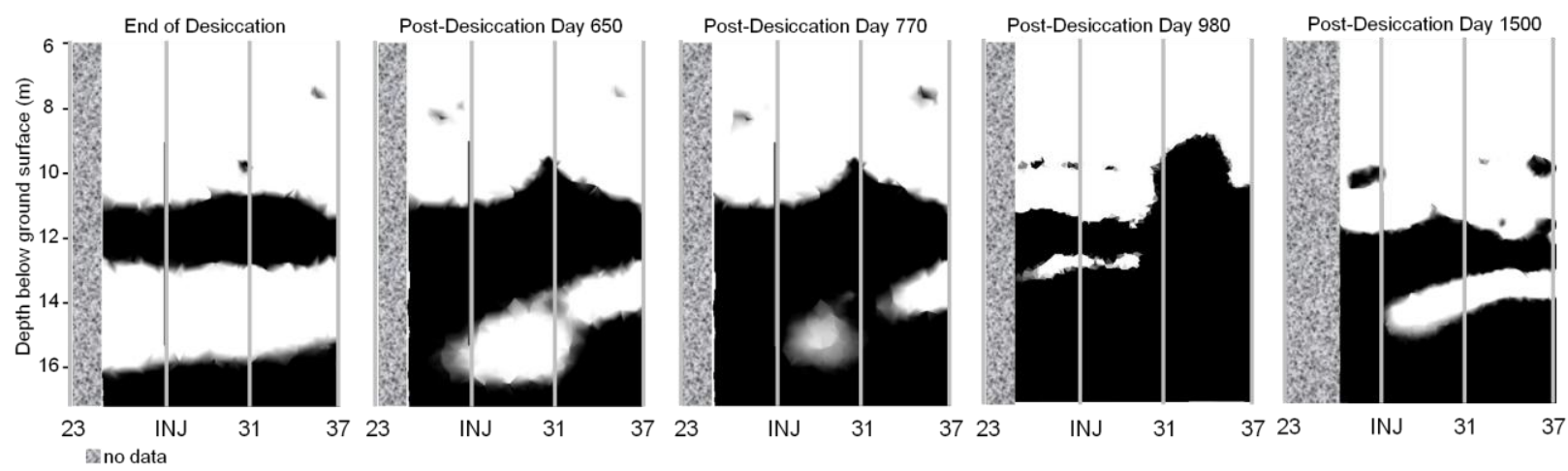

Figure 4.18. 2D image showing regions where GPR low-loss conditions (white) are valid, resulting in higher confidence in GPR-derived moisture content estimates. Locations are shown as INJ (injection well) and logging well locations are indicated by the last two numbers in the location identifier (e.g., $23=\mathrm{C} 7523$ ).

ERT monitoring was continued without interruption after active desiccation was terminated. Figure 4.19 shows the ERT interpretation of changes in the VMC expressed as the ratio of VMC at the time of the measurement to the $\mathrm{VMC}$ at the end of active desiccation $\left(\mathrm{VMC}_{0}\right)$. A ratio of 1 designates areas that have not changed from the conditions at the end of active desiccation. Ratios higher than 1 indicate rewetting; for instance, a ratio of 3 means that the volumetric moisture content is 3 times higher than it was at the end of active desiccation. Ratios lower than 1 indicate drying; for instance, a ratio of 0.75 means that the VMC is 0.75 times what it was at the end of active desiccation. The resolution of the ERT data inversion is on the order of a cubic meter. Thus, the ERT images cannot show sharp contrasts in wetting or drying zones over time, but show a "smoothed" image of how the subsurface is changing. As time progresses, some regions in the test area get wetter (proceeding from green to yellow to orange in color). The moisture for rewetting is being drawn from adjacent regions, as shown by areas that have become dryer (darker blue color). Day 1500 data shows some apparent receding of the rewetting extent, although this is contrary to the expected trend based on neutron moisture data. 

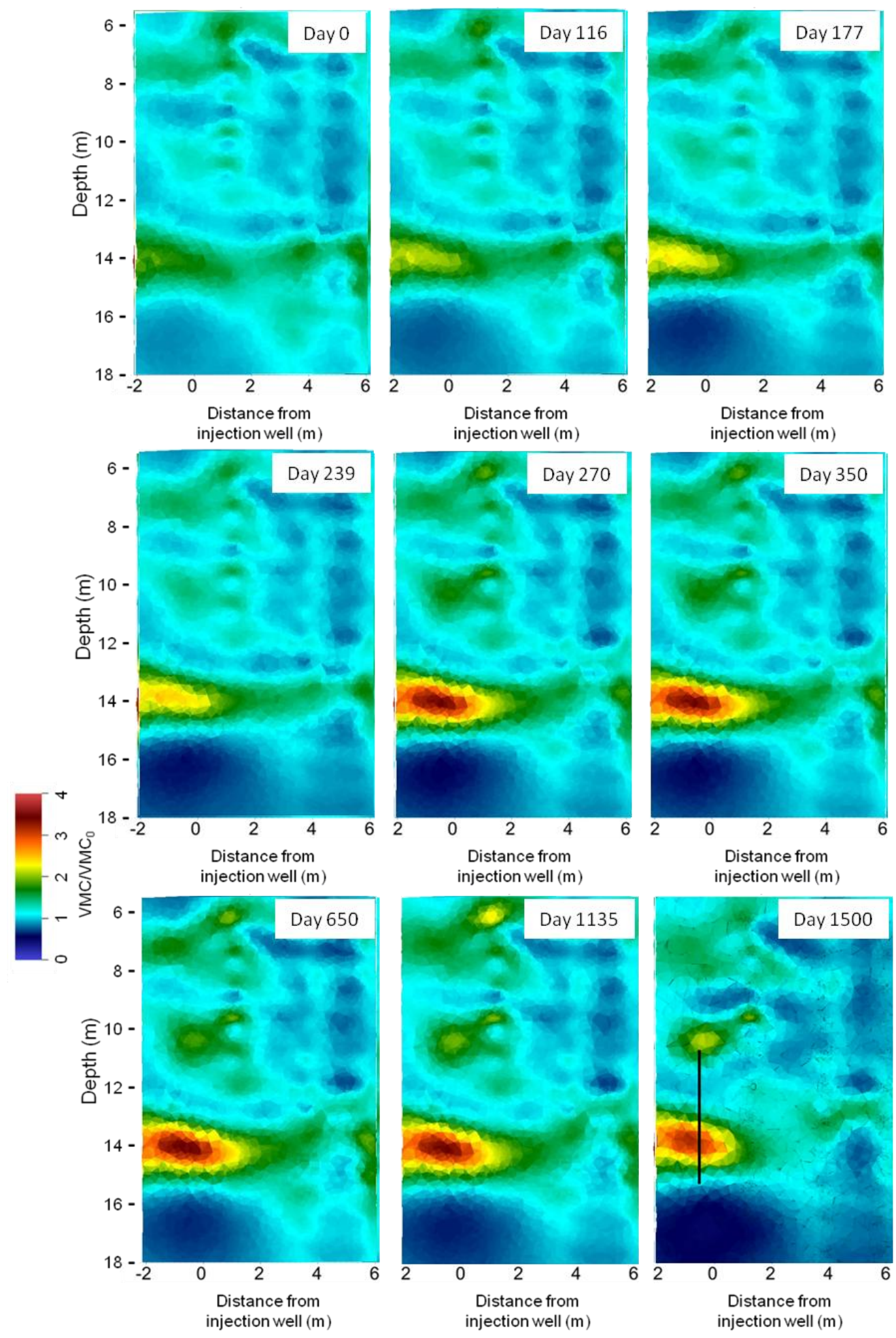

Figure 4.19. Ratio of Volumetric Moisture Content (VMC) to the Volumetric Moisture Content at the End of Active Desiccation $\left(\mathrm{VMC}_{0}\right)$ over time along the axis between the injection and extraction wells from cross-hole electrical resistivity tomography. ERT data are from sensors at locations C7522-C7534 through day 1500 of the post-desiccation period (Figure 3.6). 


\subsection{Rewetting Assessment using Three-Dimensional Flow Modeling}

In earlier assessments of the rewetting process, Truex et al. $(2013,2014)$ showed that rewetting of the desiccated zones occurs relatively fast, consistent with expectations based on related laboratory analyses. Since the end of the desiccation period in 2011, a significant portion of the desiccated zone has been rewetted over a period of three years (Section 4.1; Truex et al. 2014). The numerical analysis reported in Truex et al. (2013) showed that although some lateral rewetting through water advection could occur, the observed desiccation in the field could not fully be explained by lateral migration alone. The initial modeling results indicated that a three-dimensional (3-D) analysis is needed to fully assess subsurface rewetting. To this end, a 3-D model was developed, with numerical model implementation using the STOMP code (White et al. 2006), to conduct a number of scoping simulations.

\subsubsection{Methods}

The conceptual model represents the subsurface at the Hanford Site 200-BC-2 Operable Unit between the 30 by $45 \mathrm{~m}$ geomembrane, emplaced in June 2009, and the water table at 105 bgs. Using a laser particle size distribution measurement method for sediment samples collected from well C8388, a layered system was developed using Loamy Sand, Sandy Loam, and Silt Loam layers in an otherwise Sanddominated matrix. The hydraulic properties of these layers, according to Carsel and Parrish (1988), are shown in Table 4.1, with their depth intervals in the model listed in Table 4.2. In the simulations, the Van Genuchten (1980) water content - capillary pressure relations are used and the Mualem (1976) model is used for the water relative permeability - water content relations.

Table 4.1. Hydraulic properties of the sediments used in the STOMP simulations (Carsel and Parrish 1988)

\begin{tabular}{lccccc}
\hline Sediment & $\begin{array}{c}\text { Ran Genuchten } \\
\alpha(1 / \mathrm{cm})\end{array}$ & $\begin{array}{c}\text { Residual Volumetric } \\
\text { Water Content } \\
\left(\mathrm{m}^{3} \text { liquid }\right.\end{array}$ \\
$\mathrm{m}^{3}$ pore space $)$ & $\begin{array}{c}\text { Hydraulic } \\
\text { Conductivity, } K_{\text {sat }} \\
(\mathrm{cm} / \mathrm{hr})\end{array}$ & $\begin{array}{c}\text { Porosity } \\
(-)\end{array}$ \\
\hline Sand & $1.45 \times 10^{-1}$ & 2.68 & 0.045 & 29.70 & 0.43 \\
Sandy Loam & $7.50 \times 10^{-2}$ & 1.89 & 0.035 & 4.42 & 0.41 \\
Loamy Sand & $1.24 \times 10^{-1}$ & 2.28 & 0.037 & 14.59 & 0.41 \\
Silt Loam & $2.00 \times 10^{-2}$ & 1.41 & 0.067 & 0.45 & 0.45 \\
\hline
\end{tabular}

Table 4.2. Vertical location of lower-permeability layers. The layers in the desiccated zone $(12.25-16 \mathrm{~m} \mathrm{bgs})$ are in bold.

\begin{tabular}{cc}
\hline Sediment & Layer Depths $(\mathrm{m}$ bgs $)$ \\
\hline Sandy Loam & $5.5-6 ; 7.25-7.5 ; 11.25-11.875 ; \mathbf{1 2 . 5} \mathbf{- 1 3} ; \mathbf{1 3 . 5}-\mathbf{1 4} ; 18.5-19$ \\
Loamy Sand & $6-6.4 ; 7.5-7.75 ; 8.5-8.75 ; \mathbf{1 2 . 2 5}-\mathbf{1 2 . 5} ; \mathbf{1 4 . 7 5}-\mathbf{1 5 . 2 5}$ \\
Silt Loam & $8-8.5$ \\
\hline
\end{tabular}


A steady-state simulation was first conducted to establish the pre-operational conditions at the site. Assuming that all BC cribs were built at approximately the same time in 1955, it was assumed that prior to construction and operation, the area was most likely covered by Rupert Sand with a shrub steppe plant community. Based on recommendations by Last et al. (2006) a best estimate recharge rate of $4 \mathrm{~mm} / \mathrm{yr}$ was assumed for this period. A steady-state pressure distribution for this recharge rate was used as the initial condition for the period from 1955 to the end of the desiccation period on June 30, 2011. In the simulation, a recharge rate of $30 \mathrm{~mm} /$ year was imposed for the operation period and post-operation period from 1955 through 1981 when the groundcover consisted of disturbed Rupert Sand with no vegetation (Last et al. 2006). In 1981 the BC-crib area was surface stabilized as a single area. All surface structures (risers and vents) were removed and the area was covered with $2.5 \mathrm{ft}$ of soil and re-vegetated with wintergraze, thickspike, and crested Siberian wheatgrasses). The surface cover after stabilization and revegetation is estimated to be a disturbed Rupert Sand with a young shrub-steppe plant community. For this cover, Last et al. (2006) suggest a best estimate recharge rate of $8 \mathrm{~mm} / \mathrm{yr}$. This rate was used from 1981 through the middle of 2009 when the geomembrane was installed. For this cover, a recharge of 0 $\mathrm{mm} / \mathrm{yr}$ was used. The pressure distribution on June 302011 was then used as the initial conditions of the rewetting simulations. For these simulations, it was assumed that either a $7 \times 7 \mathrm{~m}$ or a $5 \times 5 \mathrm{~m}$ zone was instantly desiccated between 12.25 and $16.0 \mathrm{~m}$ bgs by imposing a post-desiccation matrix potential of 5 bars. The position of the two areas related to the logging wells are shown in Figure 4.20. The vertical extent of the simulated desiccation zone was chosen based on observations reported in Truex et al. (2013). The rewetting simulation time was 100 years. 


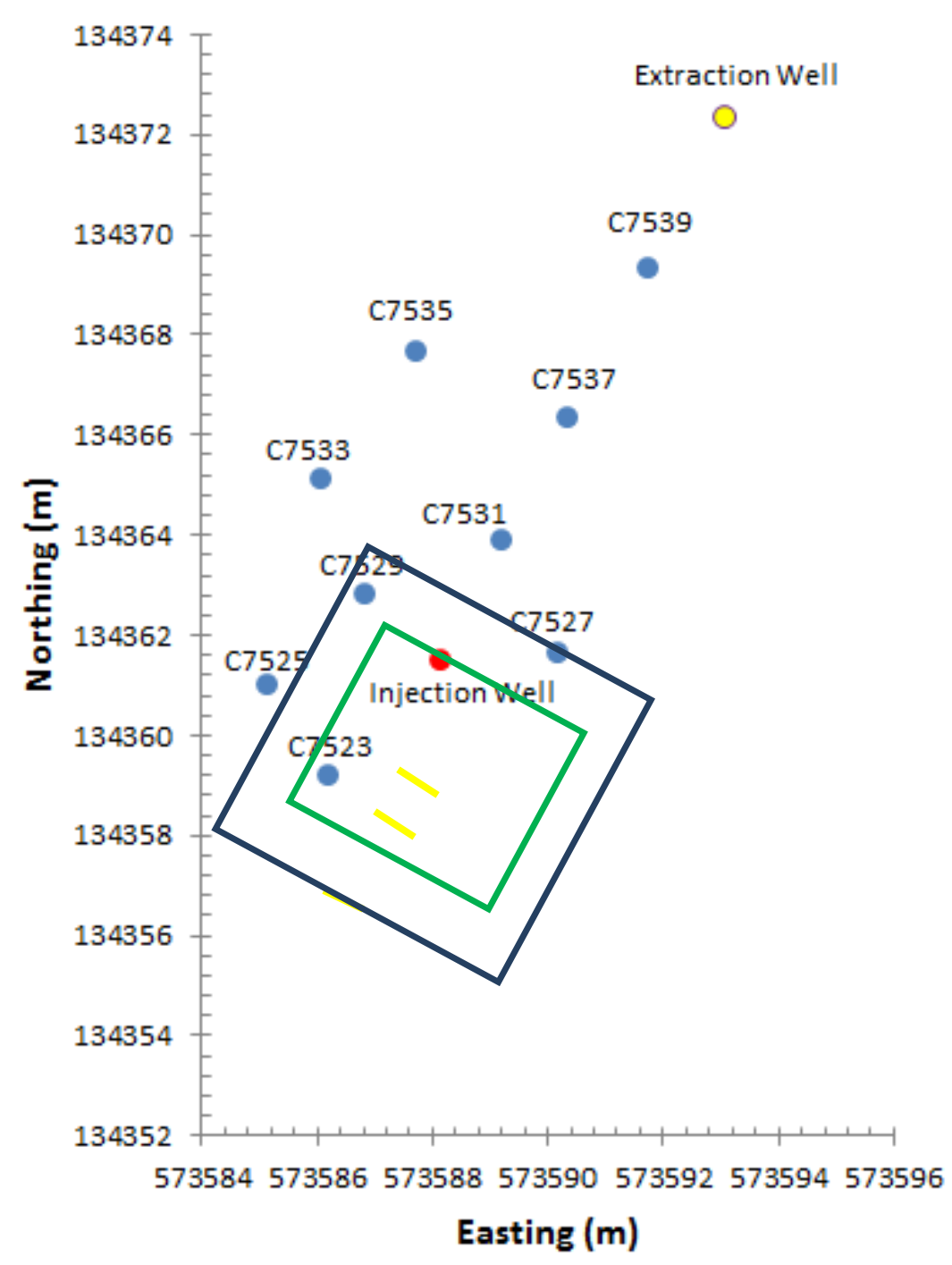

Figure 4.20. Location of test site logging wells, injecting and extraction wells, and plan views of desiccated zones. The blue and green squares denote desiccated areas of $49 \mathrm{~m}^{2}(7 \times 7 \mathrm{~m})$ and $25 \mathrm{~m}^{2}(5 \times 5 \mathrm{~m})$, respectively, that are located between $12.25 \mathrm{~m}$ and $16 \mathrm{~m}$ bgs. The yellow lines indicate 1-m wide areas for which mass fluxes are shown in Figure 4.27.

\subsubsection{Results}

Simulation results for the $7 \times 7 \mathrm{~m}$ desiccated zones are presented in Figures 4.21 through 4.28. Volumetric water contents over time after desiccation for monitoring location C7523 are shown in Figure 4.21. At this location, near the edge of the desiccated zone, the water contents bounce back relatively quickly after desiccation. Rewetting in the upper sandy loam layer at $12.5-13 \mathrm{~m}$ bgs is more rapid than for the lower sandy loam layer at 13.5 - $14 \mathrm{~m}$ (Figure 4.21b). In the lower half of the zone, containing a loamy sand layer, the predicted rewetting is considerably slower than for the upper half with the two sandy loam layers. Above the desiccated zone, small reductions in water contents are observed, indicating a potential source for the rewetting observed in the desiccated zone. The results shown in Figure 4.21 indicate that vertical downward migration from the region above the desiccated zone is an important component to the rewetting process. 
In Figure 4.22, the rewetting at monitoring location C7527 is shown. This location is closer to the injection well and therefore further away from the imposed desiccated zone boundary than C7523 (see Figure 4.20 for well locations). The results for $\mathrm{C} 7527$ also show rapid rewetting but considerably slower than for C7523, especially in the lower half of the desiccated zone. The differences between results at these two locations are consistent with field observations where slower rewetting is reported for locations closer to the injection well (Section 4.1; Truex et al. 2014). The different rewetting rates at these locations suggest a diminishing impact of lateral rewetting with distance from the initial desiccation zone edge. The results also indicate that two major processes are involved in the rewetting process: migration as a result of capillary pressure difference between the desiccated and non-desiccated sediment, and drainage from above the desiccated zone. Outside the desiccation zone (monitoring location C7533), the water contents show only small decreases over time, consistent with slow moisture drainage and potential water migration towards the desiccated zone (Figure 4.23).

The behavior observed in the water content plots in Figures $4.21-4.23$ can be explained using water mass fluxes across the desiccated zone surfaces and the associated cumulative mass changes. The mass fluxes in Figure 4.24 show that migration through the vertical sides of the zone is a process that only occurs during the first 10 years after desiccation. Migration from the top is initially smaller but is sustained over much larger times. This behavior occurs because, over time, drainage from the sediment above the desiccated zone becomes the dominant rewetting process. After an initial spike in the mass flux through the top surface due to the localized response to rewetting at the interface between desiccated and not-desiccated zones, the mass flux quickly reduces to a value of approximately $400 \mathrm{~kg} / \mathrm{yr}$ for the first few years (Figure 4.24a). That value is consistent with a recharge rate of $8 \mathrm{~mm} / \mathrm{yr}$ over the $49 \mathrm{~m}^{2}$ surface, a rate which was imposed on the domain top surface before the geomembrane was emplaced in 2009. Over time (Figure 4.24b), the rate from the top is reduced as the mobile water mass above the desiccated zone decreases. The water migration through the lower surface is of interest because initially water from below the desiccated zone is pulled upward into the desiccated zone due to the imposed capillary pressure. Over time, water drains from the bottom as water starts to migrate through the zone as part of the overall drainage process. The cumulative water masses shown in Figure 4.25 reinforce the observation that migration from the vertical sides occurs primarily over the first 10 years. The mass increase into the zone peaks at around 12 years and then slowly decreases as water drainage becomes the dominant flow process in the initially desiccated zone.

Figure 4.26 shows the diminishing effect of lateral water mass migration with distance from the desiccation zone outer edges. At the zone boundary ( $3.5 \mathrm{~m}$ from the injection well), a large initial rewetting response to desiccation is observed, driven by both lateral and vertical water migration. When moving closer to the inside of the zone, this effect rapidly diminishes. This figure shows that rewetting at the internal areas of the desiccated zone occurs primarily through water drainage from above the desiccated zone. The plots in Figure 4.27 show that the lateral migration through the vertical sides and vertical movement through the top are sustained by flow over considerable distance because the fluxes at the zone boundaries and at surfaces one meter away into the non-desiccated sediment are nearly similar. These results are important because it shows that the water rewetting the desiccated zone does not originate only from sediment directly adjacent to the desiccated zone, but is migrating from larger distances. 
In Figure 4.28, the simulated fluxes for the desiccated zone are compared with fluxes at the same surfaces for the case when the same zone was not desiccated. For the non-desiccated case, there is no migration through the vertical sides, and the flow through the top and bottom are the result of drainage only as the system is responding to the emplacement of the geomembrane in 2009, reducing the recharge from $8 \mathrm{~mm} / \mathrm{yr}$ to $0 \mathrm{~mm} / \mathrm{yr}$. The figure shows that the flux through the top is similar for both simulations after just a few years, indicating that the rewetting from the top quickly becomes dominated by drainage instead of movement due to the imposed capillary pressure in the desiccated zone. At the bottom of the zone it takes about 15 years for the fluxes from both simulations to merge. At this point in time, most of the effects of the initial desiccation have vanished.

In Figures Error! Unknown switch argument. - 4.3, the results of desiccating a smaller zone $(5 \times 5$ $\mathrm{m})$ are shown. The rewetting predicted at monitoring location C7527 is faster than for the larger desiccated zone (Figure 4.24) because the location is closer to the zone boundary. For this desiccated zone, monitoring location $\mathrm{C} 7523$ is outside that zone and no desiccation (and rewetting) occurs (Figure 4.30). Because the desiccated zone volume for the $5 \times 5 \mathrm{~m}$ case is about half of that of the $7 \times 7$ $\mathrm{m}$ case, the predicted fluxes and cumulative amounts are also smaller, as shown in Figures Error! Unknown switch argument. and 4.3. As a result of the smaller size of the desiccated zone, the importance of migration through the top for the $5 \times 5 \mathrm{~m}$ case is less than for the $7 \times 7 \mathrm{~m}$ case. 

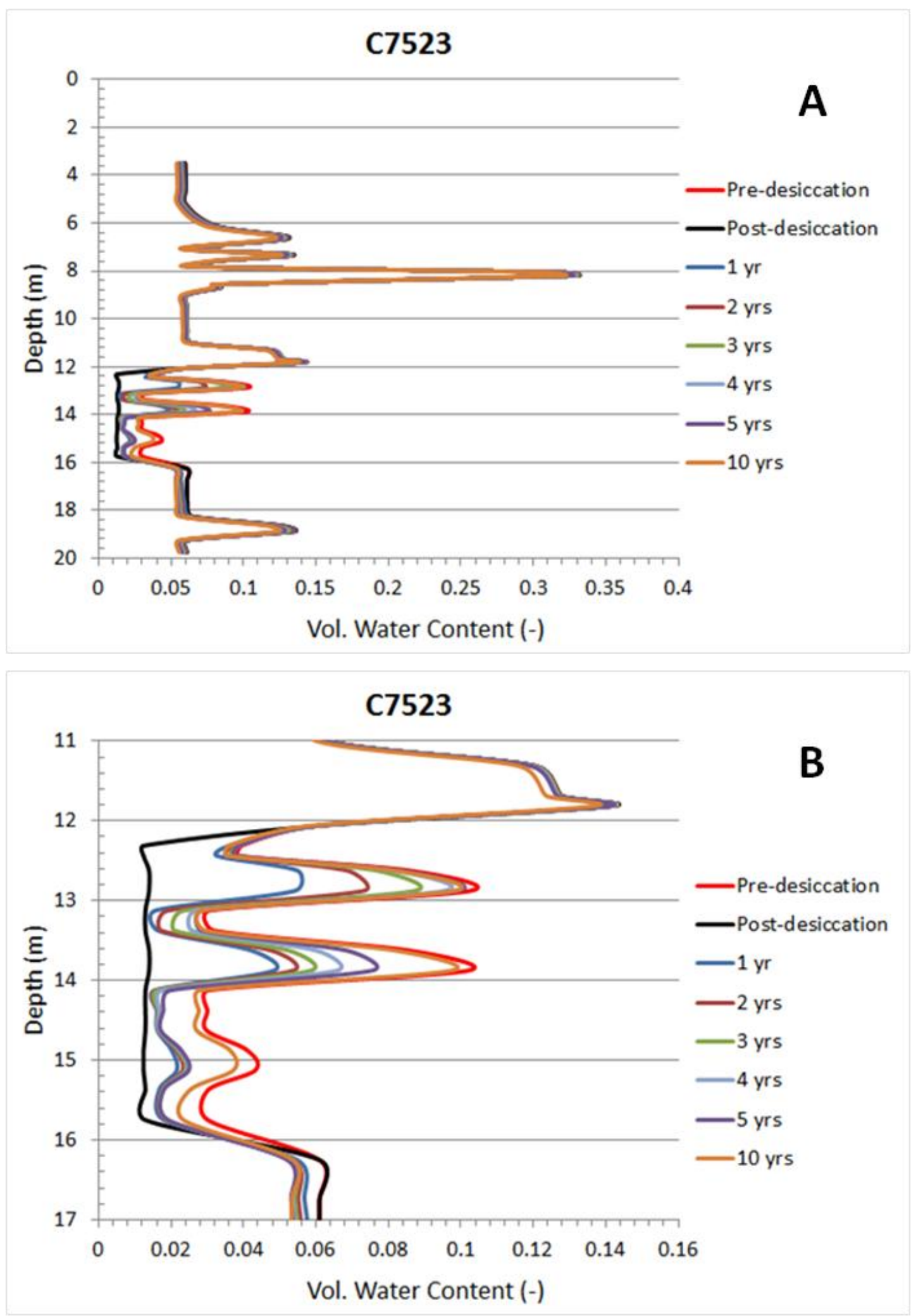

Figure 4.21. Simulated volumetric water content responses over time at location $\mathrm{C} 7523$ for the $7 \times 7 \mathrm{~m}$ desiccated zone, showing (A) the full depth profile and (B) details of the rewetting responses for the desiccated zone at $12.25-16 \mathrm{~m}$ bgs. 

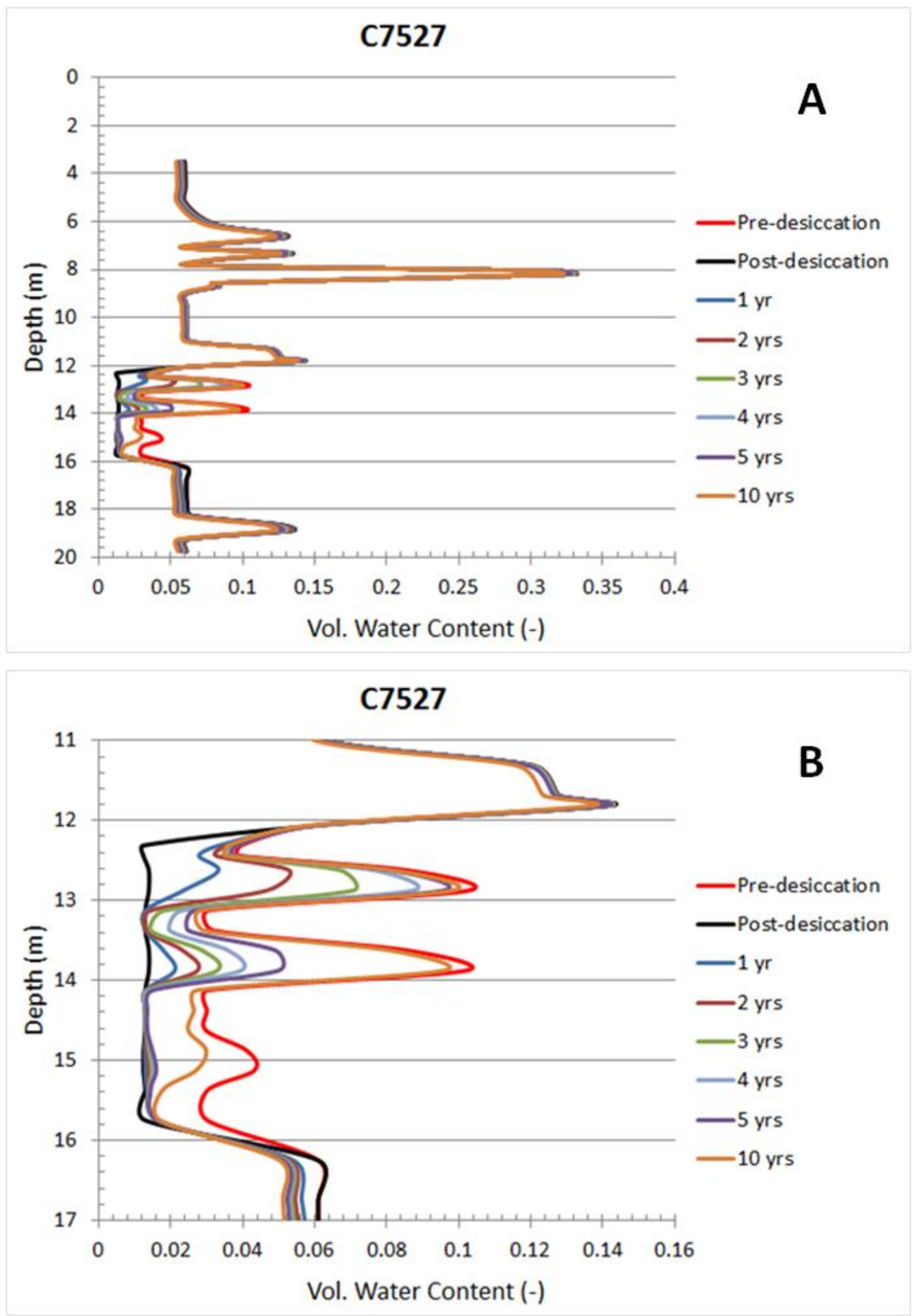

Figure 4.22. Simulated volumetric water content responses over time at location $\mathrm{C} 7527$ for the $7 \times 7 \mathrm{~m}$ desiccated zone, showing (A) the full depth profile and (B) details of the rewetting responses for the desiccated zone at $12.25-16 \mathrm{~m}$ bgs. 


\section{C7533}

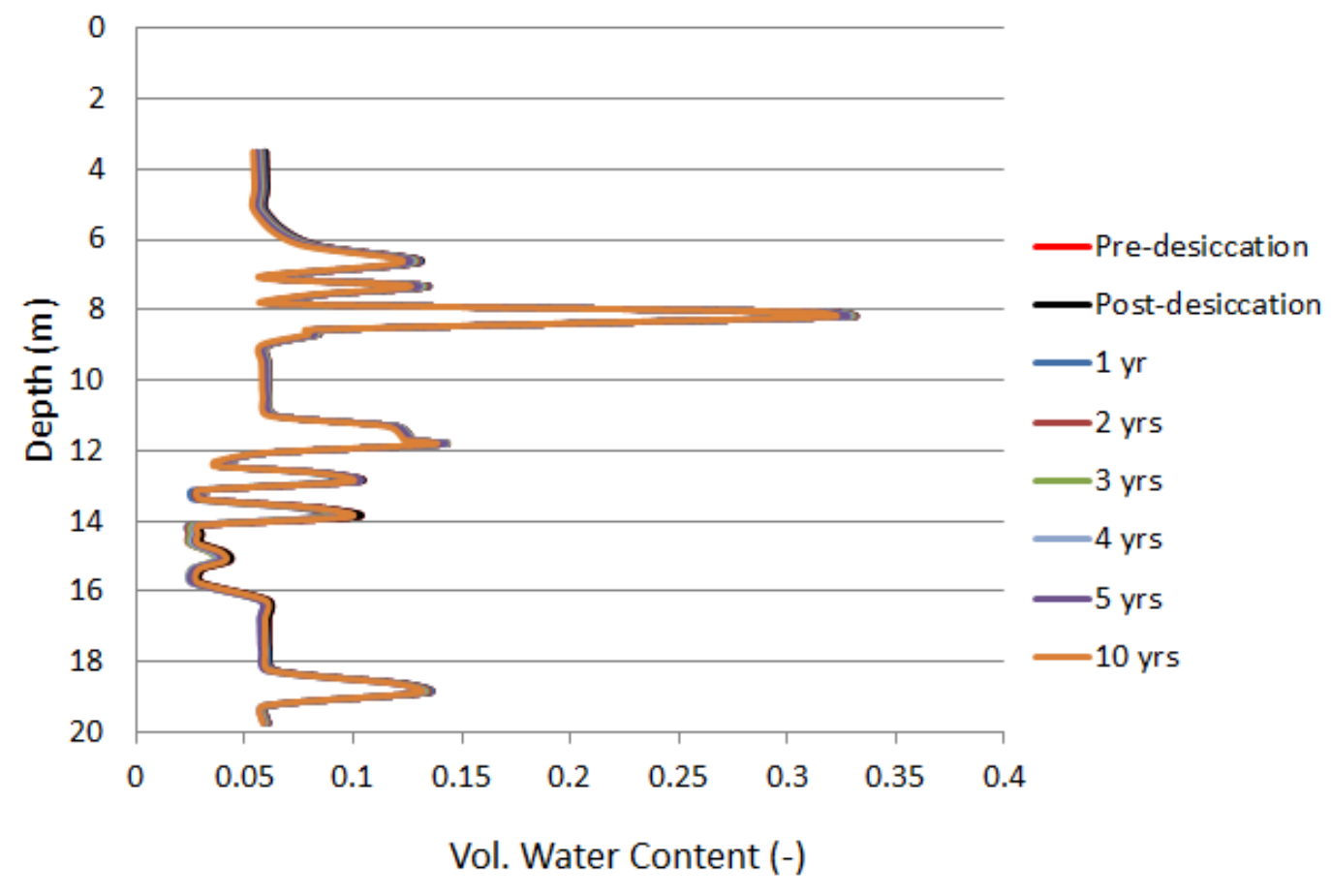

Figure 4.23. Simulated volumetric water content responses over time at location C7533 for the $7 \times 7 \mathrm{~m}$ desiccated zone. 

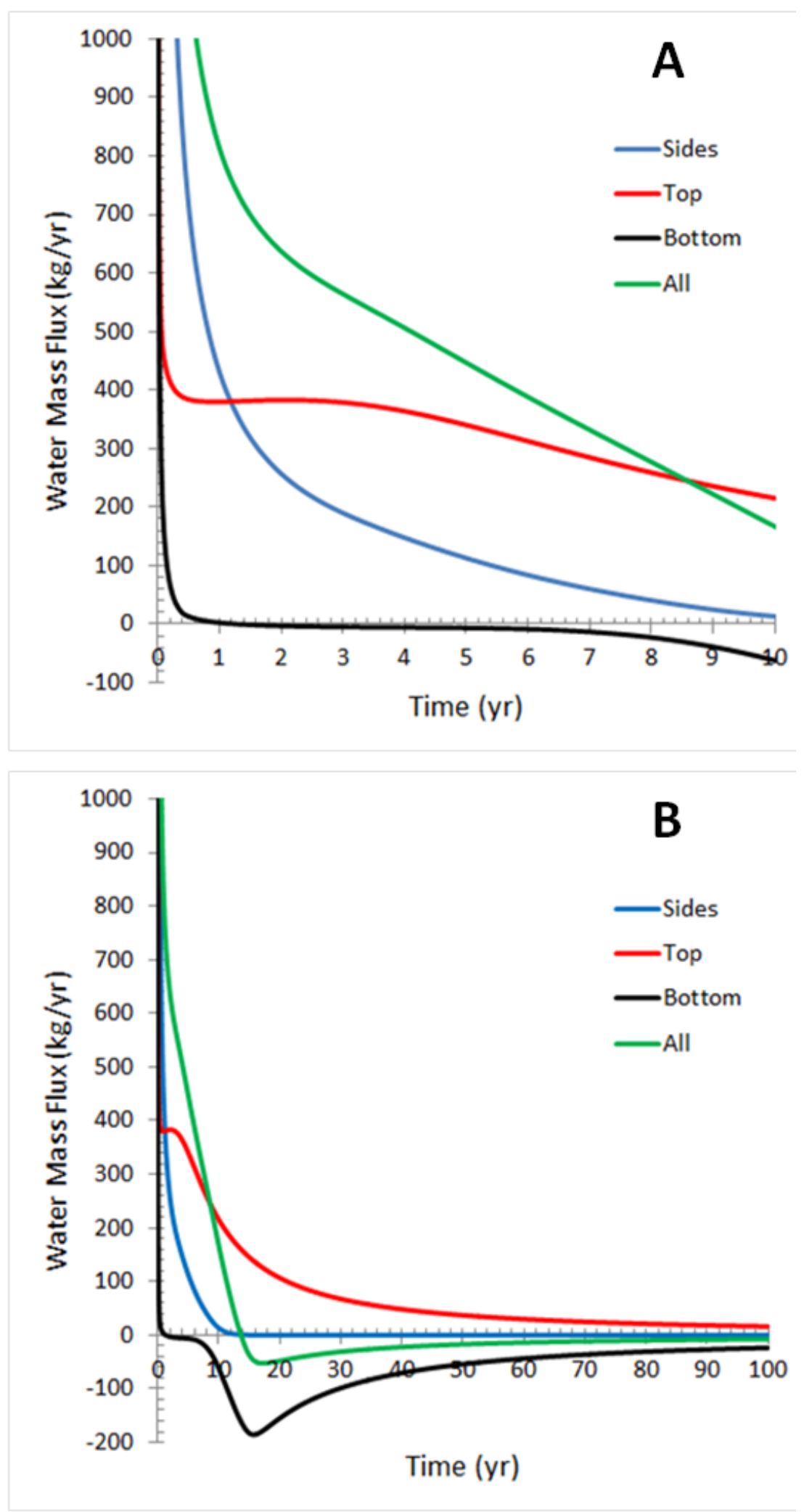

Figure 4.24. Water mass fluxes over time across the boundaries of the $7 \times 7 \mathrm{~m}$ desiccated zone (12.25$16 \mathrm{~m} \mathrm{bgs}$ ) up to (A) 10 years and (B) 100 years after desiccation. Positive values indicate migration into the initially desiccated zone. 

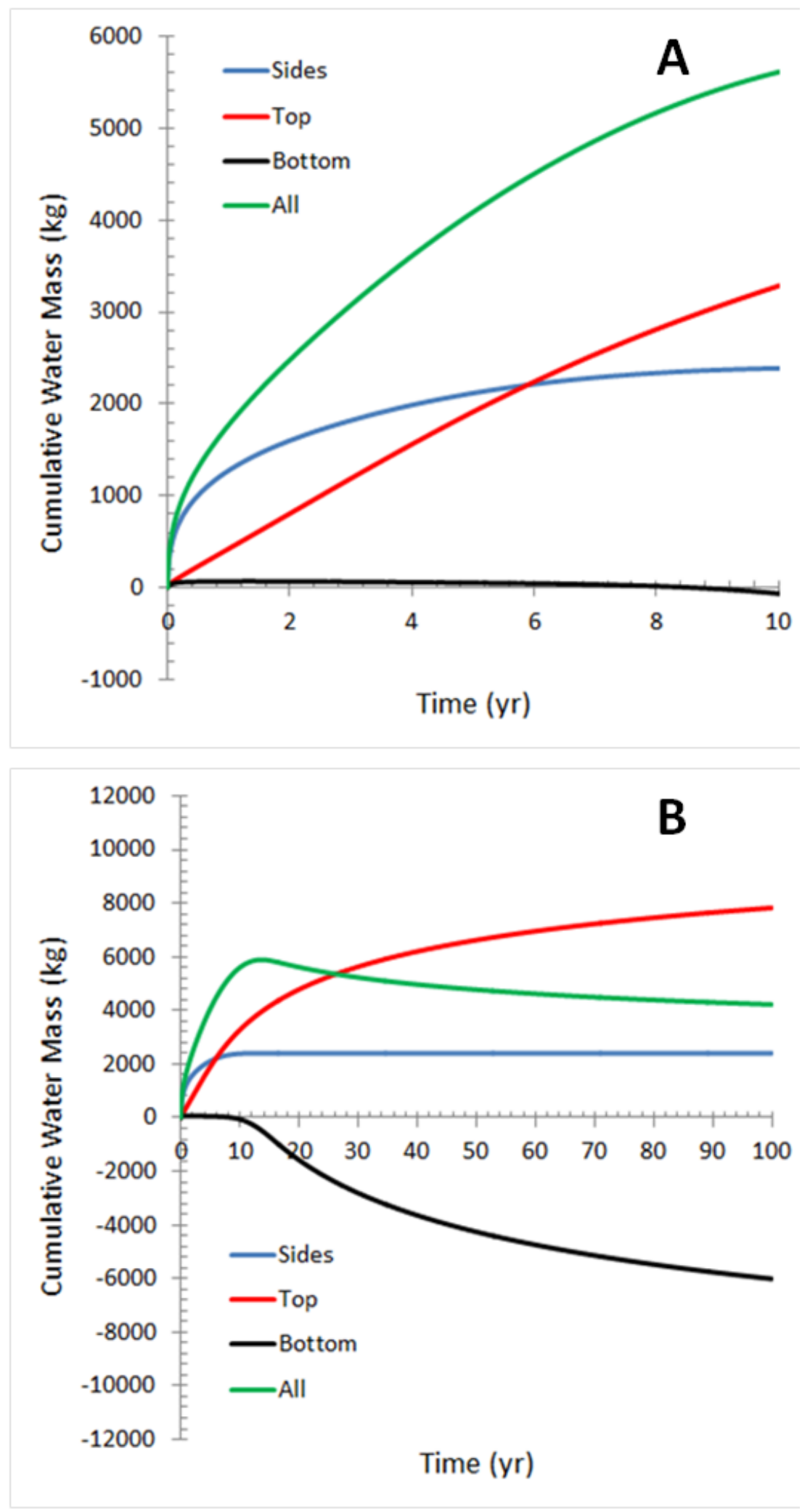

Figure 4.25. Cumulative water mass in the $7 \times 7 \mathrm{~m}$ desiccated zone (12.25-16 $\mathrm{m}$ bgs) up to (A) 10 years and (B) 100 years after desiccation. Positive values indicate an increase in water storage. 


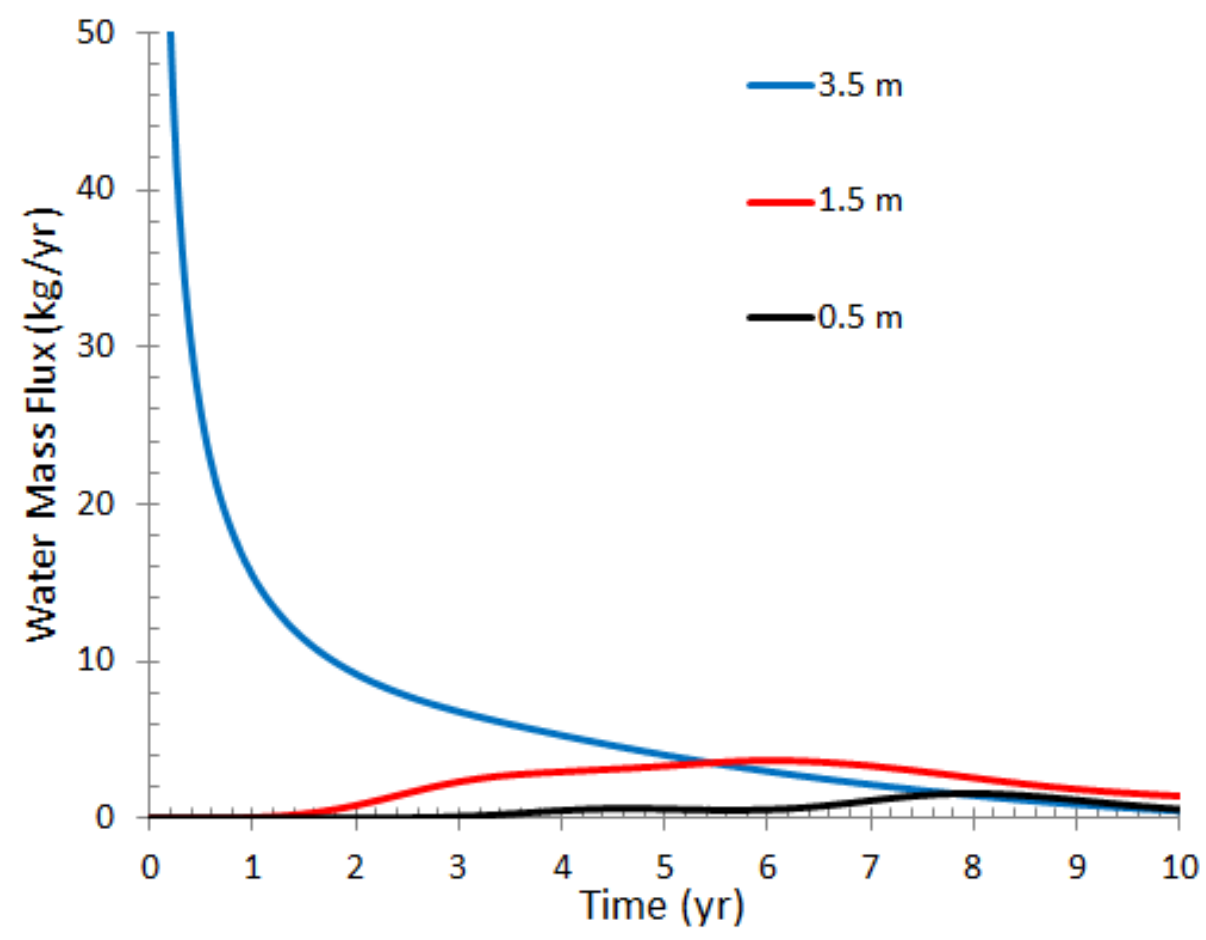

Figure 4.26. Comparison of water mass as a function of distance to the injection well. The fluxes are for 1-m wide surfaces indicated in yellow in Figure 4.20.

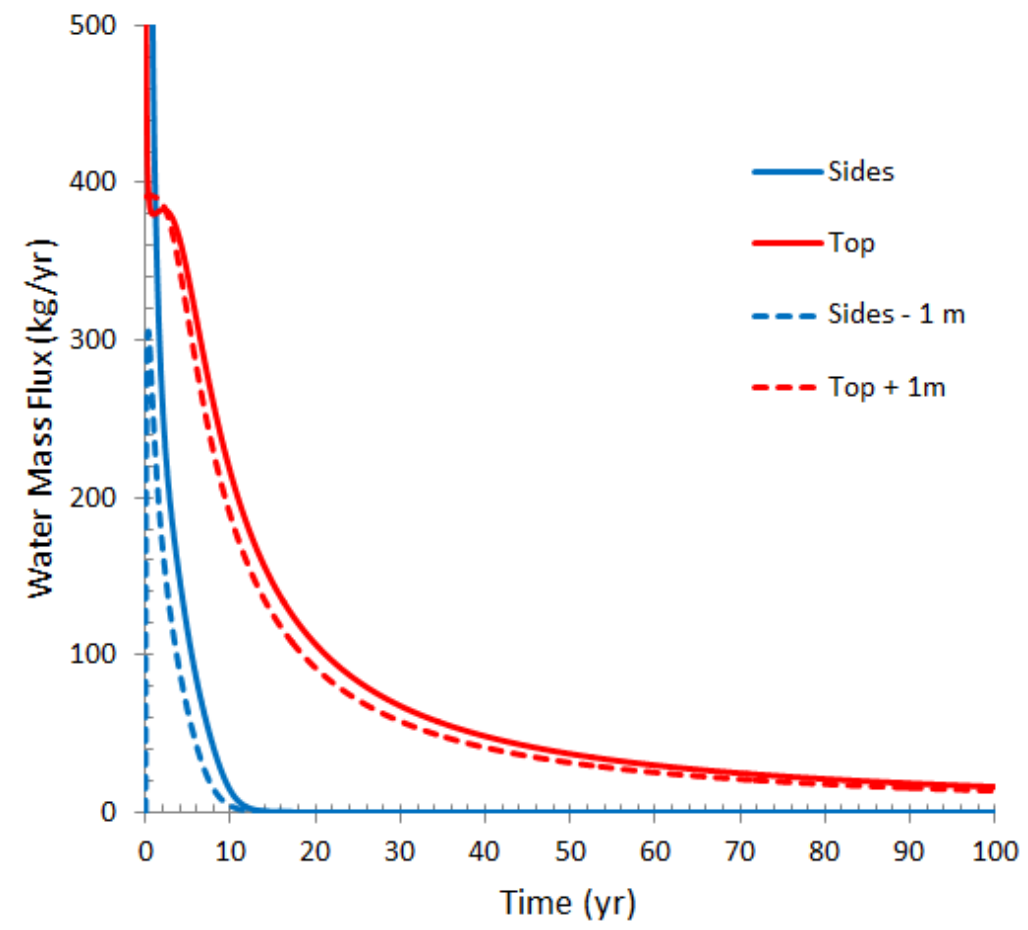

Figure 4.27. Comparison of water mass fluxes at the boundaries of the initially $7 \times 7 \mathrm{~m}$ desiccated zone between 12.25 and $16 \mathrm{~m} \mathrm{bgs}$ and at equal-size surfaces at a one-meter distance in the undesiccated sediment. 


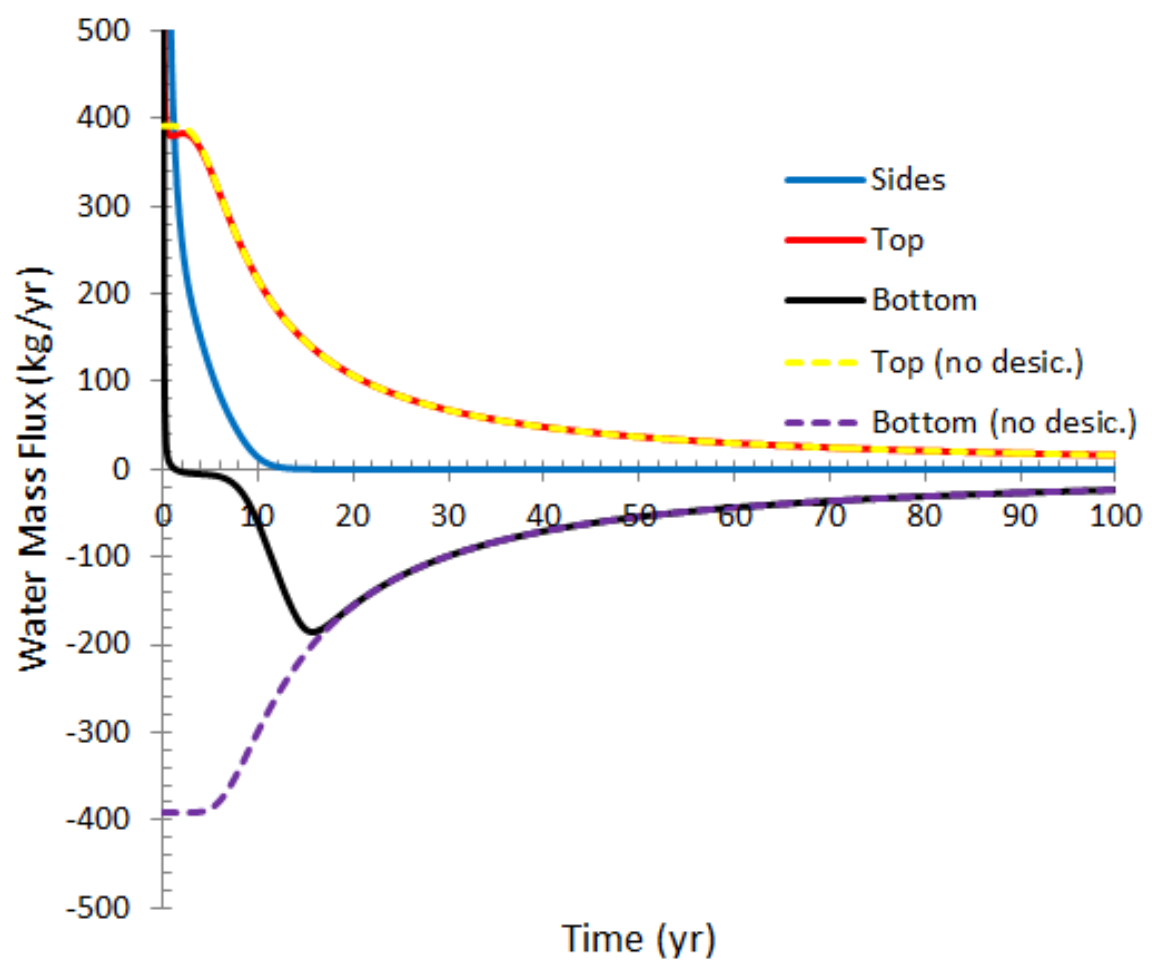

Figure 4.28. Comparison of water mass fluxes for simulations with and without the initially $7 \times 7 \mathrm{~m}$ desiccated zone between 12.25 and $16 \mathrm{~m}$ bgs. 

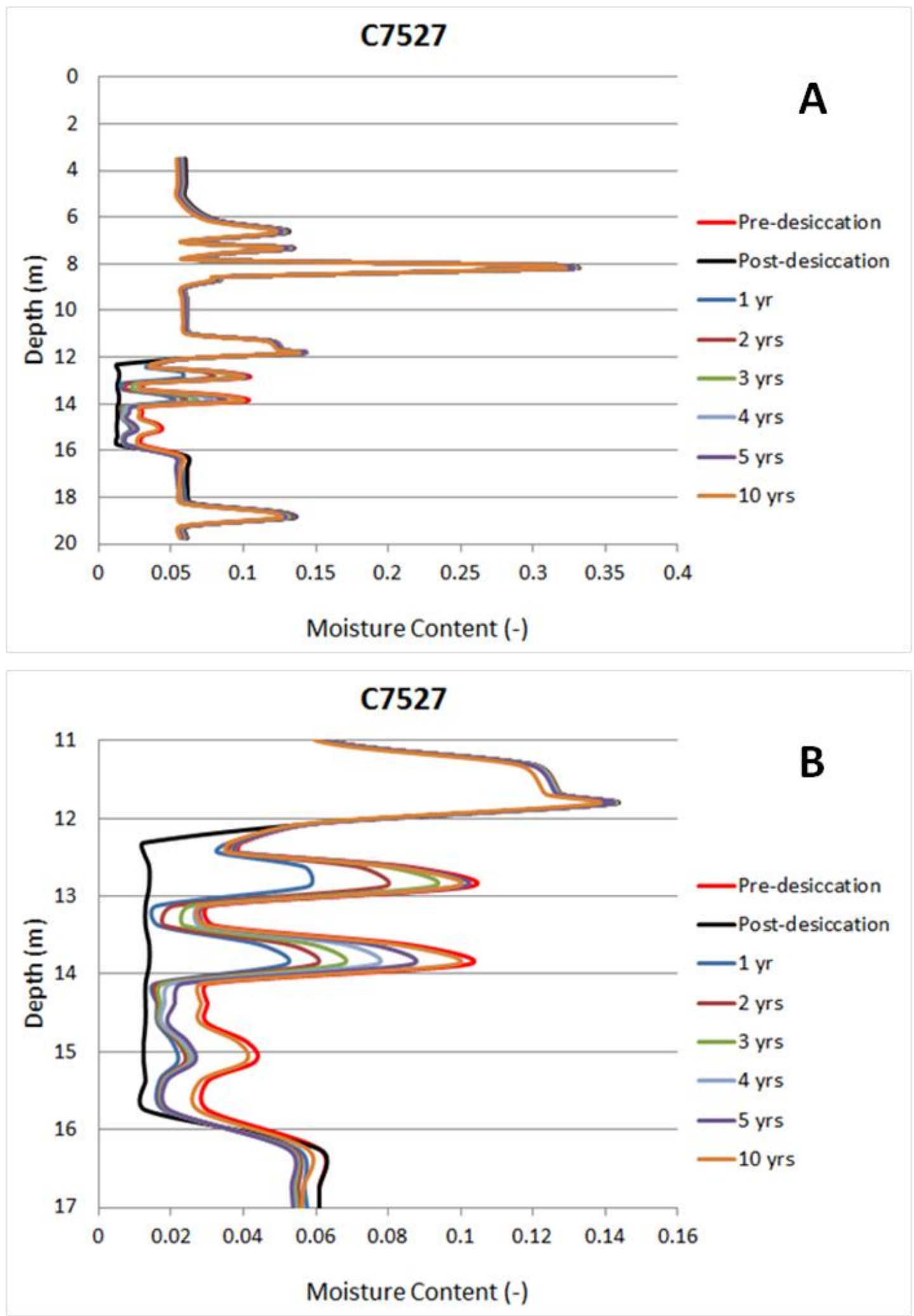

Figure 4.29. Simulated volumetric water content responses over time at location $\mathrm{C} 7527$ for the $5 \times 5 \mathrm{~m}$ desiccated zone, showing (A) the full depth profile and (B) details of the rewetting responses for the desiccated zone at $12.25-16 \mathrm{~m}$ bgs. 


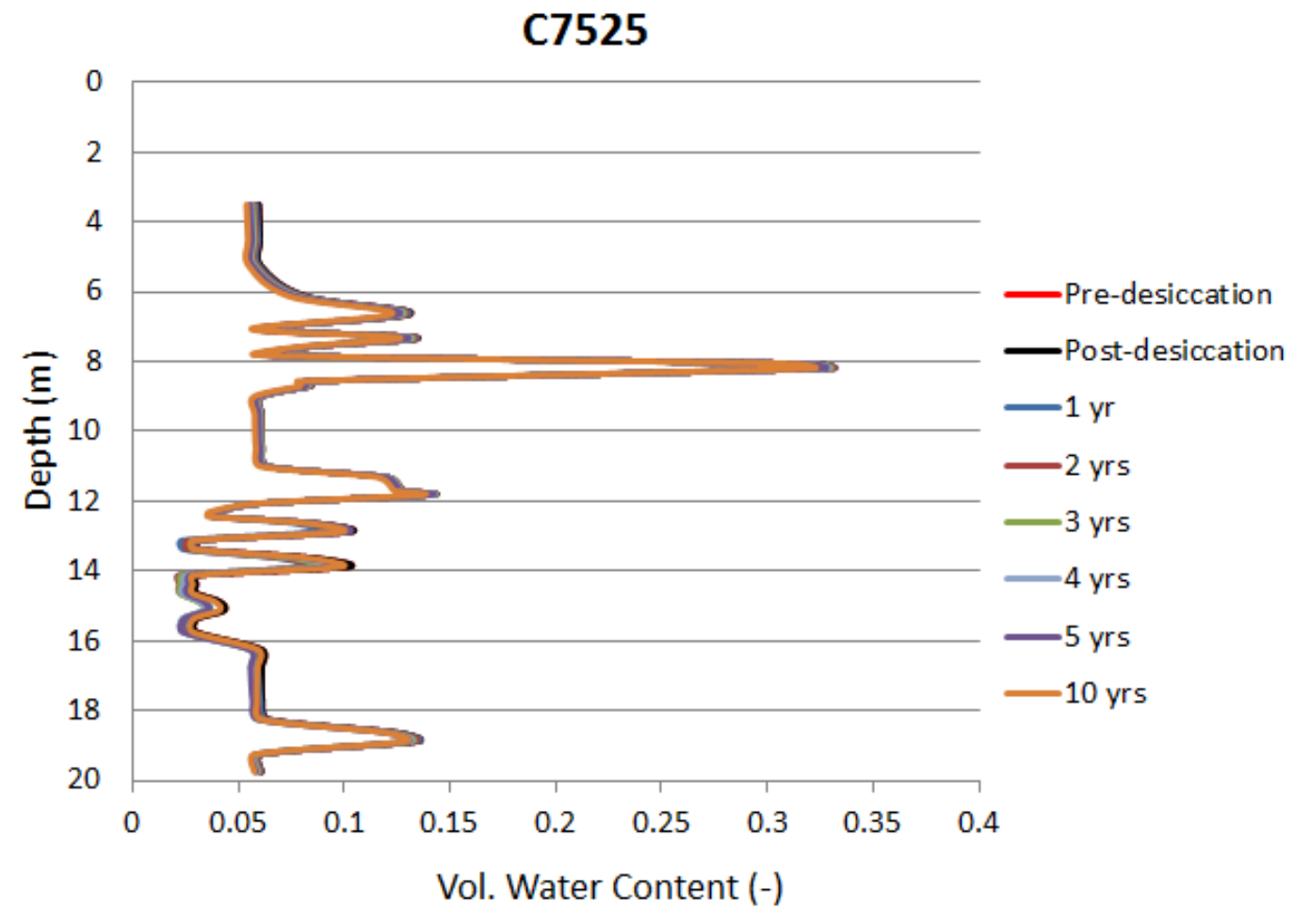

Figure 4.30. Simulated volumetric water content responses over time at location $\mathrm{C} 7525$ for the $5 \times 5 \mathrm{~m}$ desiccated zone (12.25-16 m bgs). 

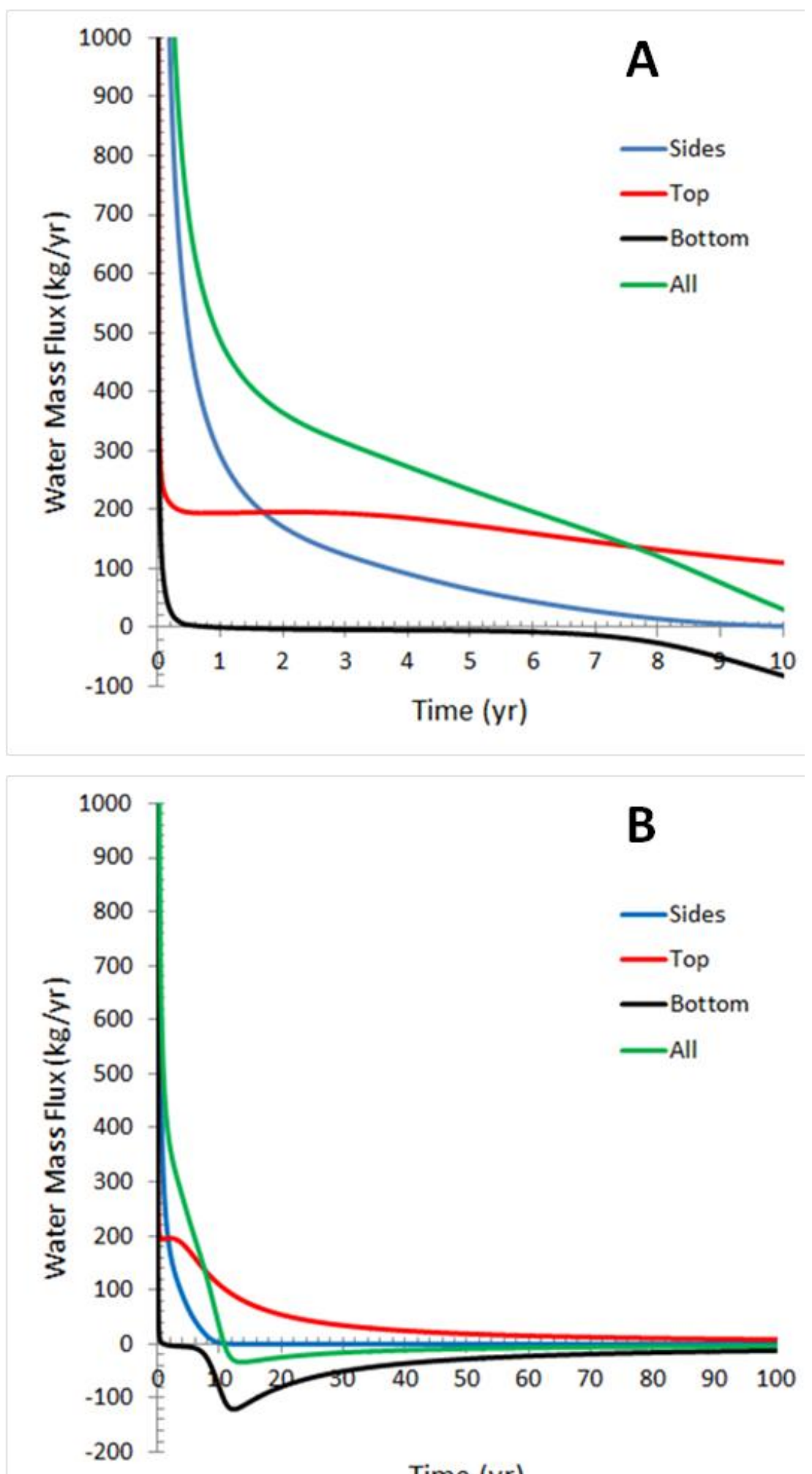

Time (yr)

Figure 4.31. Water mass fluxes over time across the surfaces of the $5 \times 5 \mathrm{~m}$ desiccated zone (12.25-16 $\mathrm{m}$ bgs) up to (A) 10 years and (B) 100 years after desiccation. Positive values indicate migration into the initially desiccated zone. 

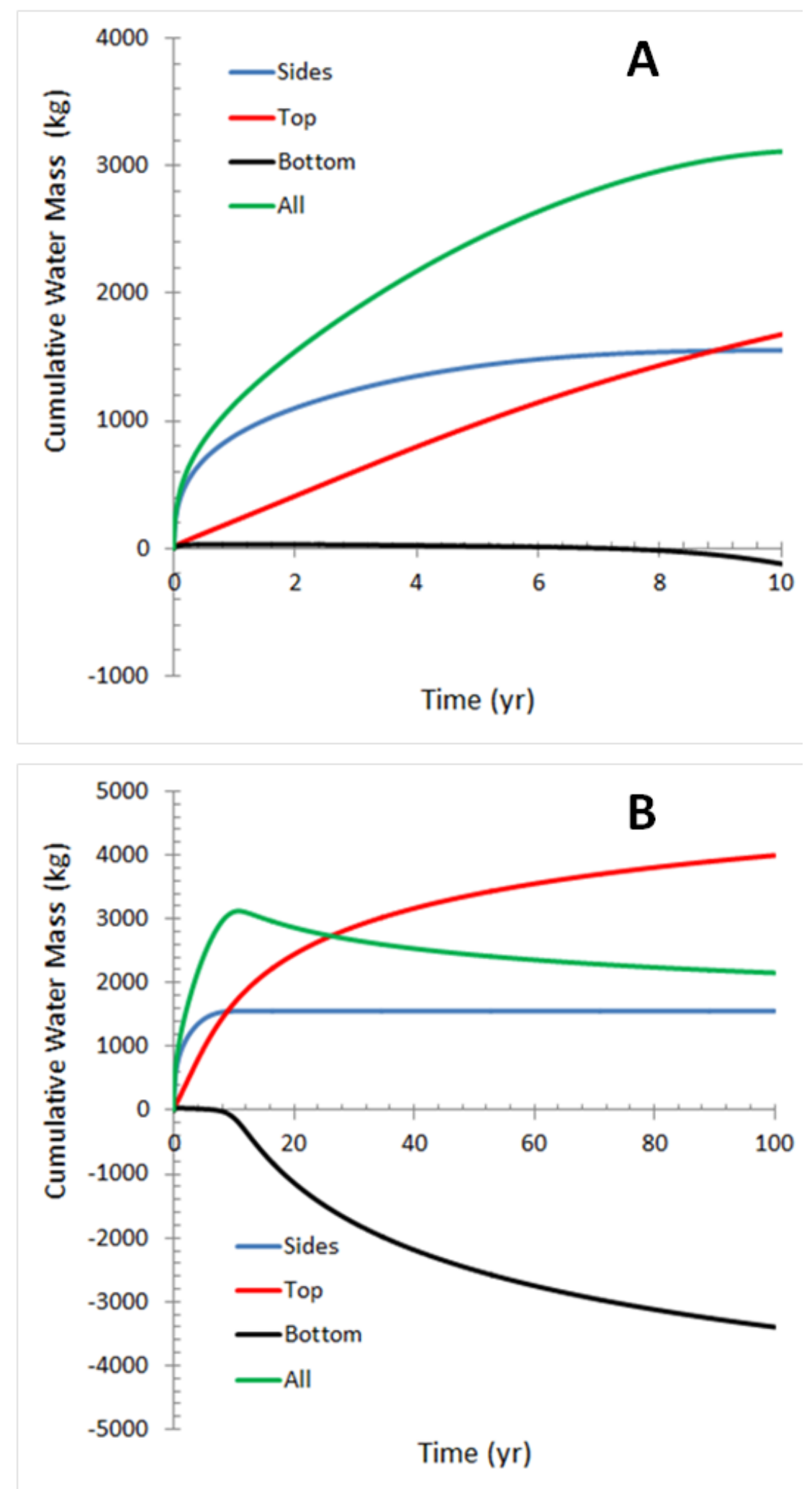

Figure 4.32. Water mass fluxes over time across the surfaces of the $5 \times 5 \mathrm{~m}$ desiccated zone (12.25-16 $\mathrm{m}$ bgs) up to (A) 10 years and (B) 100 years after desiccation. Positive values indicate migration into the initially desiccated zone. 


\subsubsection{Conclusions}

The 3-D simulation results with imposed initial desiccated zones are consistent with field observations: (1) the simulations indicate a relative fast rewetting time (on the order of years); (2) the rewetting rate is faster at the top of the zones than near the bottom, and (3) rewetting is a function of the distance to the side boundaries of the desiccated zone, with faster rewetting near the edges. The results suggest that rewetting occurs due to the imposed capillary pressure gradients and due to drainage from the vadose zone above the desiccated zone. The magnitude of the latter process is mostly independent of the desiccated zone and occurs because of the changes in recharge rates at the site. Before emplacement of the geomembrane in 2009, the estimated site recharge was $8 \mathrm{~mm} / \mathrm{yr}$. Because of the reduction in recharge rate after 2009, water has to drain from the upper vadose zone and will migrate through the desiccated zone. This observation shows the importance of evaluating past recharge behavior and estimating water volumes (and rates) that are expected to drain through a desiccated zone. Rewetting of desiccated zones will be smaller if less drainage has to occur through these zones.

The simulation results show that the developed STOMP model can be used for field design and analysis of rewetting data. It is recommended that additional simulations be conducted that test the sensitivity of hydraulic properties, desiccated zone geometries, and operation scenarios. These simulations should be combined with contaminant transport to evaluate remedy effects on future flux to groundwater.

\subsection{Post-Desiccation Monitoring Data Assessment}

Desiccation is intended to help meet remediation goals by slowing the movement of contaminated moisture through the vadose zone and thereby reducing the flux of contaminants into the groundwater. The rate at which moisture returns to the desiccated zone, here termed the rewetting rate, is important in the overall long-term performance of desiccation as part of a remedy.

Rewetting phenomena and rates have previously been studied through laboratory and modeling efforts. Laboratory data quantifying the rewetting process were collected and reported by Truex et al. (2011). Key conclusions were that vapor-phase rewetting can occur but the process only rewets the desiccated zone to a small extent, essentially to a level below the residual moisture content. Rewetting by aqueous transport occurs, consistent with standard hydraulic phenomena, such that desiccating to very low moisture content and creating very low aqueous phase hydraulic conductivity conditions leads to low rates of aqueous transport rewetting.

Previous modeling efforts (Truex et al. 2012a, 2013b) concluded that the rate of rewetting is a function of the porous media properties of both the desiccated zone and the subsurface surrounding this zone, as well as the moisture content distribution at the end of active desiccation. After active desiccation, the moisture content distribution in the target zone will trend back toward the equilibrium moisture conditions for the porous media properties. Vapor-phase rewetting will occur, but has a negligible impact on the overall rewetting process. Advective rewetting in the aqueous phase strongly depends on the porous media permeability within and surrounding the desiccated zone, the moisture content surrounding the desiccated zone, and the total thickness of the desiccated zone. For example, at the $\mathrm{C} 7527$ and C7529 monitoring locations closest to injection well, the thicker desiccated zones have shown the least rewetting. These thicker desiccated zones were associated with areas of high injected air flow due to the presence of coarser, lower-moisture content sediments. While relatively wet sediments 
are present above these zones, the sediments below are also relatively coarse and dry. Rewetting of these zones has primarily occurred from above. Analysis of rewetting in this zone after two years of rewetting was presented in Truex et al. (2013b). Additional rewetting analysis was presented in Section 4.2 herein and demonstrated the importance of 3-D moisture migration, and a dominant effect of vertical moisture migration due to drainage of water from the vadose zone above the desiccated zone.

Current data, 4-years after active desiccation was ended, show moisture redistribution in the subsurface at the test site associated with rewetting of desiccated areas. Areas that were moderately desiccated have largely returned to near pre-test conditions. Analysis demonstrates that the rewetting is partly from a local redistribution of water from wetter to dryer zones, but is primarily related to vertical moisture migration from above the desiccation zone. Rewetting is continuing for highly desiccated areas. Qualitatively, trends of moisture redistribution over a broad zone in the vicinity of the test site are observed in the GPR and ERT data. 


\subsection{Conclusions}

A field test of desiccation is being conducted at the Hanford Site 200-BC-1 Operable Unit. Desiccation technology relies on removal of water from a portion of the subsurface such that the resultant low moisture conditions inhibit downward movement of water and dissolved contaminants. A field test report (Truex et al. 2012a) describes the active desiccation portion of the test and initial post-desiccation monitoring data. Interim reports (Truex et al. 2013b, 2014) were also issued to evaluate the first three years of rewetting data after active desiccation operations. An additional year's worth of monitoring data have been collected at the field test site during the post-desiccation period and are described herein. This is a third interim report, including about 4 years out of a total of 5 years of post-desiccation monitoring proscribed by the field test plan (DOE 2010b).

The treatability test is being conducted to provide information about desiccation that is intended for use in subsequent feasibility studies for waste sites with inorganic and radionuclide contaminants in the deep vadose zone. The active desiccation portion of the field test occurred over a duration of 164 days, ending on June 30, 2011 (Truex et al. 2012a). The injection and extraction wells were 12-m apart with multiple monitored locations surrounding the injection well. A clustered monitoring approach was used in the test whereby a "sensor borehole" containing sensors, gas-sampling ports, and electrical resistance tomography electrodes was placed nominally adjacent to a cased, unscreened "logging well" that was used to conduct neutron moisture logging and cross-hole GPR. Monitoring with the in situ sensors and geophysical techniques has been continued during the post-desiccation (rewetting) phase of the test.

Over time, the rate of moisture rewetting of the desiccated zones is a function of the hydraulic gradient, water relative permeability, and porous media unsaturated flow properties. Rewetting data since the end of active desiccation are consistent with expectations based on related laboratory data and numerical simulation analyses. Analysis of the current data and associated numerical modeling have shown that the rewetting process and rate can be reasonably estimated (Section 4.2). Thus, the treatability test is on track to provide suitable desiccation technology design information for use in subsequent feasibility studies. 



\subsection{References}

Archie GE. 1942. "The Electrical Resistivity Log as an Aid in Determining Some Reservoir Characteristics." Petroleum Transactions of AIME, 146:54-62.

Bilskie J, R Clawson, and J Ritter. 2007. "Calibration of Heat Pulse Sensors for Soil Water Matric Potential.” In: Annual Meetings Abstracts [CD]. ASA, CSSA, and SSSA, Madison, Wisconsin.

Binley A, G Cassiani, R Middleton, and P Winship. 2002. "Vadose Zone Model Parameterisation Using Cross-Borehole Radar and Resistivity Imaging.” J. Hydrology, 267(3-4):147-159.

Carsel RF and RS Parrish. 1988. "Developing Joint Probability Distributions of Soil Water Retention Characteristics." Water Resources Research, 24(5):755-769.

Corbin RA, BC Simpson, MJ Anderson, WF Danielson III, JG Field, TE Jones, and CT Kincaid. 2005. Hanford Soil Inventory Model Rev. 1. RPP-26744, Rev. 0, CH2M HILL Hanford Group, Inc., Richland Washington.

Daily W and E Owen. 1991. "Cross-Borehole Resistivity Tomography." Geophysics, 56:1228-1235.

Day-Lewis FD, JM Harris, and SM Gorelick. 2002. "Time-Lapse Inversion of Crosswell Radar Data." Geophysics, 67:1740-1752.

Dresel PE, DM Wellman, KJ Cantrell, and MJ Truex. 2011. "Review: Technical and Policy Challenges in Deep Vadose Zone Remediation of Metals and Radionuclides." Environmental Science \& Technology, 45(10):4207-4216.

DOE/RL (U.S. Department of Energy Richland Office). 2008a. Deep Vadose Zone Treatability Test Plan for the Hanford Central Plateau. DOE/RL-2007-56, Rev. 0, Richland, Washington.

DOE/RL (U.S. Department of Energy Richland Operations Office). 2008b. Sampling and Analysis Plan for Characterization of the Soil Desiccation Pilot Test Site. DOE/RL-2008-67, Rev. 0, Richland, Washington.

DOE/RL (U.S. Department of Energy Richland Operations Office). 2010a. Characterization of the Soil Desiccation Pilot Test Site. DOE/RL-2009-119, Rev. 0, Richland, Washington.

DOE/RL (U.S. Department of Energy Richland Operations Office). 2010b. Field Test Plan for the Soil Desiccation Pilot Test. DOE/RL-2010-04, Rev. 0, Richland, Washington.

Evett SR. 2005. "International Soil Moisture Sensor Comparison.” In: Irrigation Insights No. 1, Second Edition, Soil Water Monitoring, P. Charlesworth, ed. Land \& Water Australia, Braddon, Australia. pp. 68-71.

Flint AL, GS Campbell, KM Ellett, and C Calissendorff. 2002. "Calibration and Temperature Correction of Heat Dissipation Matric Potential Sensors.” Soil Science Society of America J., 66:1439-1445.

Hubbard SS, JE Peterson, EL Majer, PT Zawislanski, J Roberts, KH Williams, and F Wobber. 1997. "Estimation of Permeable Pathways and Water Content Using Tomographic Radar Data." The Leading Edge of Exploration, 16(11):1623-1628. 
Huisman JA, C Sperl, W Bouten, and JM Verstraten. 2001. "Soil Water Content Measurements at Different Scales: Accuracy of Time Domain Reflectometry and Ground-Penetrating Radar." J. Hydrology, 245:48-58.

Jackson MJ and DR Tweeton. 1994. MIGRATOM - Geophysical Tomography Using Wavefront Migration and Fuzzy Constraints. Report of Investigations 9497, U.S. Department of the Interior, Bureau of Mines, Pittsburgh, Pennsylvania.

Johnson TC, RJ Versteeg, A Ward, FD Day-Lewis, and A Revil. 2010. "Improved Hydrogeophysical Characterization and Monitoring Through Parallel Modeling and Inversion of Time-Domain Resistivity and Induced Polarization Data." Geophysics, 75(4):WA27-WA41.

Last GV, WE Nichols, and CT Kincaid. 2006. Geographic and Operational Site Parameters List (GOSPL) for Hanford Assessments. PNNL-14725, Rev. 1, Pacific Northwest National Laboratory, Richland, Washington.

Lindberg M. 2011. Analytical Data Report for Sediment Samples Collected from SDPT GroundTruthing Boreholes C8387 and C8388. PNNL-15782, Pacific Northwest National Laboratory, Richland, Washington.

Mualem Y. 1976. "A New Model Predicting the Hydraulic Conductivity.” Geoderma, 65:81-92.

Oostrom M, TW Wietsma, JH Dane, MJ Truex, and AL Ward. 2009. "Desiccation of Unsaturated Porous Media: Intermediate-Scale Experiments and Numerical Simulation." Vadose Zone Journal, 8:643-650.

Oostrom M, GD Tartakovsky, TW Wietsma, MJ Truex, and JH Dane. 2011. "Determination of Water Saturation in Relatively Dry and Desiccated Porous Media Using Gas-Phase Partitioning Tracer Tests." Vadose Zone Journal, 10:1-8. doi:10.2136/vzj2010.0101.

Oostrom M, TW Wietsma, CE Strickland, VL Freedman, and MJ Truex. 2012a. "Instrument Testing During Desiccation and Rewetting at the Intermediate Laboratory Scale." Vadose Zone Journal, 11(1):10 pp. doi:10.2136/vzj2011.0089.

Oostrom, M., V.L. Freedman, T.W. Wietsma, and M.J. Truex. 2012b. "Effects of Porous Medium Heterogeneity on Vadose Zone Desiccation: Intermediate-Scale Laboratory Experiments and Simulations." Vadose Zone Journal, 11(4):10 pp. doi:10.2136/vzj2011.0168.

Serne RJ, AL Ward, W Um, BN Bjornstad, DF Rucker, DC Lanigan, and MW Benecke. 2009. Electrical Resistivity Correlation to Vadose Zone Sediment and Pore-Water Composition for the BC Cribs and Trenches Area. PNNL-17821, Pacific Northwest National Laboratory, Richland, Washington.

Slater LD and DP Lesmes. 2002. "Electrical-Hydraulic Relationships Observed for Unconsolidated Sediments. Water Resources Research, 38:1213-1225.

Topp GC and PA (Ty) Ferré. 2002. "Water Content.” In: Methods of Soil Analysis Part 4, Physical Methods, SSSA Book Series No. 5, JH Dane and GC Topp (eds.). Soil Science Society of America, Inc., Madison, Wisconsin. pp. 417-545. 
Truex MJ, M Oostrom, VL Freedman, CE Strickland, and AL Ward. 2011. Laboratory and Modeling Evaluations in Support of Field Testing for Desiccation at the Hanford Site. PNNL-20146, Pacific Northwest National Laboratory, Richland, Washington.

Truex MJ, M Oostrom, CE Strickland, TC Johnson, VL Freedman, CD Johnson, WJ Greenwood, AL Ward, RE Clayton, MJ Lindberg, JE Peterson, SS Hubbard, GB Chronister, and MW Benecke. 2012a. Deep Vadose Zone Treatability Test for the Hanford Central Plateau: Soil Desiccation Pilot Test Results. PNNL-21369, Pacific Northwest National Laboratory, Richland, Washington.

Truex MJ, M Oostrom, CE Strickland, GB Chronister, MW Benecke, and CD Johnson. 2012b. "FieldScale Assessment of Desiccation Implementation for Deep Vadose Zone Contaminants." Vadose Zone Journal, 11(4):10 pp. doi:10.2136/vzj2011.0144.

Truex MJ, TC Johnson, CE Strickland, JE Peterson, and SS Hubbard. 2013a. "Monitoring Vadose Zone Desiccation with Geophysical Methods.” Vadose Zone Journal, 12(2):14 pp. doi:10.2136/vzj2012.0147.

Truex MJ, M Oostrom, CE Strickland, TC Johnson, CD Johnson, RE Clayton, and GB Chronister. 2013b. Deep Vadose Zone Treatability Test for the Hanford Central Plateau: Interim PostDesiccation Monitoring Results. PNNL-22826, Pacific Northwest National Laboratory, Richland, Washington.

Truex MJ, M Oostrom, CE Strickland, TC Johnson, CD Johnson, RE Clayton, and GB Chronister. 2014. Deep Vadose Zone Treatability Test for the Hanford Central Plateau: Interim Post-Desiccation Monitoring Results, Fiscal Year 2014. PNNL-23731 Pacific Northwest National Laboratory, Richland, Washington.

Um W, RJ Serne, MJ Truex, AL Ward, MM Valenta, CF Brown, C Iovin, KN Geiszler, IV Kutnyakov, ET Clayton, H-S Chang, SR Baum, and DM Smith. 2009. Characterization of Sediments from the Soil Desiccation Pilot Test (SDPT) Site in the BC Cribs and Trenches Area. PNNL-18800, Pacific Northwest National Laboratory, Richland, Washington.

van Genuchten MT. 1980. "A Closed Form Equation for Predicting the Hydraulic Conductivity of Unsaturated Soils.” Soil Science Society of America Journal, 44(5):892-898.

Van Overmeeren R, S Sariowan, and J Geherls. 1997. "Ground Penetrating Radar for Determining Volumetric Soil Water Content: Results of Comparative Measurements at Two Test Sites.” J. Hydrology, 197:316-338.

Ward AL, GW Gee, ZF Zhang, and JM Keller. 2004. Vadose Zone Contaminant Fate and Transport Analysis for the 216-B-26 Trench. PNNL-14907, Pacific Northwest National Laboratory, Richland, Washington.

Ward AL, M Oostrom, and DH Bacon. 2008. Experimental and Numerical Investigations of Soil Desiccation for Vadose Zone Remediation: Report for Fiscal Year 2007. PNNL-17274, Pacific Northwest National Laboratory, Richland, Washington.

White MD and M Oostrom. 2006. STOMP Subsurface Transport Over Multiple Phases, Version 4.0, User's Guide. PNNL-15782, Pacific Northwest National Laboratory, Richland, Washington. 

Appendix A

Neutron Moisture Probe Data 



\section{Appendix A}

\section{Neutron Moisture Probe Data}

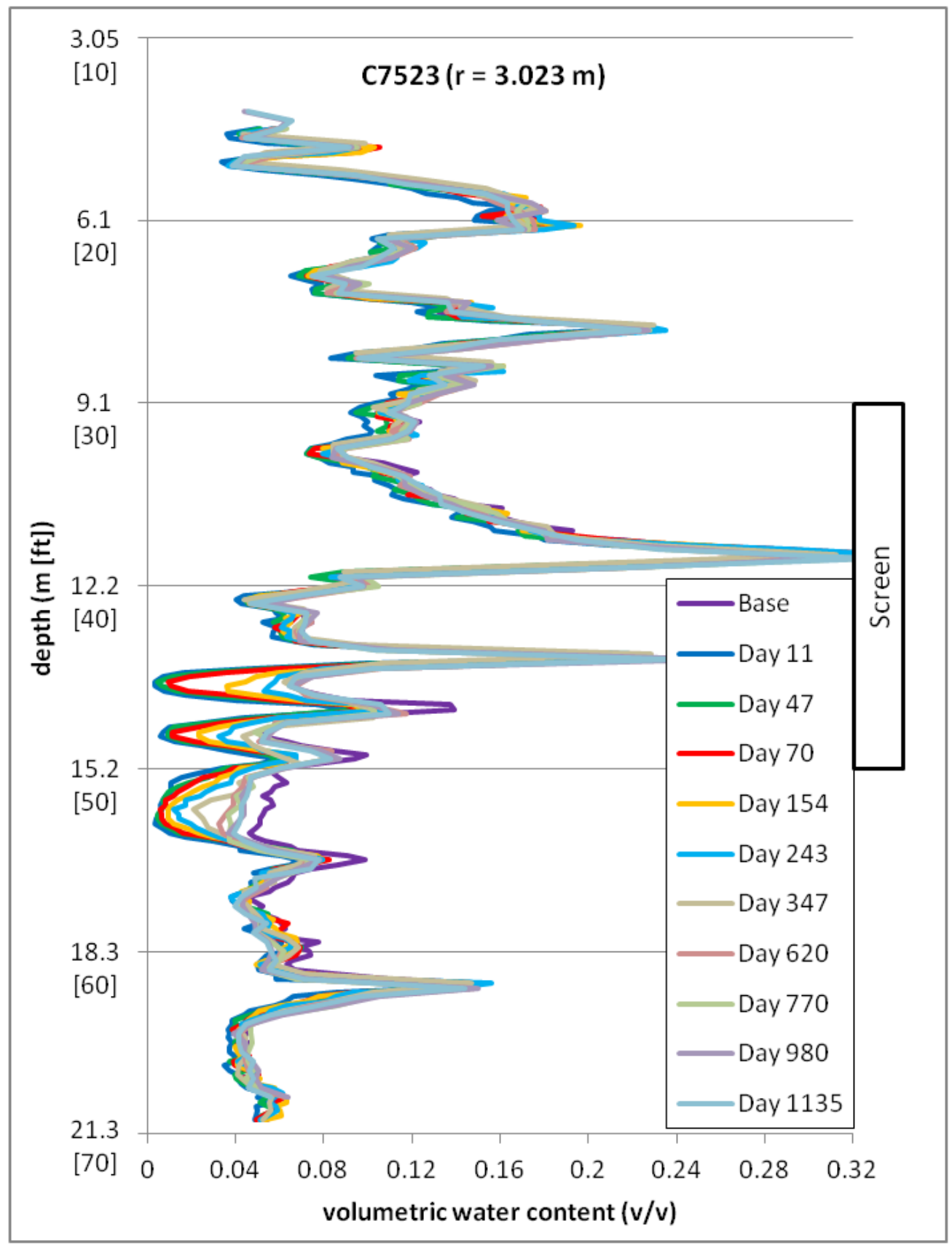

Figure A.1. Neutron Moisture Probe Response over Time for Location C7523 (3.023 m from injection well). The pre-desiccation data (Base) are for a logging event in December 2010, prior to the continuous active desiccation period. Other data are for logging events after active desiccation ended. 


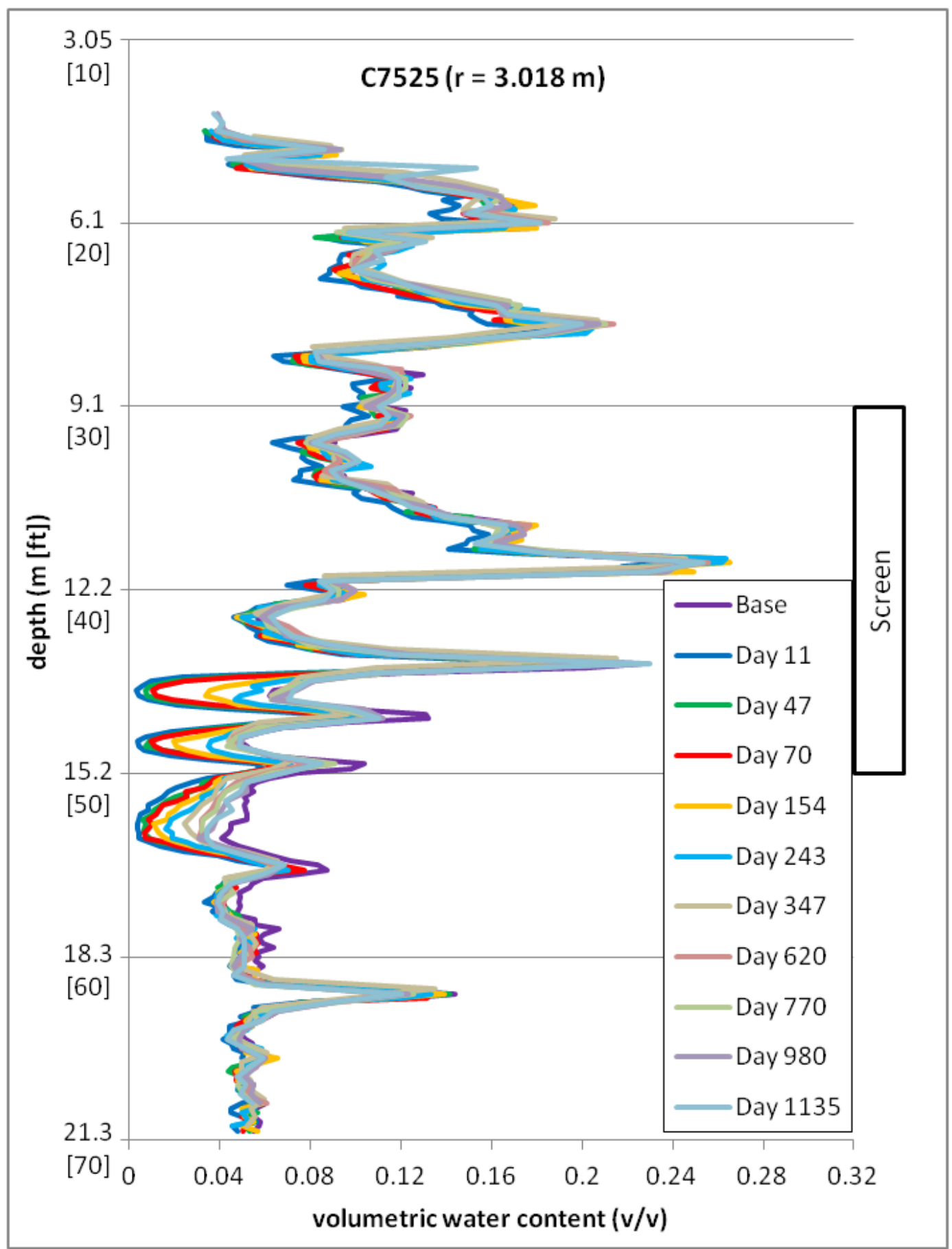

Figure A.2. Neutron Moisture Probe Response over Time for Location C7525 (3.018 m from injection well). The pre-desiccation data (Base) are for a logging event in December 2010, prior to the continuous active desiccation period. Other data are for logging events after active desiccation ended. 


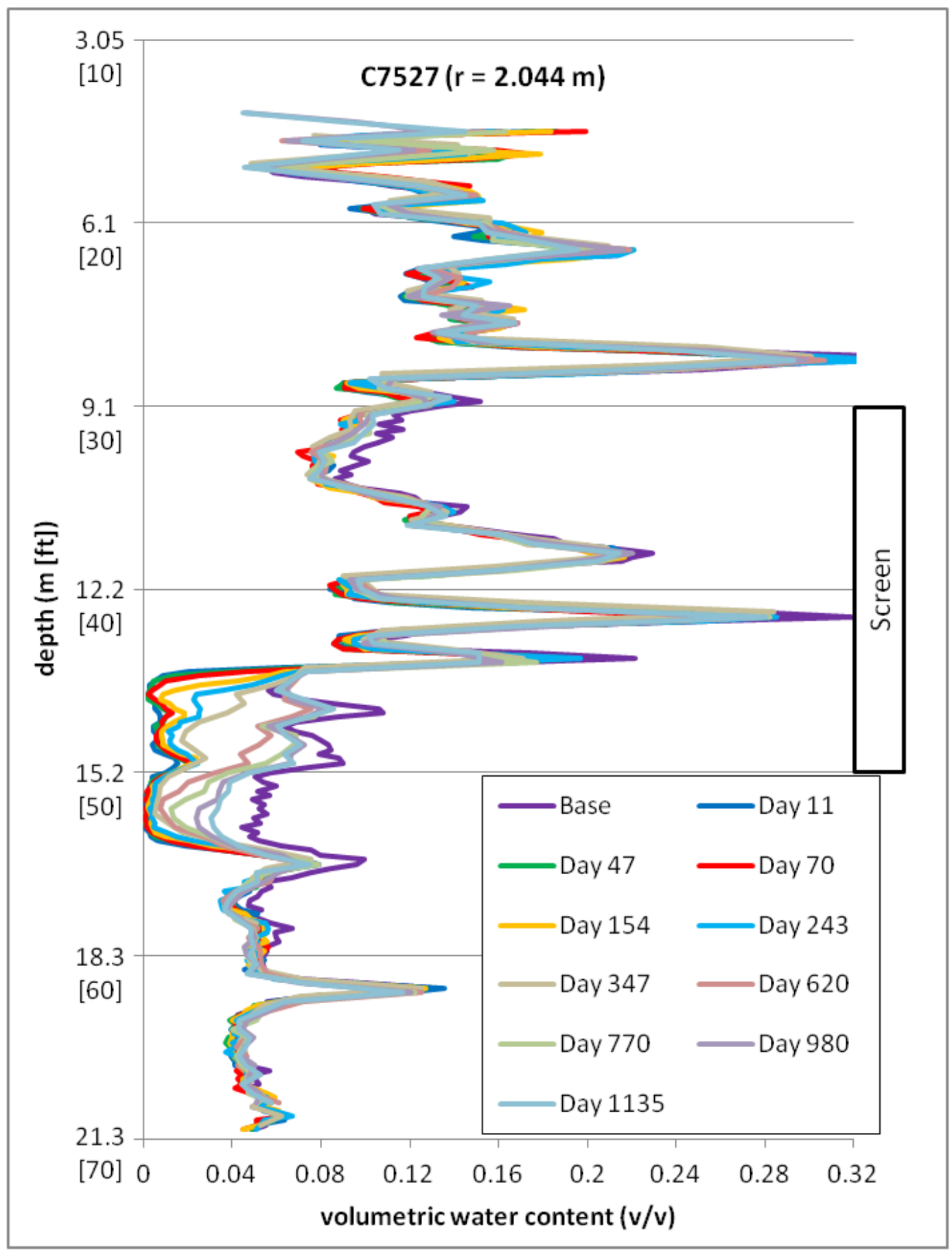

Figure A.3. Neutron Moisture Probe Response over Time for Location C7527 (2.044 m from injection well). The pre-desiccation data (Base) are for a logging event in December 2010, prior to the continuous active desiccation period. Other data are for logging events after active desiccation ended. 


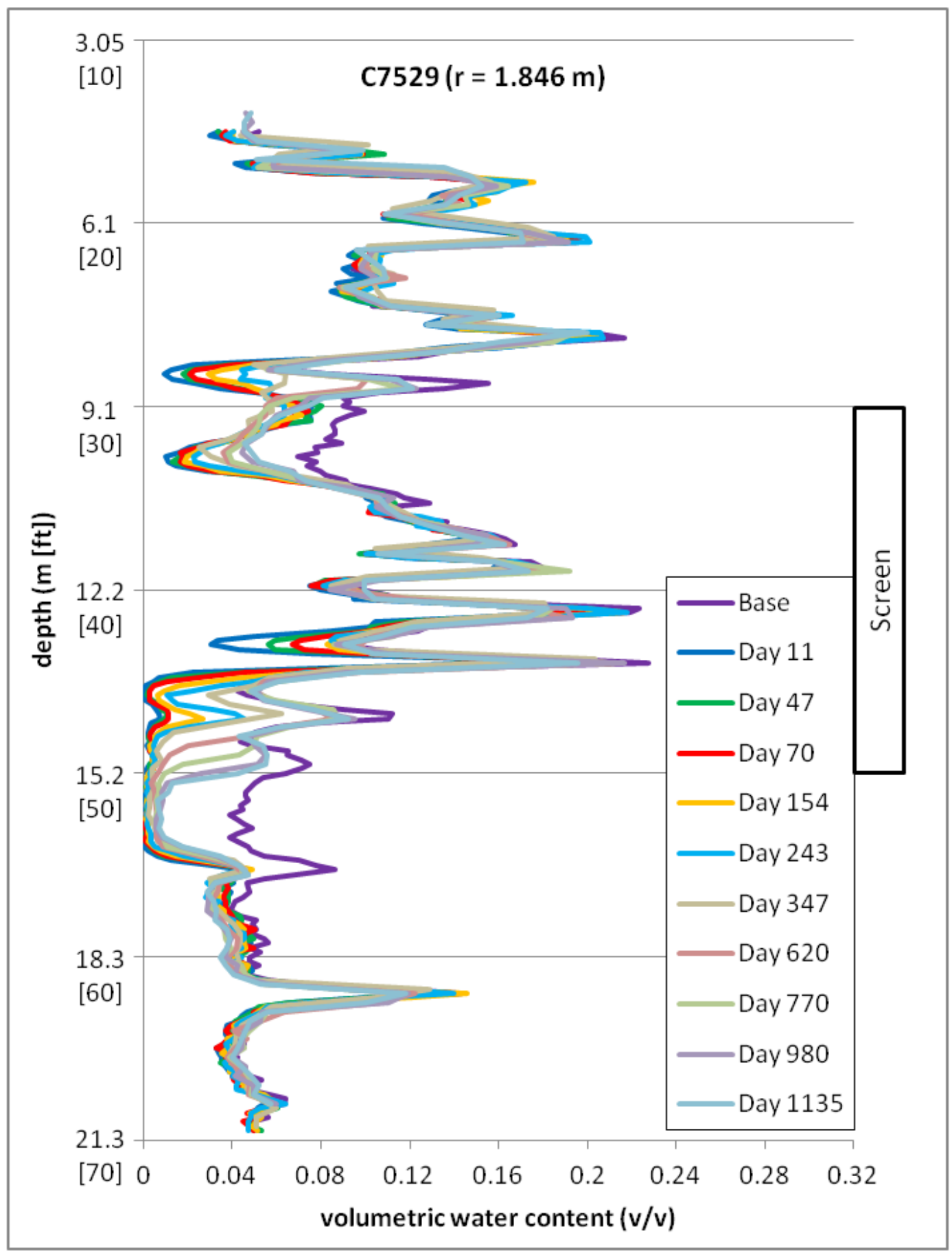

Figure A.4. Neutron Moisture Probe Response over Time for Location C7529 (1.846 m from injection well). The pre-desiccation data (Base) are for a logging event in December 2010, prior to the continuous active desiccation period. Other data are for logging events after active desiccation ended. 


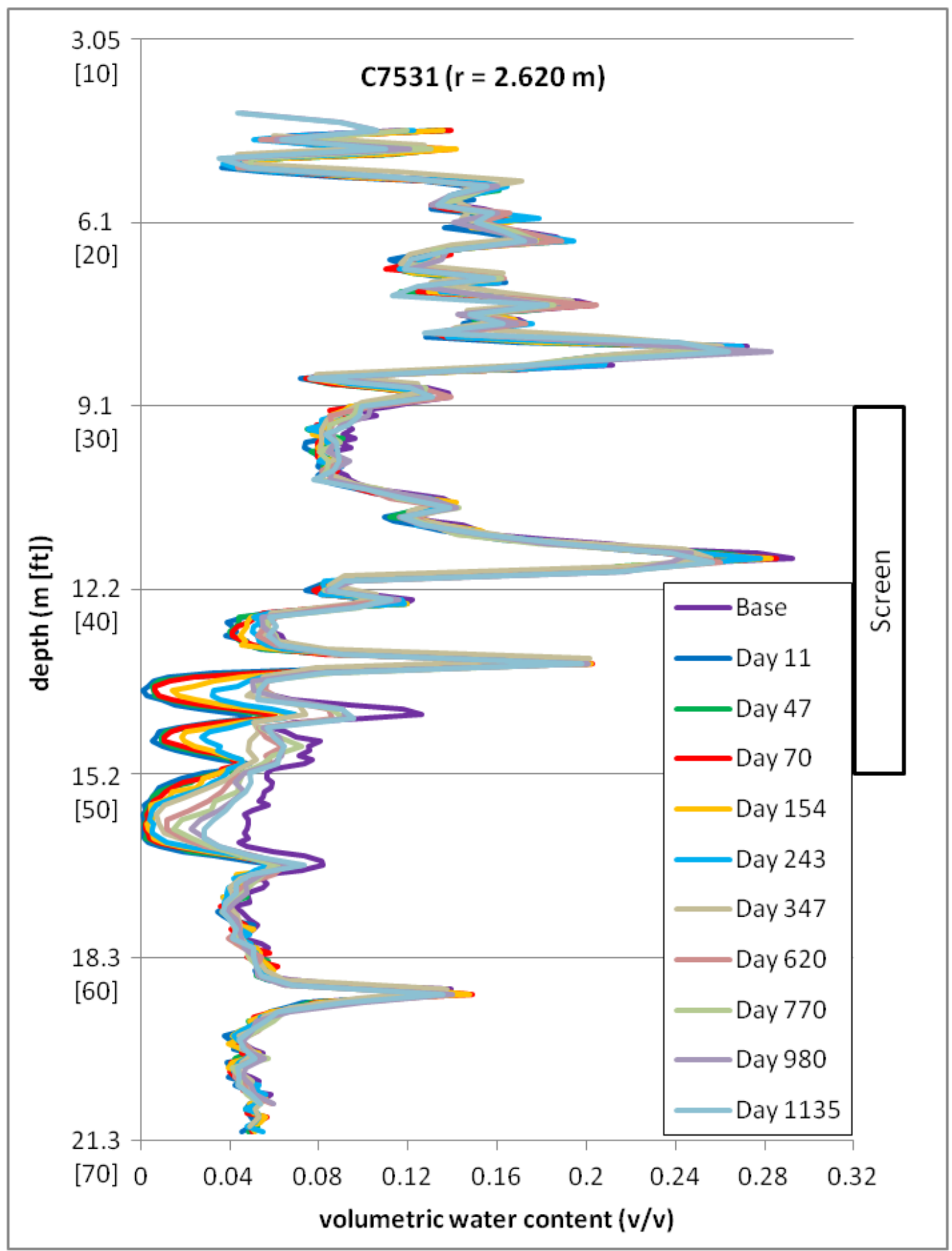

Figure A.5. Neutron Moisture Probe Response over Time for Location C7531 (2.620 m from injection well). The pre-desiccation data (Base) are for a logging event in December 2010, prior to the continuous active desiccation period. Other data are for logging events after active desiccation ended. 


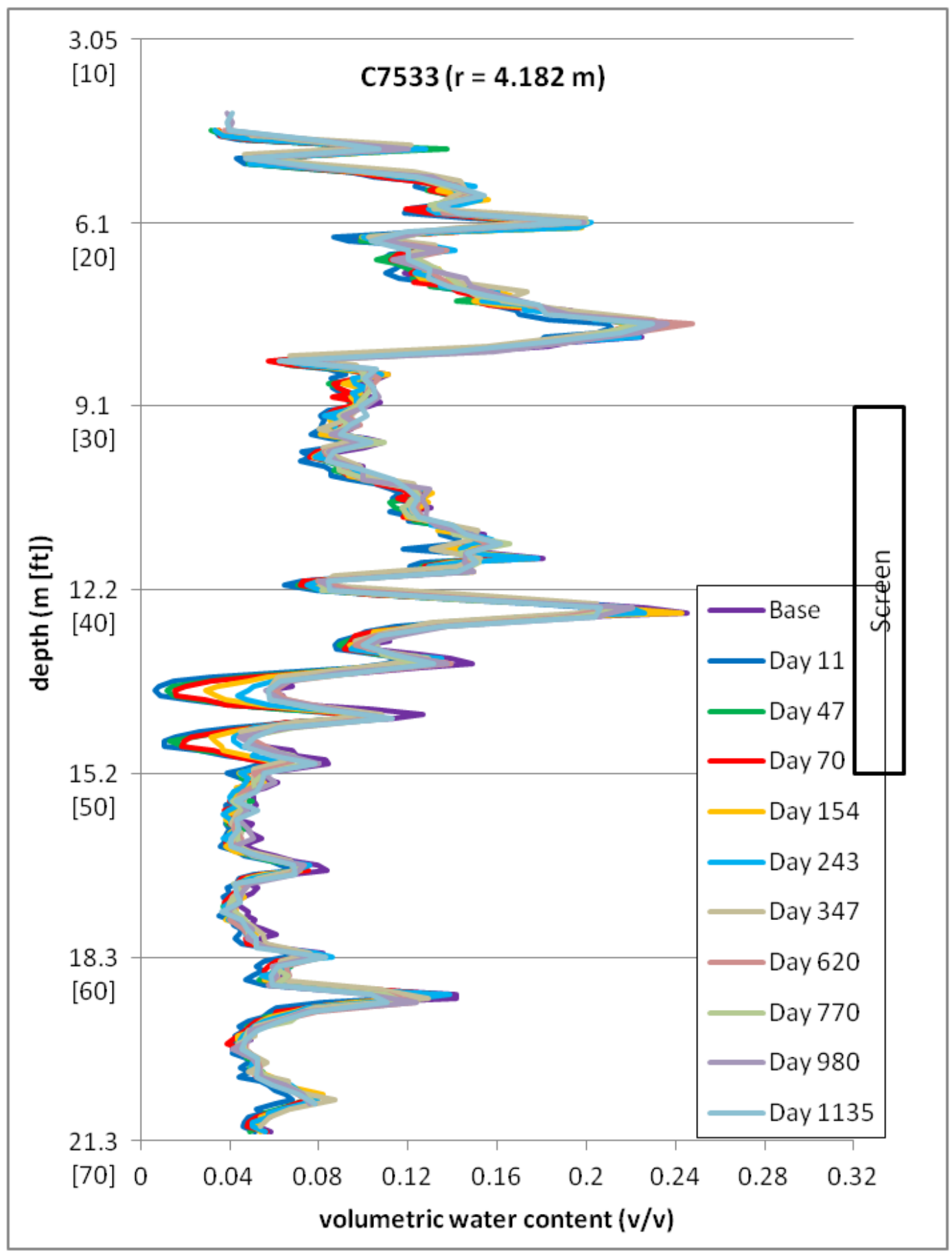

Figure A.6. Neutron Moisture Probe Response over Time for Location C7533 (4.182 m from injection well). The pre-desiccation data (Base) are for a logging event in December 2010, prior to the continuous active desiccation period. Other data are for logging events after active desiccation ended. 


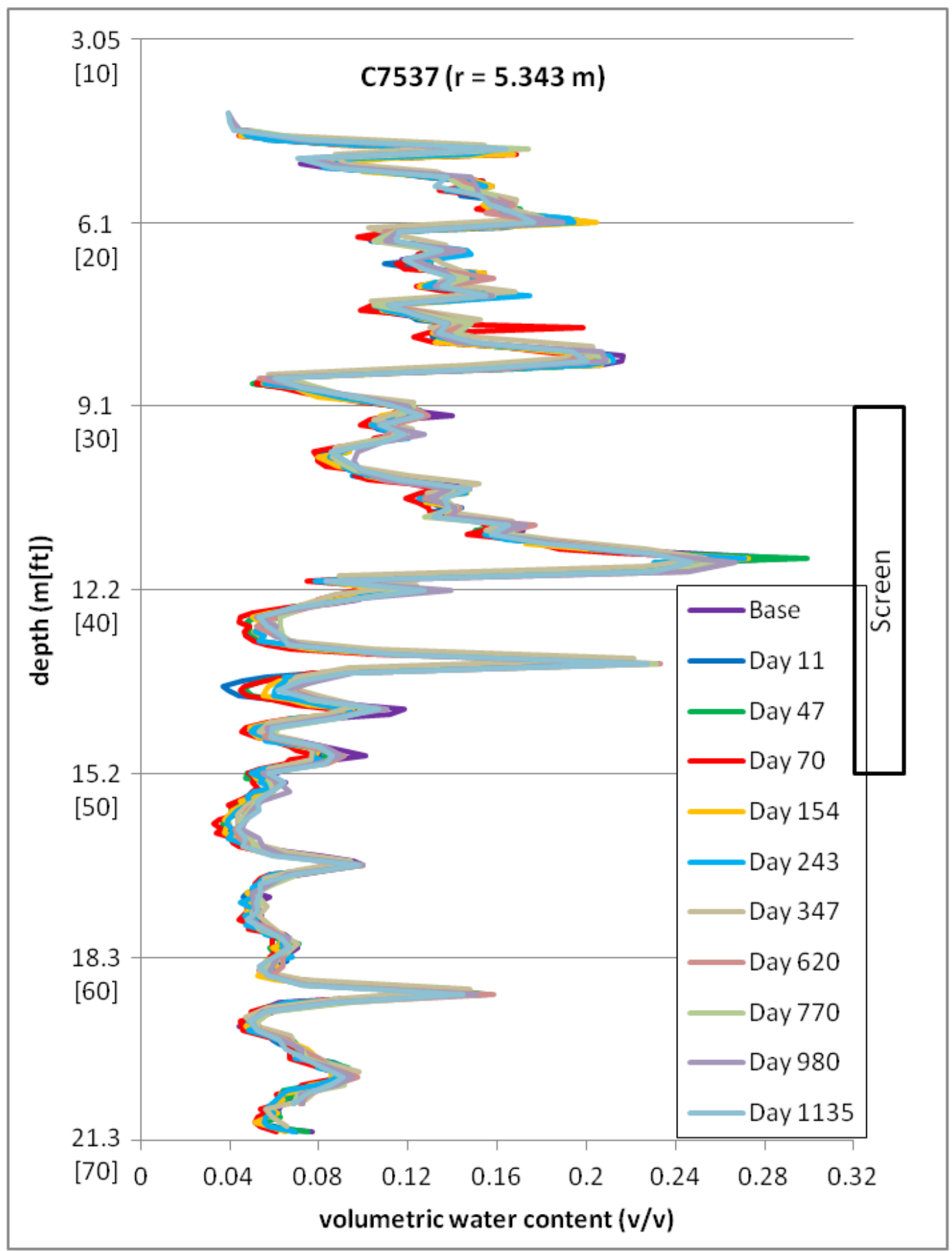

Figure A.7. Neutron Moisture Probe Response over Time for Location C7537 (5.343 m from injection well). The pre-desiccation data (Base) are for a logging event in December 2010, prior to the continuous active desiccation period. Other data are for logging events after active desiccation ended. 



\section{Distribution}

No. of

Copies

DOE Richland Operations Office

JG Morse

CH2M HILL Plateau Remediation

Company

GB Chronister
No. of

$\underline{\text { Copies }}$
Pacific Northwest National Laboratory

PDF

RE Clayton

PDF

CD Johnson

PDF

TC Johnson

PDF

CE Strickland

PDF

MJ Truex

PDF

DM Wellman

PDF

Information Release Office

PDF 




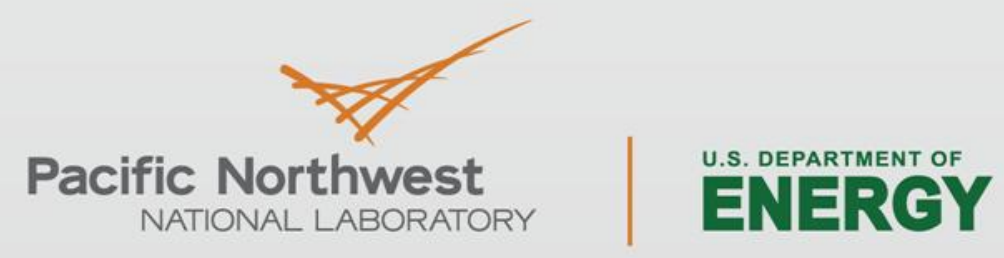

Proudly Operated by Battelle Since 1965

902 Battelle Boulevard

P.O. Box 999

Richland, WA 99352

1-888-375-PNNL (7665)

www.pnnl.gov 